Giuliano Luz Pigatti Caliari

\title{
Transformações e mapeamentos da MDA e sua implementação em três ferramentas.
}

Dissertação apresentada à Escola Politécnica da Universidade de São Paulo para obtenção do Título de Mestre em Engenharia.

São Paulo

2007 


\author{
Giuliano Luz Pigatti Caliari
}

\title{
Transformações e mapeamentos da MDA e sua implementação em três ferramentas.
}

Dissertação apresentada à Escola Politécnica da Universidade de São Paulo para obtenção do Título de Mestre em Engenharia.

Área de concentração:

Sistemas Digitais

Orientador:

Prof. Dr. Paulo Sérgio Muniz Silva

São Paulo

2007 


\section{Agradecimentos}

Ao professor Dr. Paulo Sérgio Muniz Silva pela oportunidade concedida, pela paciência e apoio na formação do meu pensamento científico, pela orientação e avaliações sinceras e objetivas, fundamentais para a melhora da pesquisa, e pela fé na minha evolução.

Aos meus pais, Antônio de Pádua e Vania, pelo apoio e carinho dedicados ao longo do período do mestrado.

À minha noiva, Cristiane, pela compreensão e incentivos, por entender as minhas vontades e necessidade e se esforçar ao máximo para apoiá-los e por ficar sempre ao meu lado acreditando em mim.

A todos da LHS Américas, pelo incentivo e oportunidade de emprego cedida durante a continuação dos meus estudos.

$\mathrm{E}$ a todas as pessoas que me apoiaram e auxiliaram durante o mestrado. 


\section{Resumo}

As transformações de modelos são um ponto vital para os enfoques de desenvolvimento dirigido por modelos, incluindo a MDA. No presente trabalho apresenta-se alguns dos conceitos da MDA relacionados a transformações de modelos. São vistos os conceitos de PIM, PSM, transformações, mapeamentos e marcas. Estes conceitos são analisados no contexto de três ferramentas MDA, a OptimalJ, a AndroMDA e a ArcStyler, para verificar se as ferramentas os implementam de acordo com a MDA. Também é analisado como e quais transformações e mapeamentos de modelos estão sendo implementados pelas ferramentas, através da comparação qualitativa de definições de conceitos e de exemplos do uso destes.

Além de verificar os conceitos relacionados às transformações, faz-se um estudo de caso qualitativo para analisar as transformações e mapeamentos providos pelas ferramentas e como as ferramentas trabalham com eles. Mostram-se as dificuldades de se criar um modelo PIM do sistema do estudo de caso e adaptá-lo para cada uma das ferramentas.

Palavras-chave: MDA. Modelo Independente de Plataforma. PIM. Transformação de modelos. Mapeamento de modelos. Marcas. 


\section{Abstract}

Model transformations are a vital point for model driven development, including MDA. In the present essay we introduce some of the MDA concepts related with model transformations. We present the concept of PIM, PSM, transformations, mappings and marks. These concepts are analyzed in the context of three MDA tools, OptimalJ, AndroMDA and ArcStyler, to verify if the tools implement the concepts according to MDA. We also analyze how and which model transformations and model mappings are being implemented by the tools, through a qualitative comparison of the definition of these concepts and using some examples of their intended use.

In addition to verifying the concepts related to transformations, we create a qualitative case study to analyze the model transformations and model mappings provided by the tools, and how the tools work with them. We show a few of the problems faced when creating a PIM model of the case study's system and the adaptations it required for each tool.

Keywords: MDA. Platform Independent Model. PIM. Model Transformation. Model Mapping. Marks. 


\section{Sumário}

Lista de Figuras

Lista de Tabelas

Lista de Abreviaturas e Siglas

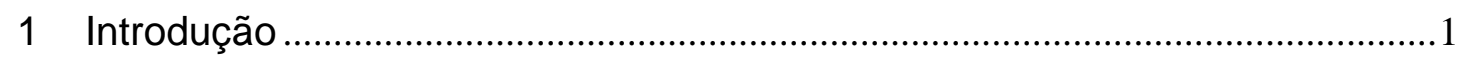

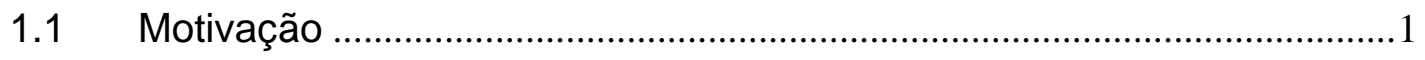

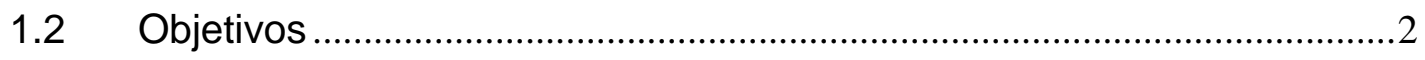

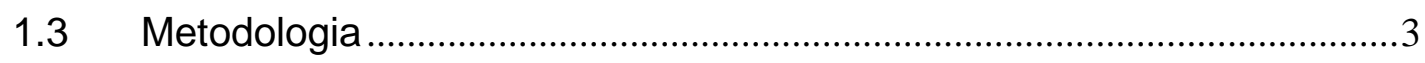

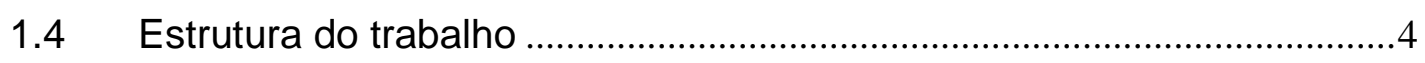

2 Transformações e Mapeamentos da MDA.........................................................

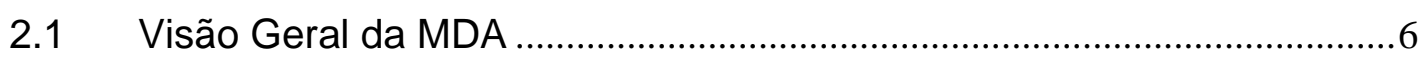

2.1.1 Arquitetura Dirigida por Modelos (MDA)..............................................6

2.1.2 O Processo de desenvolvimento da MDA...............................................

2.1.3 Sobre o conceito de Modelo ...................................................................10

2.2 Transformações e mapeamentos da MDA ...............................................11

2.2.1 Caracterização de transformações e mapeamentos............................11

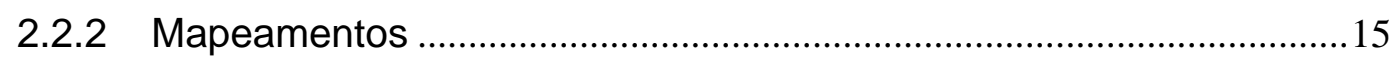

2.2.3 Transformações e mapeamentos de Modelos ......................................23

2.3 Exemplos de mapeamentos .................................................................28

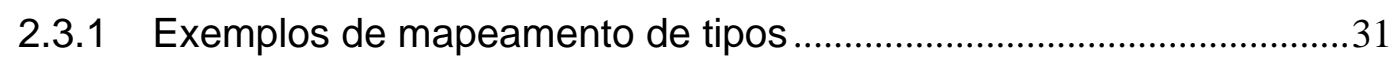

2.3.2 Exemplo de mapeamento de subtipos...................................................33

2.3.3 Exemplo de mapeamento de tipos com valores de instâncias...........34

2.3.4 Exemplo de mapeamento de instâncias.................................................35

2.3.5 Exemplo de transformação ................................................................38

3 Analise de três ferramentas MDA ...................................................................4

3.1 Descrição das ferramentas ..................................................................4 


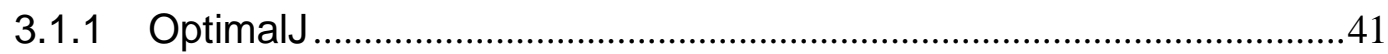

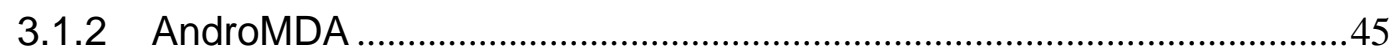

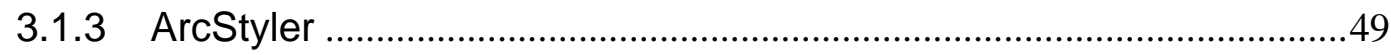

3.2 Transformações e mapeamentos nas ferramentas ..................................52

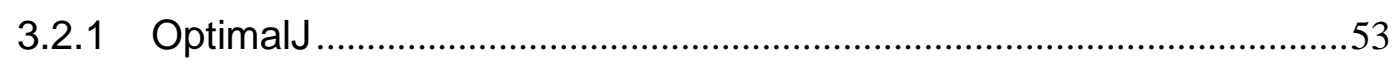

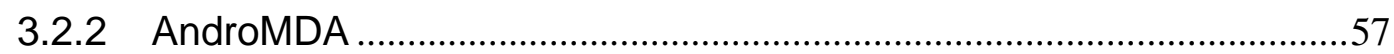

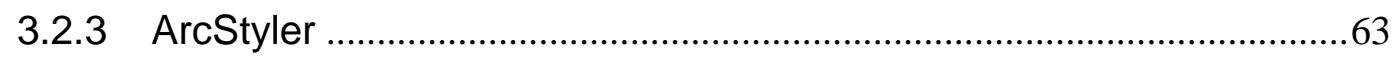

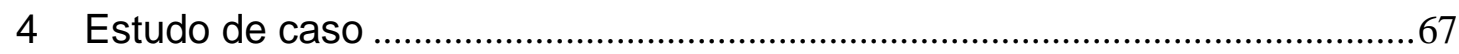

4.1 Preparação do Estudo de Caso ..............................................................67

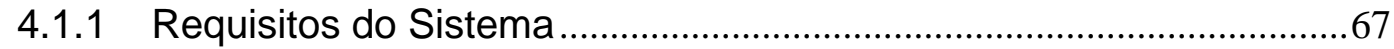

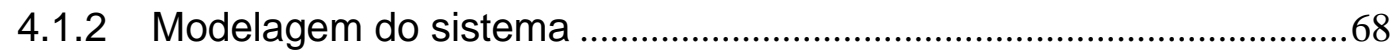

4.1.3 Requisitos de modelagem das ferramentas ......................................73

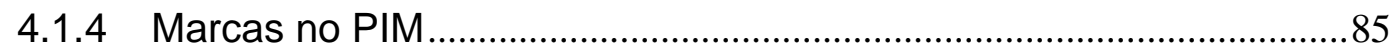

4.1.5 Observações gerais sobre configurações adicionais e o código gerado 90

4.2 Transformações e mapeamentos utilizados .............................................93

4.3 Conclusões gerais da análise qualitativa das ferramentas ....................95

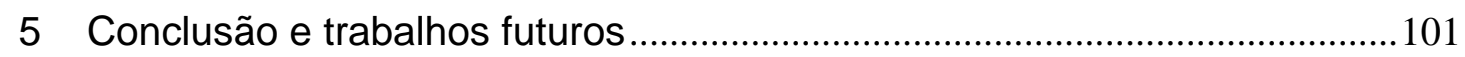

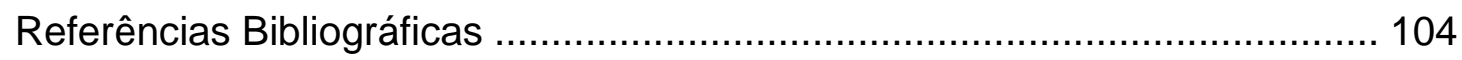

Apêndice A - Código da classe Cliente gerado pela ferramenta OptimalJ ........108

Apêndice B - Código da classe Cliente gerado pela ferramenta AndroMDA.....113

Apêndice C - Código da classe Cliente gerado pela ferramenta ArcStyler.........120 


\section{Lista de Figuras}

1 Relação entre a transformação, o mapeamento e os modelos fonte e alvo.

2 Mapeamentos um para um, muitos para um e um para muitos.

3 Mapeamento de tipos.

4 Mapeamento de instâncias.

5 Mapeamento de instâncias com marcas providas pelo mapeamento.

6 Mapeamento de instâncias com marcas de um perfil UML.

7 Mapeamento de instâncias com marcas de um modelo de marcas. 21

$8 \quad$ Exemplo de perfil UML para EJB. 22

$9 \quad$ Significados dos elementos gráficos para as Figuras 10 a 14.

10 Transformações de modelos usando marcas. 25

11 Transformações de meta-modelos. 26

12 Transformação de modelos utilizando tipos. 26

13 Transformação de modelos usando gabaritos e tipos. 27

14 Transformação de modelos utilizando união de modelos. 28

15 Subconjunto do meta-modelo da UML. 29

16 Subconjunto do meta-modelo da linguagem Java. 30

17 Exemplo de mapeamento de tipos. 31

18 Outro exemplo de mapeamento de tipos. 32

19 Exemplo de mapeamento de subtipos. 33

20 Exemplo de mapeamento de tipos com valores de instâncias. 35

21 Exemplo de mapeamento de instâncias. 35

22 Exemplo de mapeamento de instâncias utilizando marcas. 37

23 Exemplo de mapeamento híbrido de tipos e instâncias. 37

24 PIM simplificado usado como entrada no exemplo da 38 
transformação.

25 Código gerado pela regra 1 para a classe pessoa. 39

26 Código gerado pela regra 2 para a classe Papa. 39

27 Exemplo de registro da transformação. 40

28 Exemplo do método getChildClasses(...). 54

29 Exemplo de um mapeamento de tipos na OptimalJ. 56

30 Exemplo de mapeamento de tipos com valores de instância na 56 OptimalJ.

31 Exemplo de um mapeamento de subtipos na OptimalJ. 57

32 Exemplo de um mapeamento de tipos de dados na AndroMDA. 58

33 Exemplo de um mapeamento de descritores de cartuchos na 59 AndroMDA.

34 Exemplo de definição de marcas na AndroMDA. 60

35 Exemplo de mapeamento de tipos na AndroMDA. 61

36 Exemplo de mapeamento de tipos com valores de instâncias na 62 AndroMDA.

37 Exemplo de mapeamento de instâncias na AndroMDA. 62

38 Estrutura dos mapeamentos da ArcStyler. 63

39 Exemplo de mapeamento da ArcStyler. 64

40 Exemplo de modelo de um mapeamento de tipos da ArcStyler. 65

41 Exemplo de código de um mapeamento de tipos da ArcStyler. 65

42 Exemplo de código de um mapeamento de instâncias da ArcStyler. $\quad 67$

43 Diagrama de casos de uso do sistema. 70

44 Diagrama de classes do sistema. 72

45 Diagrama de atividade descrevendo o caso de uso Comprar Filme. 73

46 Subconjunto do diagrama de classes substituindo a Classe de $\quad 74$ Associação.

47 Diagrama de classes do sistema para a ferramenta OptimalJ. 76

48 Diagrama de atividades do caso de uso Compra Filme para a $\quad 77$ ferramenta OptimalJ. 
49 Subconjunto do diagrama de classes de Objetos de Valor da AndroMDA.

50 Diagrama de casos de uso do sistema adaptado para a AndroMDA.

51 Diagrama de atividades do caso de uso Comprar Filme adaptado para a AndroMDA.

52 Diagrama de atividades para o caso de uso Compra Filme adaptado para a ArcStyler.

53 Diagrama de classes para a atividade AdicionarFilme. 84

54 Diagrama de casos de uso adaptado para a ferramenta AndroMDA 86 e marcado.

55 Diagrama de classes adaptado para a ferramenta AndroMDA e marcado.

56 Diagrama de atividades do caso de uso Compra Filme adaptado para a ferramenta AndroMDA e marcado.

57 Diagrama de classes adaptado e marcado para a ferramenta ArcStyler.

58 Diagrama de atividades para o caso de uso Comprar Filme adaptado para a ferramenta ArcStyler e marcado.

59 Diagrama de classes marcado para a atividade AdicionarFilme. 


\section{Lista de Tabelas}

1 Caminhos gráficos incluídos nas Figuras 1 a 7.

2 Estereótipos usados nas Figuras 17 a 24.

3 Cobertura de modelos MDA com modelos da OptimalJ. 44

4 Cobertura de modelos MDA com modelos da AndroMDA. 48

5 Cobertura de modelos MDA com modelos da ArcStyler. 51

6 Tipos de mapeamentos possíveis em cada ferramenta. 95

7 Tipos de mapeamentos utilizados por cada ferramenta no estudo 95 de caso.

$8 \quad$ Contagem dos diagramas de casos de uso e seus elementos nos $\quad 97$ modelos.

9 Contagem dos diagramas de classes e seus elementos nos 98 modelos.

10 Contagem dos diagramas de atividades e seus elementos nos 99 modelos.

11 Modelos da MDA e suas implementações nas ferramentas. 


\section{LISTA DE ABREVIATURAS E SIGLAS}

\begin{tabular}{|c|c|c|}
\hline MDA & Model Driven Architecture & Arquitetura Dirigida por Modelos \\
\hline \multirow[t]{2}{*}{ MDD } & Model Driven Development & Desenvolvimento Dirigido por \\
\hline & & Modelos \\
\hline \multirow[t]{2}{*}{ CIM } & Computation Independent & Modelo Independente de \\
\hline & Model & Computação \\
\hline \multirow[t]{2}{*}{ PIM } & Platform Independent Model & Modelo Independente de \\
\hline & & Plataforma \\
\hline PSM & Platform Specific Model & Modelo Específico de Plataforma \\
\hline \multirow[t]{2}{*}{ OMG } & Object Management Group & Grupo de Gerenciamento de \\
\hline & & Objetos \\
\hline \multirow[t]{2}{*}{ UML } & Unified Modeling Language & Linguagem de Modelagem \\
\hline & & Unificada \\
\hline QVT & Query-View-Transformation & Consulta-Visão-Transformação \\
\hline MOF & Meta-Object Facility & Infra-estrutura de Meta-Objetos \\
\hline $\mathrm{XML}$ & eXtensible Markup Language & Linguagem de Marcação Extensível \\
\hline EJB & Enterprise Java Beans & Java Beans Empresariais \\
\hline JEE & Java Enterprise Edition & Java Edição de Empresas \\
\hline
\end{tabular}


Página 1

\section{Introdução}

\subsection{Motivação}

A importância do uso de modelos no desenvolvimento de software é um fato comprovado (SELIC, 2003), (FOWLER, 2004). Modelos elevam o nível de abstração do desenvolvimento dos sistemas, ajudando a planejá-los e entendêlos. Apesar disso, o uso de modelos ainda é visto como um trabalho a mais a ser feito, pois além do código é necessário fazer os modelos e mantê-los em sincronia com o código. Existem enfoques diferentes para resolver o problema da sincronia do software com o modelo (BROWN, 2004), mas uma abordagem que vem ganhando força nos últimos anos é a geração automática de código a partir do modelo do sistema.

O desenvolvimento dirigido por modelos é uma iniciativa que tenta seguir essa idéia, promovendo o modelo ao artefato principal do desenvolvimento de software, e não o código. A Arquitetura Dirigida por Modelos (Model Driven Architecture - MDA) (OMG, 2003) é uma das iniciativas do desenvolvimento dirigido por modelos e tendo sido o foco de muitos estudos recentemente.

A MDA, além de pregar o uso de modelos como artefato principal do desenvolvimento, possibilita que a geração de código a partir do modelo deve ser automática. A MDA também introduz a noção de separação entre o modelo e a plataforma que lhe dá suporte, possibilitando a independência entre a solução computacional e a tecnologia na qual ela é implementada, a fim de melhorar a portabilidade, interoperabilidade e reusabilidade (KLEPPE et al., 2003). A motivação por trás da MDA é facilitar o trabalho de desenvolvimento de software e, ao mesmo tempo, promover uma solução computacional que seja independente de tecnologias.

A promessa da MDA precipitou o aparecimento de várias ferramentas 
que dizem implementá-la utilizando seus conceitos (TARIQ, 2005). Apesar de uma das motivações da MDA ser a geração automática de código, a simples geração de código a partir de modelos não é o suficiente para classificar uma ferramenta como sendo uma ferramenta MDA. É necessário analisar se realmente existe uma correspondência entre os conceitos da MDA e suas implementações nas ferramentas. Esta dissertação é motivada pela necessidade de investigar implementações da MDA, como a MDA realmente está sendo implementada.

Idealmente, um modelo de um sistema deve ser construído e usado como entrada em uma ferramenta, que transforma automaticamente o código para o modelo do sistema. Para realizar a geração automática de código a partir do modelo, a MDA propõe o uso de transformações entre modelos. O conceito de transformações da MDA é baseado na noção de mapeamentos entre modelos. Os mapeamentos criam correspondências semânticas entre elementos dos modelos, ditando assim quais elementos de um modelo fonte devem ser transformados em quais elementos de um modelo alvo. Outra motivação do presente trabalho é a escassez de análises sobre a dificuldade da geração automática de código e das transformações da MDA.

\subsection{Objetivos}

O presente trabalho possui três objetivos. O principal deles é estudar alguns aspectos da implementação de transformações de modelos da MDA em três ferramentas disponíveis atualmente: OptimalJ, AndroMDA e ArcStyler. Para isso, analisam-se, do ponto de vista estritamente qualitativo, principalmente os seguintes conceitos da MDA envolvidos nas transformações de modelos: PIM, PSM, transformações, mapeamentos e marcas. A análise é feita comparando as definições desses conceitos, encontradas nas especificações da MDA, com as definições de seus equivalentes nas ferramentas, analisando se o uso destes conceitos confere com suas definições na MDA. 
As definições da MDA possuem graus de liberdade, possibilitando interpretações diferentes para seus conceitos e, conseqüentemente, implementações diferentes. Uma conseqüência é que os mapeamentos da MDA podem ser feitos de diferentes maneiras, permitindo às implementações da MDA escolherem de qual modo eles serão realizados. Assim, outro objetivo do presente trabalho é analisar qualitativamente quais tipos de mapeamentos definidos pela MDA estão sendo implementados pelas ferramentas, e também quais outros mecanismos de auxílio às transformações as ferramentas dispõem. Para tanto, é feito um estudo de caso que faz uso das transformações e dos mapeamentos, analisando qualitativamente o uso dos conceitos pertinentes nas três ferramentas.

Um outro objetivo é fazer uma análise qualitativa de algumas das modificações necessárias ao PIM, para que as ferramentas possam trabalhar com ele como modelo de entrada nas transformações de PIM para PSM. Cada uma das ferramentas especifica restrições próprias para o PIM conforme suas necessidades. Algumas das restrições mencionadas encontradas foram: a definição de uma linguagem de modelagem, a necessidade do uso de determinados diagramas, uma especificação de organização para elementos dos diagramas e para os diagramas do modelo, etc.

\subsection{Metodologia}

O estudo de caso foi realizado através dos seguintes passos. Primeiramente foi realizado o modelo de domínio de uma aplicação e foi escolhida a plataforma para a qual o código seria gerado. Em seguida, foram avaliados os construtos utilizados da linguagem de modelagem, as particularidades dos diagramas aceitos e o nível de abstração requerido por cada uma das ferramentas. Com a linguagem de modelagem e os diagramas especificados, um modelo do sistema foi construído, com um nível de abstração mínimo comum às ferramentas. 
O modelo criado foi utilizado como entrada para as ferramentas, e os resultados observados. Observando-se que as ferramentas exigiam adaptações ao modelo de entrada, foi realizada uma análise das necessidades específicas de modelagem de cada uma das ferramentas. O modelo original foi adaptado de acordo com essas necessidades e três modelos diferentes foram gerados, um para cada ferramenta. Além das necessidades de modelagem, algumas configurações nas ferramentas tiveram de ser feitas.

Os três novos modelos foram submetidos às ferramentas e o código do sistema gerado. Por fim, foi feita uma análise do código resultante e do resultado geral do estudo de caso.

\subsection{Estrutura do trabalho}

O capítulo 2 apresenta os fundamentos conceituais do trabalho. Apresenta-se uma síntese do que é a MDA, incluindo seu histórico, motivos, conceitos, definições e seu estado atual. O capítulo enfoca os conceitos mais relacionados a este trabalho, tais como modelos, PIM, PSM, transformações e mapeamentos entre modelos. Detalham-se as transformações e os mapeamentos da MDA, apresentando-se: como os mapeamentos são usados nas transformações, as abordagens de transformação propostas pela MDA, os tipos de mapeamentos e exemplos dos mapeamentos, ilustrando como são feitos.

O capítulo 3 introduz as ferramentas utilizadas neste trabalho, fazendose uma breve comparação entre os principais conceitos da MDA e como estes estão presentes nas ferramentas. Nesse capítulo, faz-se um estudo mais aprofundado sobre os conceitos de transformações e mapeamentos nas ferramentas, mostrando-se, em detalhes, quais os tipos de mapeamentos possíveis em cada uma das ferramentas e como cada um deles é 
implementado. São dados exemplos de utilização para a criação de mapeamentos e transformações apresentados.

O capítulo 4 apresenta o estudo de caso que analisa os mapeamentos e as transformações nas ferramentas, detalhando como o estudo de caso foi feito, o que foi analisado e os resultados obtidos. Aqui também é apresentado um guia geral de soluções possíveis para os problemas de modelagem encontrados na criação dos modelos do sistema para cada uma das ferramentas.

O capítulo 5 apresenta as conclusões e contribuições do presente trabalho e um esboço de trabalhos futuros. 


\section{Transformações e Mapeamentos da MDA}

O presente capítulo trata da Arquitetura Dirigida por Modelos. Apresentam-se alguns dos conceitos encontrados na especificação da MDA e o processo de desenvolvimento descrito por esta. Em particular, detalham-se os conceitos de mapeamentos e transformações, apresentam-se os tipos de transformações e os tipos de mapeamentos definidos pela MDA e mostram-se alguns exemplos de como estes mapeamentos podem ser feitos.

\subsection{Visão Geral da MDA}

\subsubsection{Arquitetura Dirigida por Modelos (MDA)}

A MDA é uma abordagem de desenvolvimento de sistemas de software orientada por modelos que se caracteriza por separar a lógica do negócio da plataforma que lhe dá suporte. Ser orientada por modelos significa utilizar modelos como artefatos principais do desenvolvimento: são eles que dirigem o entendimento, o projeto, a construção, a implantação, a operação, a manutenção e a modificação do sistema. A separação da especificação da operação de um sistema de seus detalhes, e de como o sistema usa uma plataforma, é a principal diferença entre a MDA e outros enfoques de desenvolvimento dirigido por modelos. A MDA provê uma metodologia que possibilita: a criação de ferramentas para especificar sistemas independentes de plataforma, especificar plataformas, escolher uma ou mais plataformas, transformar a especificação do sistema em uma especificação acoplada à escolhida plataforma e gerar o código executável do sistema para a plataforma escolhida (OMG, 2003). As definições que seguem são baseadas em (OMG, 2003). 
Modelo: A MDA caracteriza um modelo de sistema como uma especificação de uma parte da função, comportamento e/ou estrutura deste sistema, e seu ambiente para um determinado propósito. Dirigir por modelos significa utilizar modelos para o entendimento, projeto (design), construção, instalação, operação, manutenção e modificação do sistema. Os modelos são, portanto, os artefatos principais do desenvolvimento.

Arquitetura de um sistema: uma especificação das partes, conectores do sistema e regras para a interação entre estas partes. Portanto, Arquitetura Dirigida por Modelos significa criar, com modelos, especificações das partes de sistemas e regras para a interação entre estas partes, utilizando estes modelos para entender, projetar, construir, instalar, operar, manter e modificar o sistema.

Plataforma: uma plataforma é um conjunto de subsistemas e tecnologias que provêem um conjunto coerente de funções através de interfaces e especificações de padrões de uso, de tal modo que qualquer aplicação que se apóie nesta plataforma possa usar os serviços e funções sem se preocupar com os detalhes de como eles são implementados.

Desse modo, apesar de o sistema construído estar atrelado à tecnologia usada, a especificação do sistema é independente desta tecnologia, podendo ser usada para implementar o mesmo modelo de sistema em diferentes plataformas tecnológicas.

\subsubsection{O Processo de desenvolvimento da MDA}

A MDA define uma seqüência de atividades para o de desenvolvimento de software. Essas atividades são divididas em etapas, começando com o levantamento dos requisitos do sistema e criando um Modelo Independente de Computação (Computation Independent Model - CIM), baseado nestes requisitos. O modelo independente de computação é um modelo que explora uma visão de um sistema centrada no ambiente e nos requisitos do sistema; os 
detalhes das estruturas e processamento são omitidos ou não foram identificados. O CIM, também chamado de modelo de domínio (OMG, 2003), mostra os requisitos do sistema no ambiente em que ele será operado e ajuda a comunicar precisamente o que o sistema deve fazer. Os requisitos do sistema representados no CIM devem ser mapeados para os modelos que lhe seguem.

A partir do CIM, deve-se gerar o Modelo Independente de Plataforma (Platform Independent Model - PIM) através de um processo normalmente manual. Um modelo independente de plataforma enfoca a operação de um sistema escondendo os detalhes da plataforma, mostrando a parte da especificação que não muda com a alteração da plataforma. O nível de independência de plataforma do PIM deve ser tal que seja possível utilizar este modelo com diferentes plataformas que provêem os mesmos serviços. O PIM pode usar uma linguagem de modelagem genérica ou uma linguagem específica para o domínio em que o sistema será usado. Nesse passo são adicionados os detalhes computacionais ao modelo. $O$ uso da plataforma é descrito, mas em um grau de abstração tal que ainda seja possível utilizar diferentes plataformas.

Com o PIM criado, uma transformação deve ser aplicada a ele para gerar o próximo modelo. Informalmente, transformações de modelos podem ser definidas como o processo de convergir um modelo para outro modelo do mesmo sistema, seguindo um mapeamento. Um mapeamento é formado por regras de mapeamento, que descrevem uma correspondência entre os elementos do modelo-fonte com elementos do modelo-alvo. A transformação utiliza essa correspondência para, a partir de cada elemento de um modelofonte, gerar os elementos correspondentes no modelo-alvo.

Uma transformação deve ser aplicada ao PIM para que se possa gerar um Modelo Específico de Plataforma (Platform Specific Model - PSM). Esse modelo combina as especificações no PIM com os detalhes que especificam como o sistema usa um determinado tipo de plataforma. 
Para realizar essa transformação, uma ou mais plataformas são escolhidas e um mapeamento para estas plataformas deve ser construído (se já não existirem). Um mapeamento provê especificações para transformar um PIM em um PSM para uma determinada plataforma. O mapeamento é utilizado como uma das entradas para a transformação do PIM em um PSM, especificando como ela deve ser feita. A MDA possibilita que as ferramentas transformem o PIM em um PSM ou diretamente em código. Neste trabalho, transformações de PIM para PSM são subentendidas como transformações de PIM para PSM ou diretamente para código. Essa é a principal transformação da MDA e será explicada em detalhes na seção 2.2 .

Para criar um mapeamento, usa-se um modelo da plataforma. O modelo da plataforma provê um conjunto de conceitos técnicos representando os tipos diferentes de partes que fazem uma plataforma e os serviços providos por ela. Ele também provê conceitos representando os diferentes tipos de elementos a serem usados ao especificar o uso da plataforma pela aplicação no PSM.

A saída da transformação é o registro de transformação e o PSM ou código. O registro da transformação guarda um mapeamento dos elementos do PIM aos seus correspondentes elementos no PSM após a transformação, mostrando quais partes do mapeamento foram utilizadas por cada parte da transformação. O registro da transformação possibilita rastrear como a transformação foi executada e possibilita que esta seja bidirecional.

O PSM pode ser usado para gerar o código do sistema ou ser refinado em outro PSM. Se o PSM for prover toda a informação necessária para construir um sistema e colocá-lo em operação, ele será considerado uma implementação. Uma implementação é uma especificação que provê toda a informação necessária para construir um sistema e colocá-lo em operação. Se o PSM for utilizado para maiores refinamentos em outro PSM que pode ser diretamente implementado, ele estará agindo como um PIM. 


\subsubsection{Sobre o conceito de Modelo}

Para falar sobre a MDA é necessário detalhar a noção de modelo. Nesta seção são definidos alguns conceitos relacionados a modelos. Um modelo de um sistema é um conjunto de elementos que descreve o sistema (MELLOR, 2004) com um grau de abstração maior do que o do sistema (KLEPPE et al., 2003). É comum utilizar uma linguagem de modelagem como a Linguagem de Modelagem Unificada (Unified Modeling Language - UML) para representar os modelos. A UML é a linguagem de modelagem recomendada pela OMG para ser usada juntamente com a MDA no desenvolvimento dos sistemas.

A UML é uma linguagem visual para especificação, construção e documentação de artefatos de sistemas. É uma linguagem de modelagem com propósitos genéricos que pode ser utilizada com diversas abordagens de desenvolvimento de software, e pode ser aplicada a qualquer domínio de aplicações (OMG, 2006b).

Meta-modelos são modelos de uma linguagem de modelagem. Eles definem a estrutura, a semântica e as restrições para uma família de modelos, isto é, grupos de modelos que compartilham uma sintaxe e uma semântica comuns (MELLOR, 2004). Um meta-modelo é uma definição precisa das construções e regras necessárias para criar modelos semânticos. Modelos podem ser instanciados a partir de um meta-modelo.

O meta-modelo da UML é uma instância da Infra-estrutura de MetaObjetos (Meta-Object Facility- MOF), como visto em (OMG, 2006a). O MOF é um arcabouço de gerenciamento de meta-dados e um conjunto de serviços de meta-dados que possibilitam o desenvolvimento e interoperabilidade de sistemas dirigidos por modelos e meta-dados. Resumidamente, a MOF é designada para a criação de meta-modelos, sendo chamado de meta-metamodelo.

Perfil UML é um mecanismo de extensão da UML que permite a personalização de meta-modelos definidos pelo MOF, como a UML, para 
diferentes plataformas tecnológicas ou domínios de aplicação (OMG, 2006c). Os perfis UML permitem a personalização de qualquer meta-modelo definido pela MOF, adicionando novos tipos de elementos da linguagem ou restringindo a linguagem para adaptar os meta-modelos para diferentes propósitos. Um perfil UML pode também especificar outro perfil UML. A noção de perfil UML é utilizada pela MDA. A seção 2.2.2.3 mostra como perfis UML são utilizados pela MDA.

\subsection{Transformações e mapeamentos da MDA}

Transformações são a atividade de gerar um modelo alvo a partir de um modelo fonte, de acordo com um mapeamento, formado por um conjunto de regras de mapeamentos, que juntas descrevem como um modelo na linguagem fonte pode ser transformado em um modelo na linguagem alvo (KLEPPE et al., 2003). As transformações da MDA são baseadas em mapeamentos. Mapeamentos provêm especificações para transformar um PIM em um PSM para uma determinada plataforma, eles fazem isso através de regras de mapeamento que ditam quais elementos do modelo fonte correspondem a quais elementos do modelo alvo.

\subsubsection{Caracterização de transformações e mapeamentos}

Definições formais para mapeamentos e transformações podem ser encontradas em (LOPES et al., 2005).

"Dado $M_{1}(s) / M_{a}$ e $M_{2}(s) / M_{b}$, em que $M_{1}$ é um modelo de um sistema $s$ criado utilizando o meta-modelo $M_{a}$ e $M_{2}$ é um modelo do mesmo sistema $s$ criado utilizando o metamodelo $M_{b}$, um mapeamento pode ser definido como $C_{M a \rightarrow M b} / M_{c}$, em que $C_{M a \rightarrow M b}$ é o mapeamento entre os metamodelos $M_{a}$ e $M_{b}$ criado com a utilização do meta-modelo 
$M_{c}$. Uma transformação pode ser definida como a função $\operatorname{Transf}\left(M_{1}(s) / M_{a}, C_{M a \rightarrow M b} / M_{c}\right) \rightarrow M_{2}(s) / M_{b}$. (LOPES et al., 2005).

O modelo $M_{1}(s) / M_{a}$ e o mapeamento $C_{M a \rightarrow M b} / M_{c}$ são utilizados como entrada na transformação $\operatorname{Transf}\left(M_{1}(s) / M_{a}, C_{M a \rightarrow M b} / M_{c}\right) \rightarrow M_{2}(s) / M_{b}$, e o modelo $M_{2}(s) / M_{b}$ é a saída gerada pela transformação.

Diversas entidades estão envolvidas na transformação do PIM para o PSM da MDA: um meta-meta-modelo (como por exemplo, o MOF), metamodelos fonte e alvo, modelos fonte e alvo, um modelo de mapeamento, um meta-modelo de transformação, um modelo de transformação e um gerador de transformações (ou máquina de transformações). Os meta-modelos fonte, alvo e da transformação são baseados em um meta-meta-modelo, como por exemplo, o MOF. Primeiramente é gerado um modelo de transformação baseado no meta-modelo de transformação. O modelo fonte deve ser construído baseado no meta-modelo fonte. A transformação recebe o modelo fonte e fornece um modelo alvo, baseado no meta-modelo alvo, como saída. A Figura 1, adaptada de (LOPES et al., 2005), mostra o processo de transformação relacionando as entidades envolvidas. A Tabela 1 explica os elementos gráficos usados fora do padrão da UML.

Em (LOPES et al., 2005) é proposto uma separação entre especificação de mapeamento e definição da transformação.

Mapeamento: o termo mapeamento é utilizado como sinônimo de correspondência entre elementos de dois meta-modelos. Um mapeamento entre dois elementos define uma correspondência entre estes.

Transformação é a atividade de transformar os elementos de um modelo fonte em elementos de um modelo alvo. 


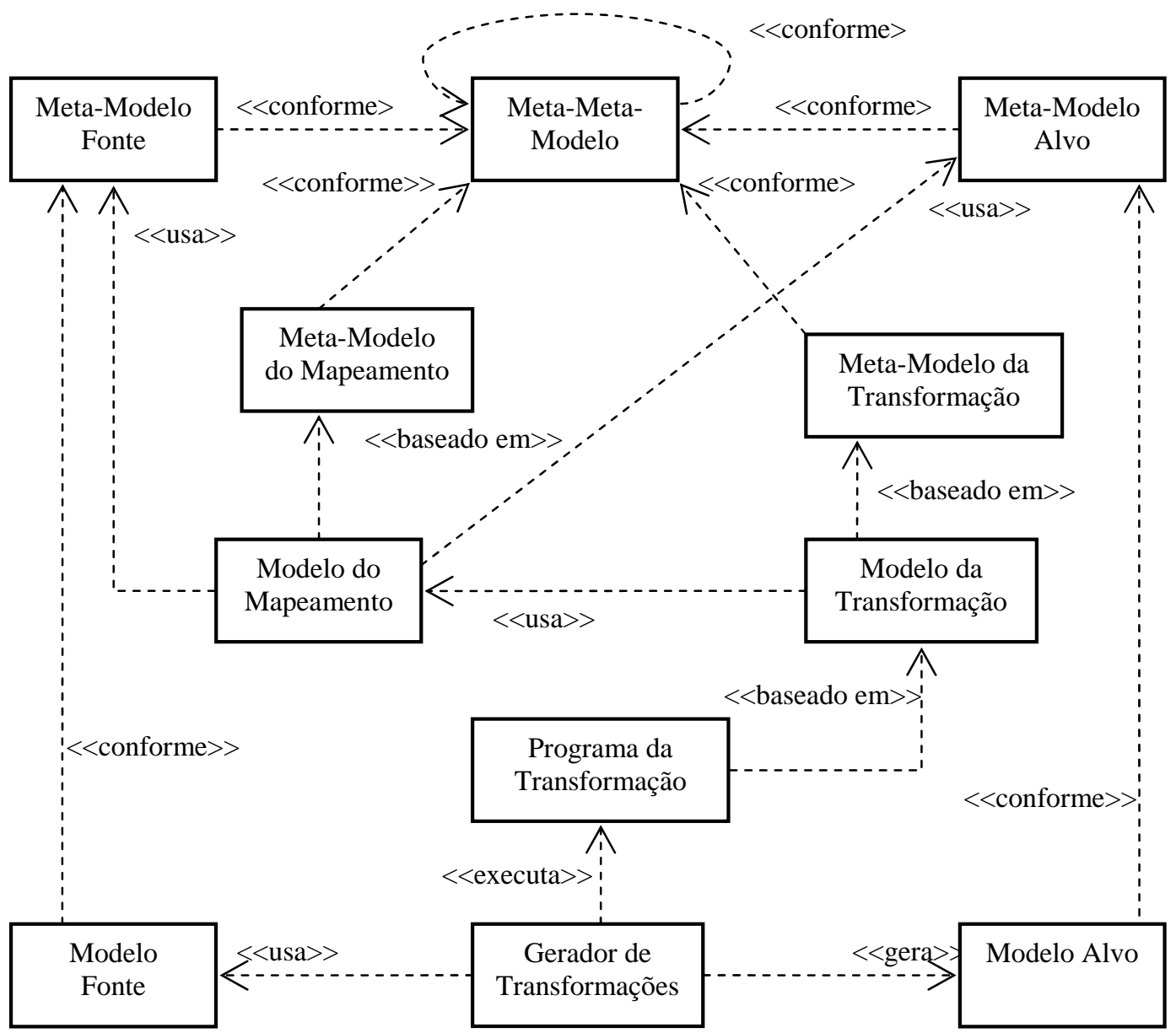

Figura 1: Relação entre a transformação, o mapeamento e os modelos fonte e alvo.

Mapeamentos ligam elementos do modelo fonte a elementos do modelo alvo. Os mapeamentos podem ser feitos ligando elementos de um para um, de um para muitos ou de muitos para um. Os mapeamentos são caracterizados por elementos no modelo alvo que representam a mesma estrutura e semântica de elementos do modelo fonte. Por isso, um mapeamento de um para um elemento (1:1), representa que um elemento do modelo alvo possui a mesma semântica de um elemento do modelo fonte. Mapeamentos de muitos para um (n:1) significam que um elemento do modelo alvo possui a mesma semântica de um conjunto de elementos do modelo fonte e mapeamentos de um para muitos (1:n) representam que um conjunto de elementos no modelo alvo possui a 
mesma semântica de um elemento do modelo fonte. Os conjuntos de elementos dos mapeamentos de um para muitos e muitos para um podem ser dados por gabaritos ${ }^{1}$. Esses mapeamentos são ilustrados na Figura 2.

Tabela 1: Caminhos gráficos incluídos nas Figuras 1 a 7.

\begin{tabular}{|c|c|c|}
\hline Tipo de Nó & Notação & Referência \\
\hline Dependência & $<<$ conforme $>>>>$ & $\begin{array}{l}\text { Denota que um elemento está em conformidade } \\
\text { com as regras impostas por outro elemento. }\end{array}$ \\
\hline Dependência & $<<$ baseado em $>>$ & $\begin{array}{l}\text { Denota que um elemento é baseado em outro } \\
\text { elemento. }\end{array}$ \\
\hline Dependência & $<<$ usa $>>$ & $\begin{array}{l}\text { Denota que um elemento faz uso de outro } \\
\text { elemento. }\end{array}$ \\
\hline Dependência & $<<$ gera $>>>---->$ & Denota que um elemento cria outro elemento. \\
\hline Dependência & $<<$ executa $>>>>$ & $\begin{array}{l}\text { Denota que um elemento executa uma atividade } \\
\text { definida por outro elemento. }\end{array}$ \\
\hline Dependência & $<<$ especifica $>>$ & Denota que um elemento determina outro. \\
\hline
\end{tabular}

Na Figura 2 são mostrados os mapeamentos de um para um, de um para muitos e de muitos para um respectivamente. O mapeamento de um para um é dado por um elemento A1 correspondendo a um elemento B1, e a correspondência dos atributos do elemento $A 1, A 11$ e $A 12$, aos atributos do elemento B1, respectivamente B11 e B12.

\footnotetext{
${ }^{1}$ Gabaritos são definidos na seção 2.2.2.5. Eles podem ser usados em regras de mapeamento para transformar um padrão de elementos de um modelo em outro padrão de elementos de modelo. (OMG, 2003).
} 
O mapeamento de um para muitos é dado por um elemento A1 correspondendo aos elementos $\mathrm{B} 1$ até $\mathrm{Bn}$, com um mapeamento equivalente para os atributos de $\mathrm{A} 1$, em que cada atributo é mapeado para um atributo em cada um dos elementos B1 até Bn. O mapeamento de muitos para um é dado pelos elementos $A 1$ até $A n$ correspondendo ao elemento $B 1$, com um mapeamento equivalente para os atributos de A1 até An.

PIM

PSM

$(1: 1)$

\begin{tabular}{|c|c|c|c|c|}
\hline A1 & & $<<$ mapeamento $>>$ & & B1 \\
\hline +A11 : Tipo_1 & fonte & A para B & alvo & +B11 : Tipo_3 \\
\hline +A12 : Tipo_2 & & & & +B12 : Tipo_4 \\
\hline
\end{tabular}
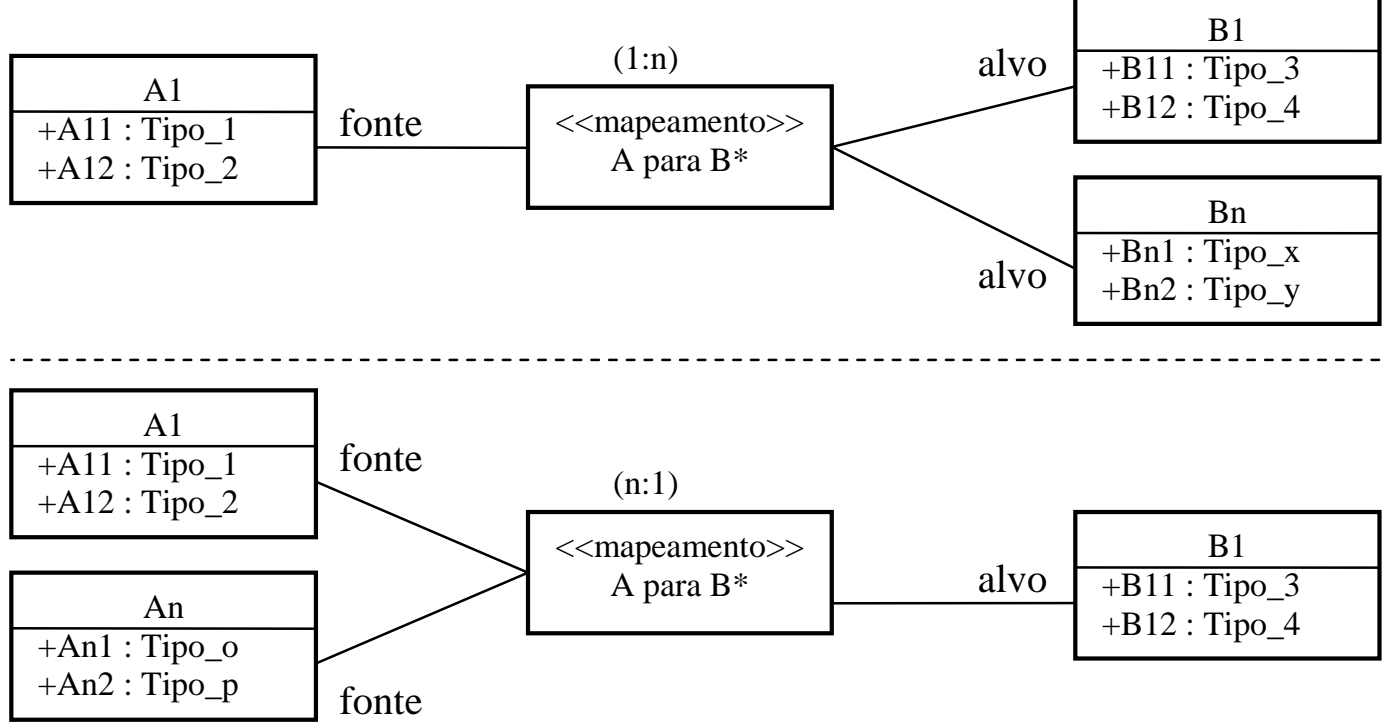

Figura 2: Mapeamentos um para um, muitos para um e um para muitos.

\subsubsection{Mapeamentos}

Um mapeamento provê especificações para a transformação de um PIM para um PSM ou código para uma determinada plataforma. O mapeamento pode ser especificado utilizando tipos, instâncias ou uma combinação dos dois, além disso, um mapeamento também pode conter gabaritos. 
A MDA (OMG, 2003) define dois tipos de mapeamentos possíveis: os mapeamentos de tipos e os mapeamentos de instâncias. Mapeamentos de tipos criam uma relação entre tipos do meta-modelo fonte e tipos do metamodelo alvo. Mapeamentos de instâncias criam relações entre elementos do modelo fonte e tipos do meta-modelo alvo.

\subsubsection{Mapeamentos de tipos}

Mapeamentos de tipos mapeiam tipos da linguagem do PIM para tipos da linguagem do PSM ou da linguagem do código. Os elementos do PIM possuem tipos definidos na linguagem do PIM. Esses tipos são mapeados em tipos definidos na linguagem do PSM. Quando a transformação é executada, cada um dos elementos do PIM tem seu tipo analisado, os mapeamentos destes tipos são verificados, e os tipos do PSM apontados por estes mapeamentos são utilizados para criar elementos do PSM, cujos valores são tirados do correspondente elemento no PIM. A Figura 3 ilustra uma simplificação dos mapeamentos de tipos.

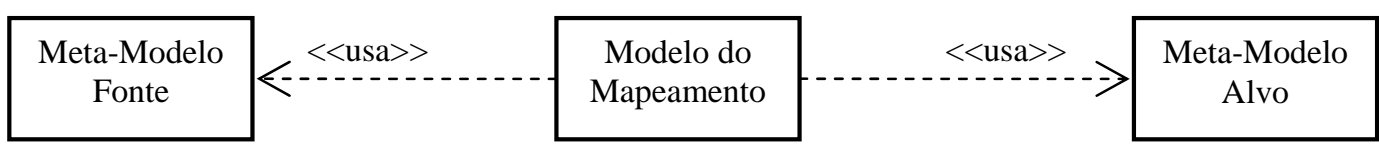

Figura 3: Mapeamento de tipos.

Se forem definidos elementos $E F_{1} \ldots E F_{n}$ pertencentes ao meta-modelo fonte, e elementos $E A_{1} \ldots E A_{n}$ pertencentes ao meta-modelo alvo, um mapeamento de tipos irá especificar uma equivalência semântica entre esses elementos, por exemplo $E F_{1} \rightarrow E S_{1}, E F_{2} \rightarrow E S_{2} \ldots E F_{n} \rightarrow E S_{n}$. Uma transformação que utiliza esse mapeamento deverá verificar o modelo fonte por elementos cujos tipos são $E F_{1}, E F_{2} \ldots E F_{n}$, e criar elementos no modelo alvo cujos tipos são $E A_{1}, E A_{2} \ldots E A_{n}$, respectivamente. 
Mapeamentos de tipos também podem ser feitos utilizando subtipos do meta-modelo fonte, ou atribuindo valores a propriedades de instâncias dos elementos do modelo. Mapeamentos que utilizam subtipos são feitos de modo equivalente a mapeamentos de tipos. Os tipos utilizados no mapeamento da fonte não são tipos do meta-modelo, e sim subtipos desses. Esse mecanismo possibilita a criação de mapeamentos diferentes e exclusivos para um mesmo tipo. Não é possível, utilizando apenas mapeamentos de tipos, criar um mapeamento em que certo tipo $T F_{1}$ possa ser mapeado para um tipo $T A_{1}, T A_{2}$ ou $T A_{3}$, mas apenas um destes três tipos deve ser escolhido. Utilizando subtipos, é fácil resolver esse problema criando subtipos de $T F_{1}, T F_{11}, T F_{12}$, e $T F_{13}$, e estes subtipos serem mapeados respectivamente para $T A_{1}, T A_{2}$ e $T A_{3}$. Apesar de resolver o problema, a solução acima requer alterações no metamodelo fonte, o que pode não ser trivial.

Outra possibilidade de mapeamentos de tipos é utilizar valores de instâncias. Nesse caso, um determinado valor é atribuído a um atributo da instância de um tipo do meta-modelo fonte. O mapeamento estipula que se esse atributo possuir um determinado valor em alguma instância do dado tipo, ele será mapeado de determinada maneira, normalmente diferente do mapeamento utilizado para aquele tipo. Uma vantagem desse mecanismo sobre o mecanismo de subtipos, é que não há necessidade de se alterar o meta-modelo fonte.

Regras de mapeamento também podem especificar mapeamentos de acordo com padrões do uso dos tipos do PIM. Nesse caso, a regra de mapeamento exige que um determinado padrão esteja presente no PIM para que ela seja aplicada. Esse padrão é definido em termos de elementos do PIM, como eles devem estar associados, quais devem ser seus tipos e até mesmo os valores de algumas instâncias.

A MDA nomeia mapeamento de meta-modelos aqueles mapeamentos de tipos de modelos onde os tipos dos elementos do PIM e PSM são especificados 
utilizando meta-modelos baseados na MOF. Nesse caso, as regras de mapeamento são expressas em termos de todas as instâncias baseadas em cada um dos tipos do meta-modelo especificando a linguagem do PIM, resultando na geração de instâncias baseadas em tipos do meta-modelo especificando a linguagem do PSM.

\subsubsection{Mapeamentos de instâncias}

Mapeamentos de instâncias são mapeamentos que relacionam elementos do PIM a conceitos no PSM. Eles especificam que alguns elementos do PIM devam ser transformados de uma maneira particular, dada a escolha de certa plataforma para o PSM, criando uma correspondência entre o elemento do PIM e um ou mais tipos do meta-modelo do PSM. A idéia geral do mapeamento de instâncias pode ser ilustrada como na Figura 4.

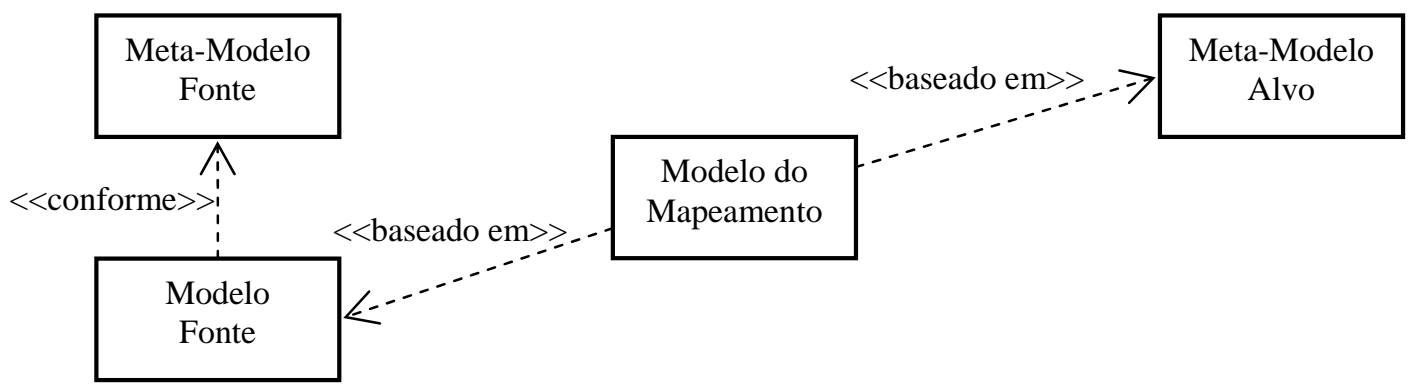

Figura 4: Mapeamento de instâncias.

Enquanto mapeamentos de tipos podem ser utilizados para transformar todas as instâncias que correspondam ao tipo descrito no mapeamento em suas saídas respectivas, mapeamentos de instâncias mapeiam um elemento a uma saída. Em mapeamentos de instâncias, o mapeamento para o PSM é feito da mesma maneira que em mapeamentos de tipos, mas a fonte do mapeamento necessita de mecanismos para indicar quais elementos deverão ser mapeados desta maneira. 


\subsubsection{Marcas}

Para realizar mapeamentos de instâncias, a MDA especifica marcas. Marcas representam conceitos no PSM e são aplicadas a elementos do PIM para indicar como estes devem ser transformados, isto é, quais elementos devem ser criados no PSM a partir do elemento marcado do PIM para realizar o conceito dado pela marca (OMG, 2003).

O uso de marcas nas transformações da MDA adiciona um passo ao processo geral definido pela OMG. No processo original, o PIM deve ser usado como entrada para as transformações, mas para utilizar marcas, elas devem ser aplicadas ao PIM antes das transformações serem realizadas, criando outro modelo. Esse novo modelo, o PIM adicionado de marcas, é chamado de PIM marcado. O PIM marcado deve ser utilizado com entrada nas transformações para PSM ou código ao invés do PIM.

Marcas também podem especificar requisitos no modelo alvo, ao invés de especificar o alvo de uma transformação (OMG, 2003). Assim elas podem ser usadas para especificar requisitos de qualidade de serviços. Outra particularidade de marcas é que elas podem utilizar parâmetros.

Para serem corretamente utilizadas, marcas podem precisar ser estruturadas, restringidas ou modeladas. Por exemplo, determinadas marcas podem ser aplicadas somente a certos elementos do modelo, enquanto que outras marcas podem ser mutuamente exclusivas.

Marcas podem ser providas pelo mapeamento, por um perfil UML ou por um modelo de marcas. Marcas providas por um mapeamento são específicas deste mapeamento e, por isso, associadas à plataforma do modelo alvo. Por serem associadas a uma plataforma, modelos marcados com essas marcas tornam-se específicos desta plataforma. Marcas também podem ser providas por um perfil UML. Marcas providas por um perfil UML podem ser associadas a mais de um mapeamento, e marcas providas por um modelo de marcas são 
independentes de mapeamentos, podendo ser usadas com diversos mapeamentos. As Figuras 5, 6 e 7, baseadas na Figura 1, mostram as relações entre as marcas, os modelos e a transformação de maneira simplificada. Em cada figura, as marcas são providas de maneira diferente. A Figura 5 mostra marcas providas pelo mapeamento, a Figura 6 por um perfil UML e a Figura 7 por um modelo de marcas.

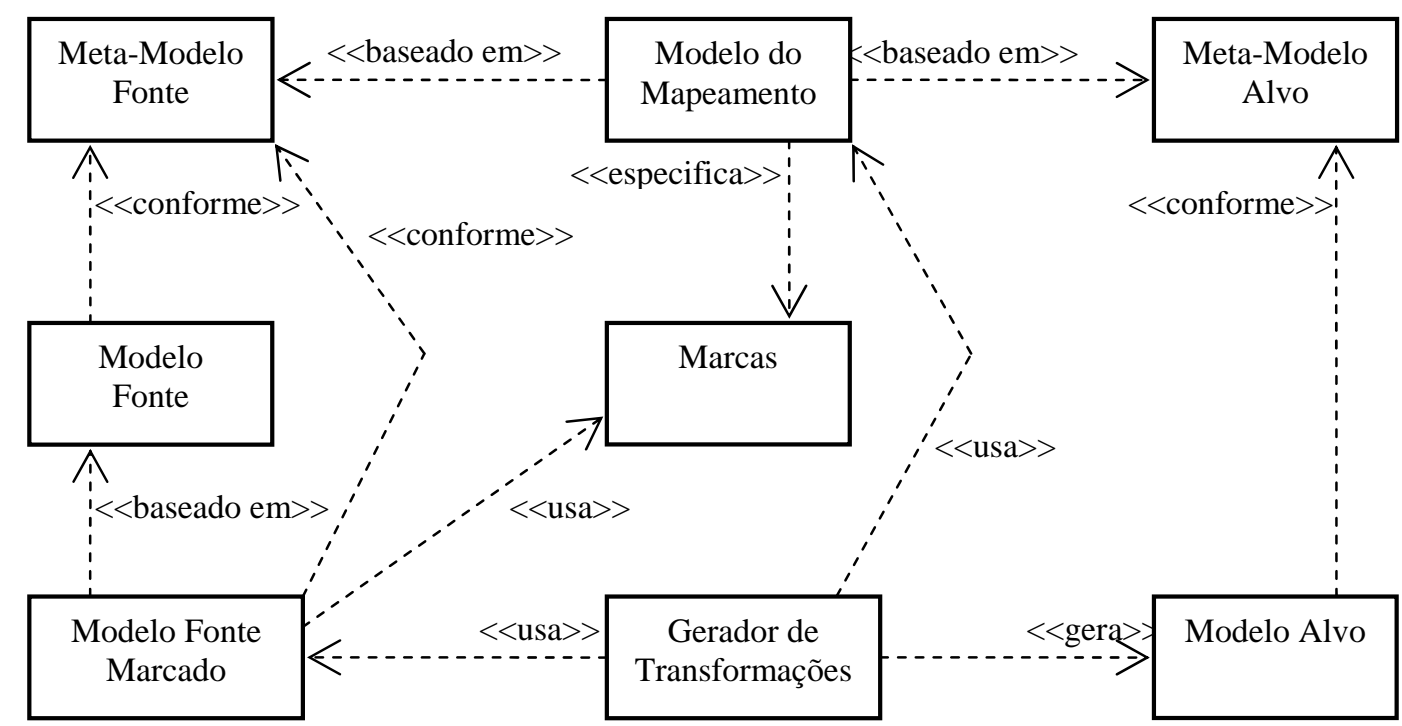

Figura 5: Mapeamento de instâncias com marcas providas pelo mapeamento.

O modelo de marcas define a estrutura e tipos de um conjunto de marcas, assim como valores padrão e regras que atribuem valores iniciais quando um valor de uma marca não é definido (MELLOR, 2004). Modelos de marcas são independentes de mapeamentos, e podem ser utilizadas com diferentes mapeamentos.

Um perfil UML pode prover marcas. O perfil UML pode fornecer vários mapeamentos para as marcas que ele dispõe. Perfis UML definem dois mecanismos básicos: estereótipos (stereotypes), restrições (constraints). Um estereótipo é definido por um nome e por um conjunto de elementos do metamodelo, e restrições podem ser associadas com estereótipos, impondo 
restrições nos elementos do meta-modelo correspondentes. As restrições podem ser expressas em qualquer linguagem, incluindo a linguagem natural ou a OCL.

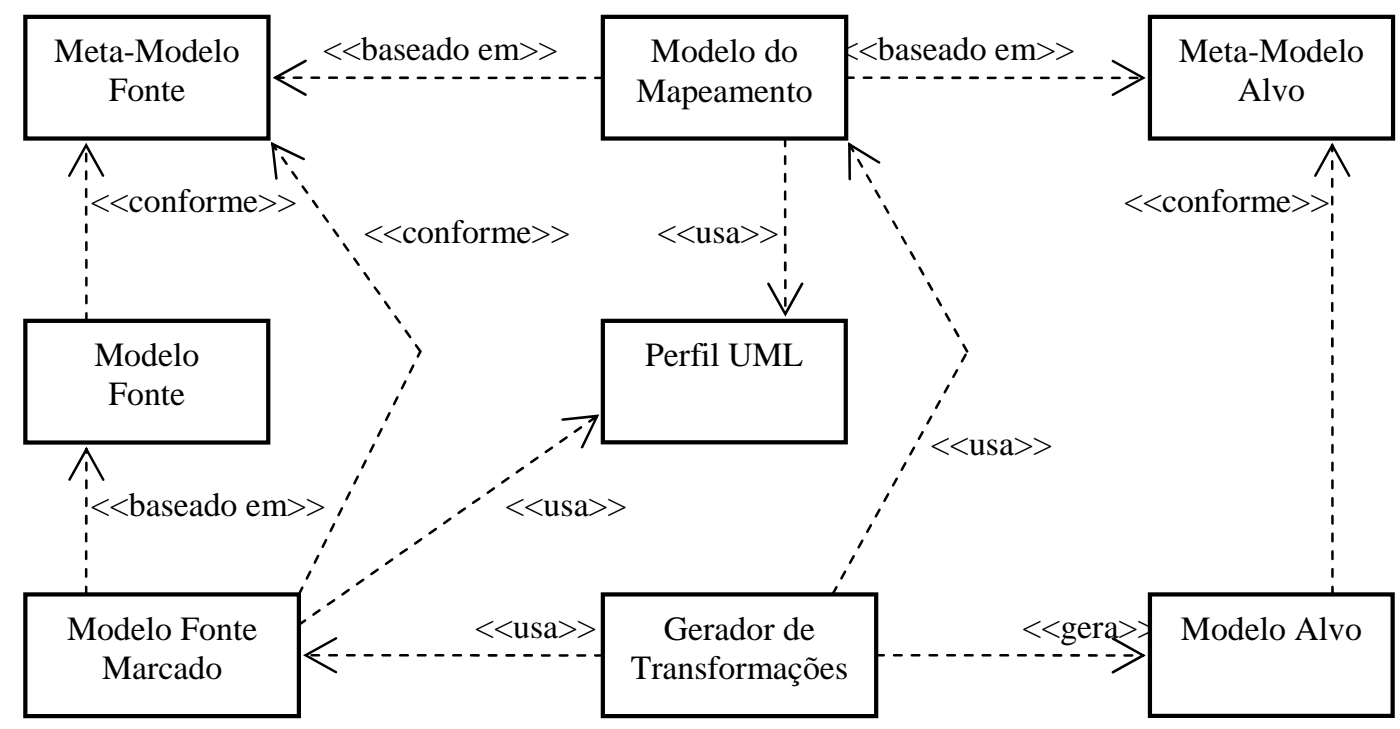

Figura 6: Mapeamento de instâncias com marcas de um perfil UML.

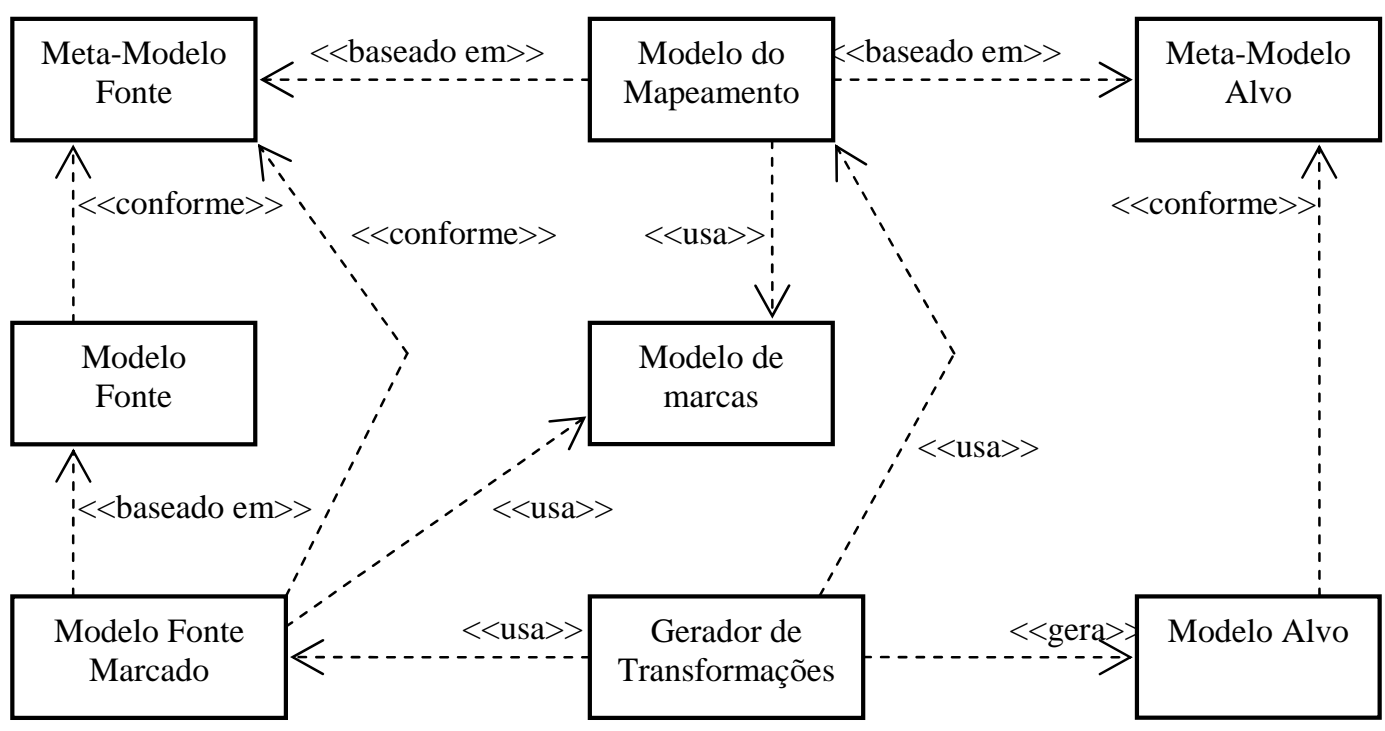

Figura 7: Mapeamento de instâncias com marcas de um modelo de marcas. 
A UML define como criar perfis de uma maneira simples (OMG, 2006c), no entanto a MDA não entra em detalhes de como associar as marcas deste perfil a um determinado mapeamento. Um exemplo de um perfil UML para EJB é mostrado na Figura 8.

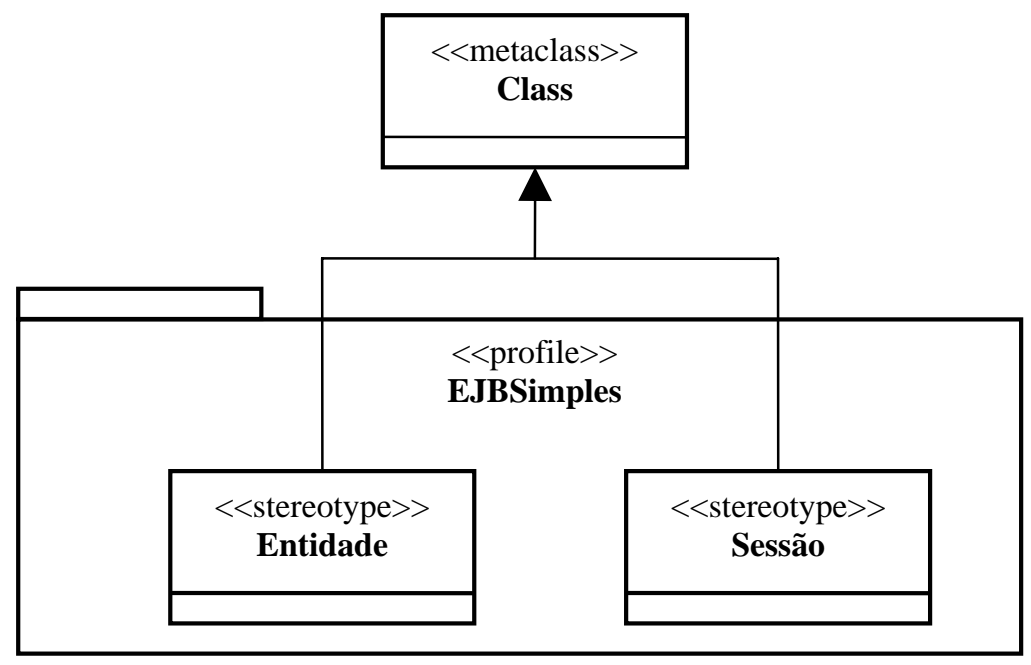

Figura 8: Exemplo de perfil UML para EJB.

Dentro de um pacote UML com o estereótipo <<profile>> são criadas duas classes Entidade e Sessão com o estereótipo <<stereotype>>. Essas classes definem estereótipos com os respectivos nomes. Ambas as classes estendem a meta-classe Class, o que define que estes estereótipos podem ser aplicados somente em instâncias de Class.

\subsubsection{Linguagem do mapeamento}

O mapeamento é especificado em uma linguagem, que pode ser linguagem natural, algoritmos, ou linguagem de mapeamento de modelos. $O$ 
campo de linguagem de mapeamentos é tão importante que a OMG criou uma especificação de linguagem de mapeamentos definida em (OMG, 2005), a MOF QVT. Ela é uma linguagem de mapeamento criada pela OMG e pode ser utilizada para fazer os mapeamentos da MDA.

As linguagens de mapeamento não são estudadas neste trabalho, são apenas mostradas as linguagens usadas nas ferramentas.

\subsubsection{Mapeamentos com gabaritos}

Um mapeamento pode incluir gabaritos, que são modelos parametrizados que especificam tipos particulares de transformações. Esses gabaritos são como padrões de projetos, mas podem incluir especificações mais específicas para guiar as transformações (OMG, 2003).

Em mapeamentos de tipos, gabaritos podem ser usados para especificar que um determinado padrão em um modelo deve ser transformado em outro determinado padrão. Esses padrões podem conter um ou mais elementos do modelo. Marcas podem ser utilizadas para especificar quais instâncias de um modelo devem ser transformadas de acordo com o gabarito, e quais valores devem preencher quais partes do gabarito.

\subsubsection{Transformações e mapeamentos de Modelos}

A MDA propõe algumas abordagens para as transformações de modelos. A principal transformação da MDA é a transformação do PIM para o PSM, sendo atualmente alvo de muitos estudos - (BÉZIVIN et al., 2005), (DELANOTE; STEEGMANS, 2006), (EUROPEAN SOFTWARE INSTITUTE, 2003), (GARCIA et al., 2002), (HUANG et al., 2003), (LANGLOIS et al., 2004), (MENS et al., 2005), (VARRÓ; PATARICZA, 2003), (WAMPLER, 2003). 
As transformações de modelos não precisam ser necessariamente feitas em uma etapa, elas podem ser feitas em partes para facilitar o desenvolvimento das transformações e diminuir sua complexidade. Em (ALMEIDA, et al., 2004a) e (ALMEIDA, et al., 2004b) é introduzida a noção de uma plataforma abstrata que seria usada para transformações parciais de PIM para PSM. As plataformas abstratas descritas representam o suporte provido por plataformas que é assumido pelo projetista na modelagem independente de plataforma. Elas são tipos genéricos de plataformas que podem ser concretizados em mais de uma plataforma concreta.

No Guia da MDA (OMG, 2003) são apresentadas cinco abordagens para as transformações: marcas, transformações de meta-modelos, transformação de modelos utilizando tipos, aplicação de padrões e união de modelos.

Os elementos gráficos definidos na Figura 9 são usados nas Figuras 10 a 14. As Figuras 10 a 14 são extraídas de (OMG, 2003).

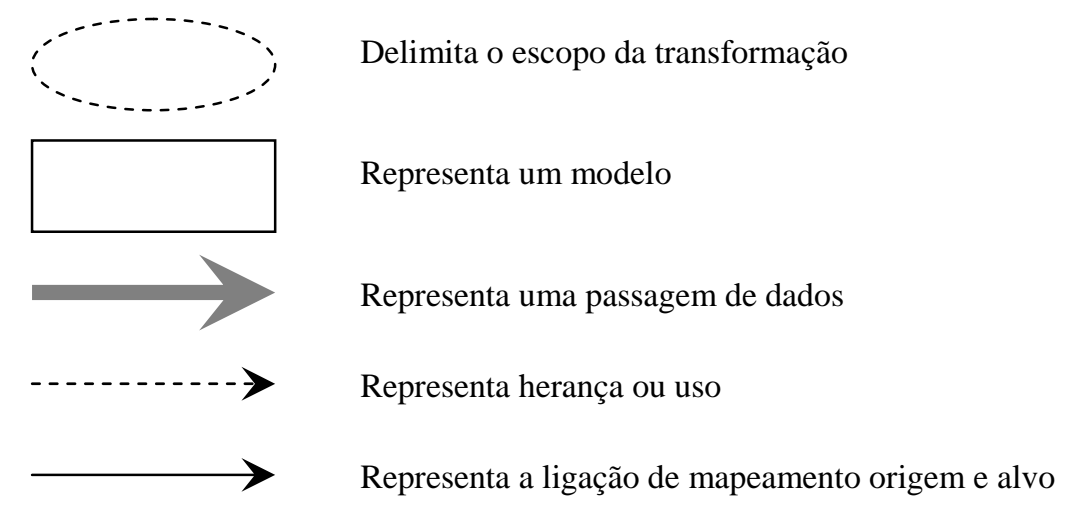

Figura 9: Significados dos elementos gráficos para as Figuras 10 a 14.

\subsubsection{Marcas}

Após a escolha da plataforma, cria-se, se não existir, um mapeamento para esta plataforma. Esse mapeamento possui um conjunto de marcas que 
devem ser usadas para marcar elementos do PIM para que este seja transformado em um PSM. Esse processo é mostrado na Figura 10, extraída de (OMG, 2003).

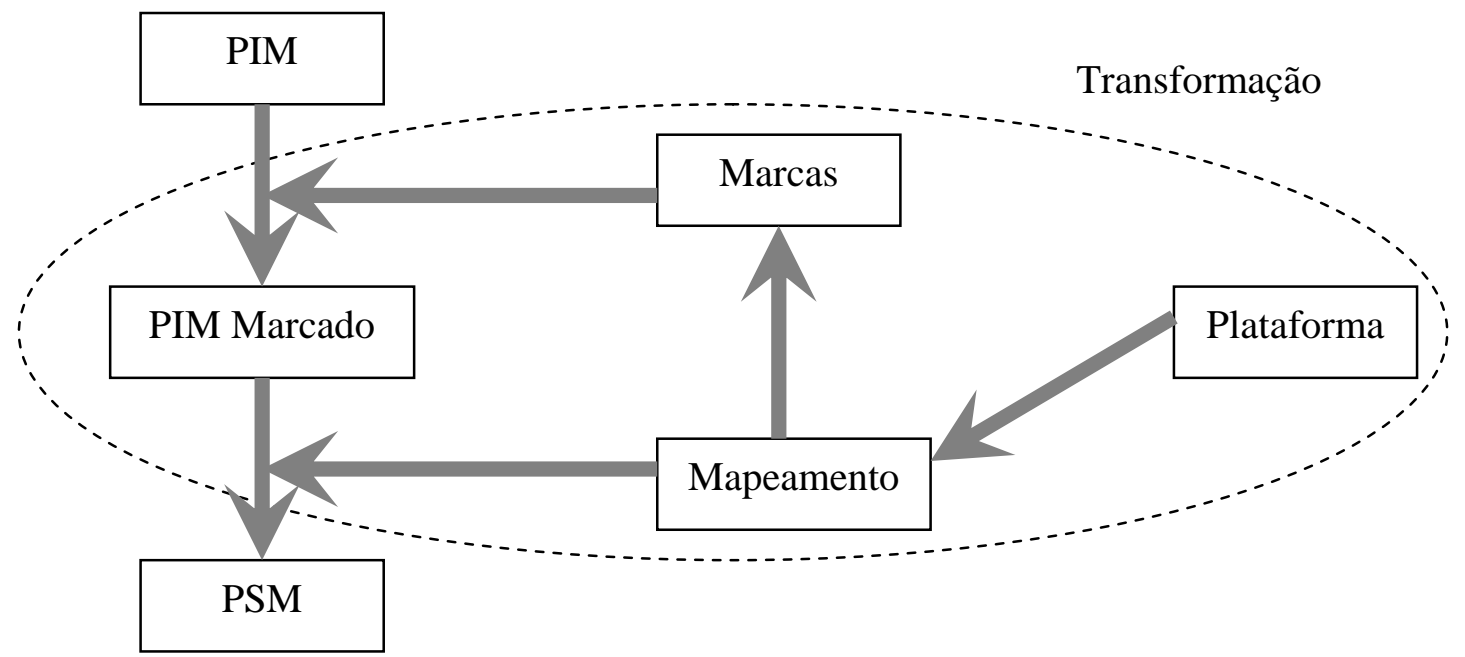

Figura 10: Transformações de modelos usando marcas.

\subsubsection{Transformações de meta-modelos}

O PIM é construído usando uma linguagem independente de plataforma especificada por um meta-modelo. Escolhe-se uma plataforma e constrói-se, se já não existir, uma especificação de uma transformação mapeando os metamodelos do PIM no PSM. A transformação segue esse mapeamento. Esse processo é mostrado na Figura 11, extraída de (OMG, 2003).

\subsubsection{Transformação de modelos utilizando tipos}

Esta transformação segue o mesmo padrão da transformação anterior, mas utilizando tipos independentes de plataforma. Os elementos do PIM são subtipos desses tipos independentes de plataforma. Esse processo é mostrado na Figura 12, extraída de (OMG, 2003). 


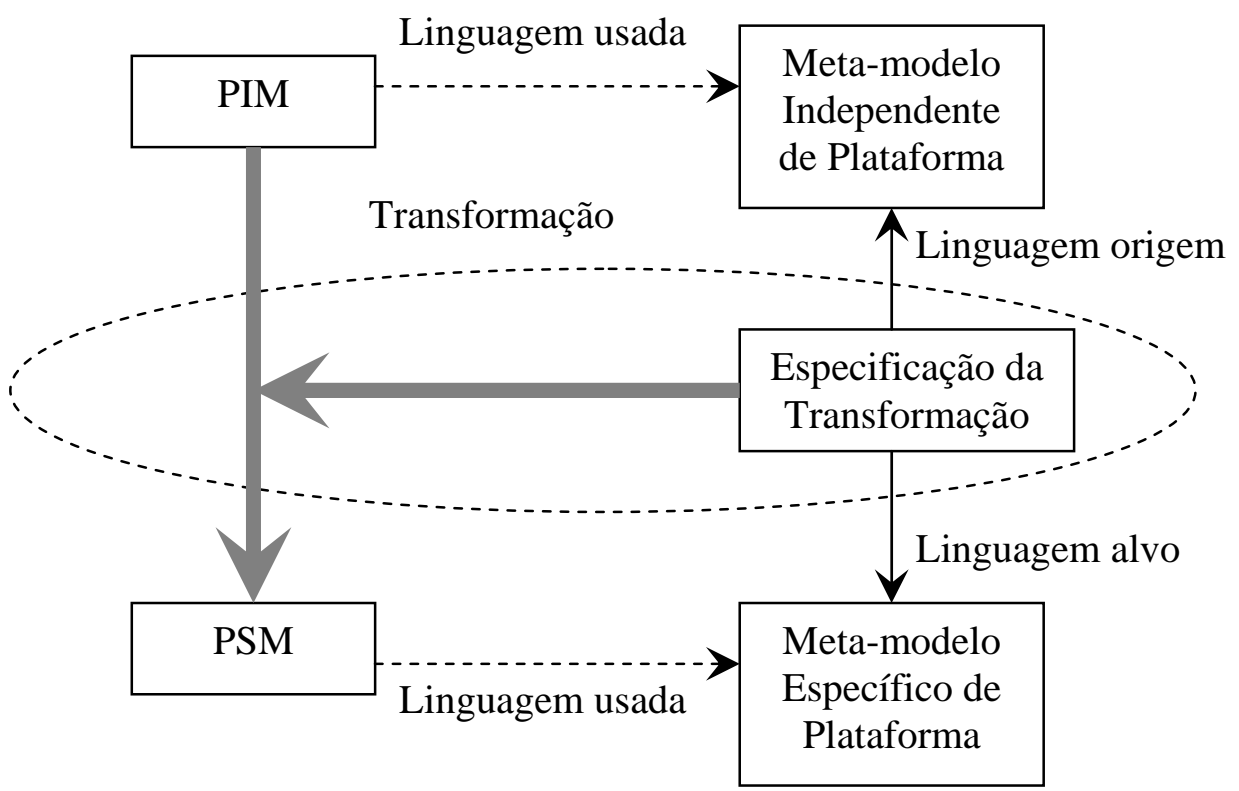

Figura 11: Transformações de meta-modelos.

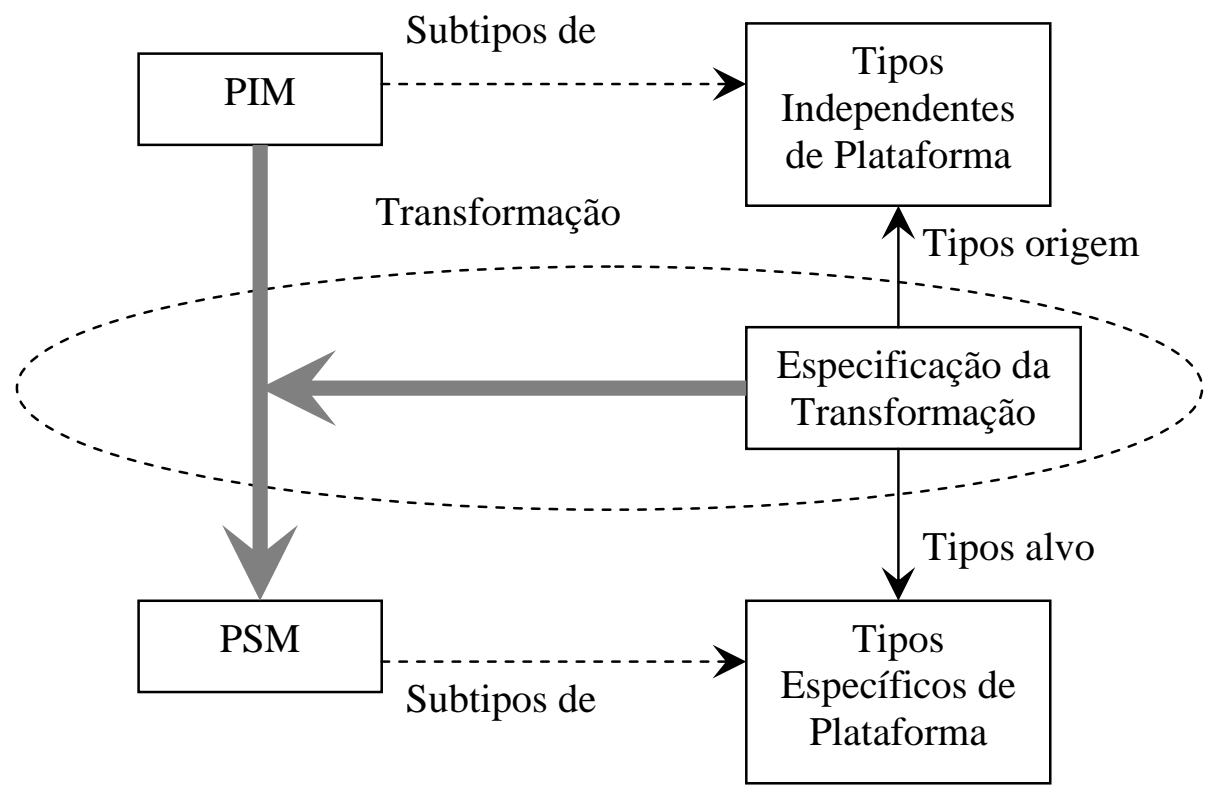

Figura 12: Transformação de modelos utilizando tipos. 


\subsubsection{Aplicação de gabaritos}

Gabaritos podem ser utilizados com transformações de meta-modelos e transformações de modelos para mapear o PIM para tipos e gabaritos no PSM. Gabaritos podem ser mapeados para padrões ou tipos no PSM. Gabaritos também podem especificar marcas que são o nome de gabaritos de projetos que são específicos para uma plataforma. Esse processo é mostrado na Figura 13, extraída de (OMG, 2003).

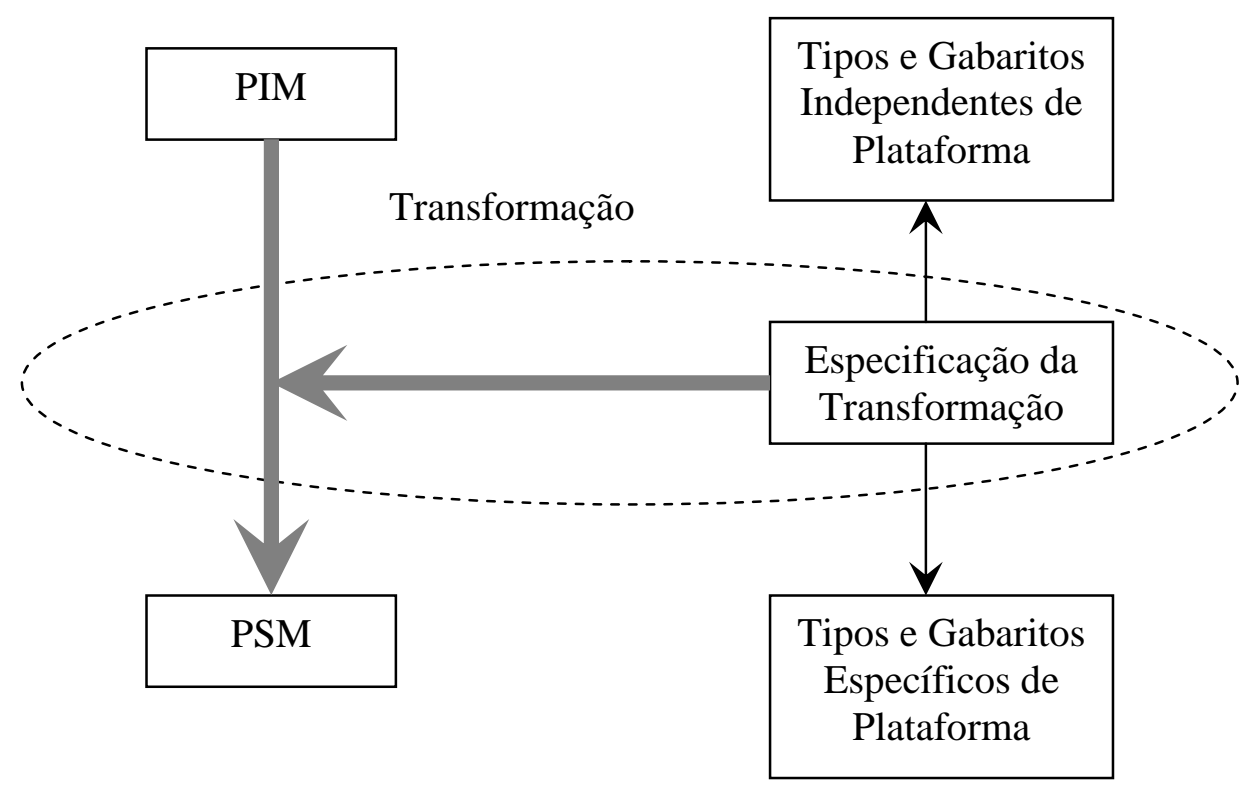

Figura 13: Transformação de modelos usando gabaritos e tipos.

\subsubsection{União de modelos}

Estas transformações são baseadas na união de modelos e são comuns na MDA. Por exemplo, o uso de padrões é considerado um tipo de união de modelos. Esse processo é mostrado na Figura 14, extraída de (OMG, 2003). 


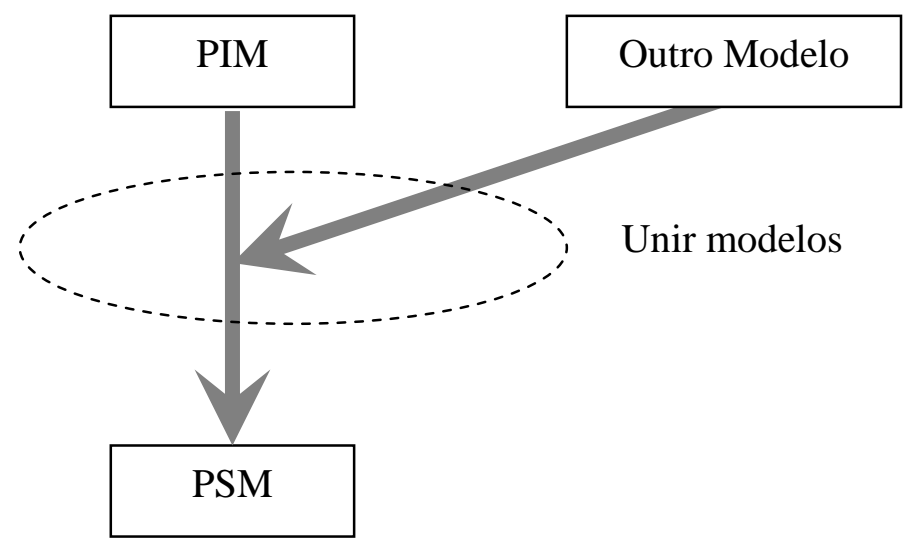

Figura 14: Transformação de modelos utilizando união de modelos.

\subsection{Exemplos de mapeamentos}

Para descrever melhor como são feitos mapeamentos, serão apresentados alguns exemplos criados para o presente trabalho, simulando uma transformação de um modelo UML para um programa em Java. Primeiramente são apresentados um subconjunto do meta-modelo da UML e um subconjunto do meta-modelo da linguagem Java. Em seguida, apresentamse exemplos de mapeamentos de tipos, subtipos, valores de instâncias e mapeamentos de instâncias, com o uso de marcas.

Para representar o PIM, foi escolhida a linguagem de modelagem recomendada pela OMG, a UML. O ponto forte da UML é a modelagem da estrutura do sistema, utilizando principalmente diagramas de classe para gerar a estrutura do sistema no PSM. Por isso, o exemplo de mapeamento será baseado na estrutura do sistema, mais precisamente, será utilizado um mapeamento de elementos do diagrama de classes da UML para a linguagem Java.

Além da UML, é necessário conhecer o meta-modelo da UML. Para os exemplos que seguem não será utilizada toda a UML e, por isso, apenas um 
subconjunto do meta-modelo é necessário, utilizando apenas alguns dos elementos relacionados ao diagrama de classes. Em (MELLOR, 2004) é apresentado um pequeno subconjunto que supre as necessidades dos exemplos, contendo os conceitos de Classe (Class), Propriedade (Property), Operação (Operation), Classificador (Classifier), Associação (Association) e Generalização (Generalization). O subconjunto apresentado em (MELLOR, 2004) é utilizado como base para a Figura 15.

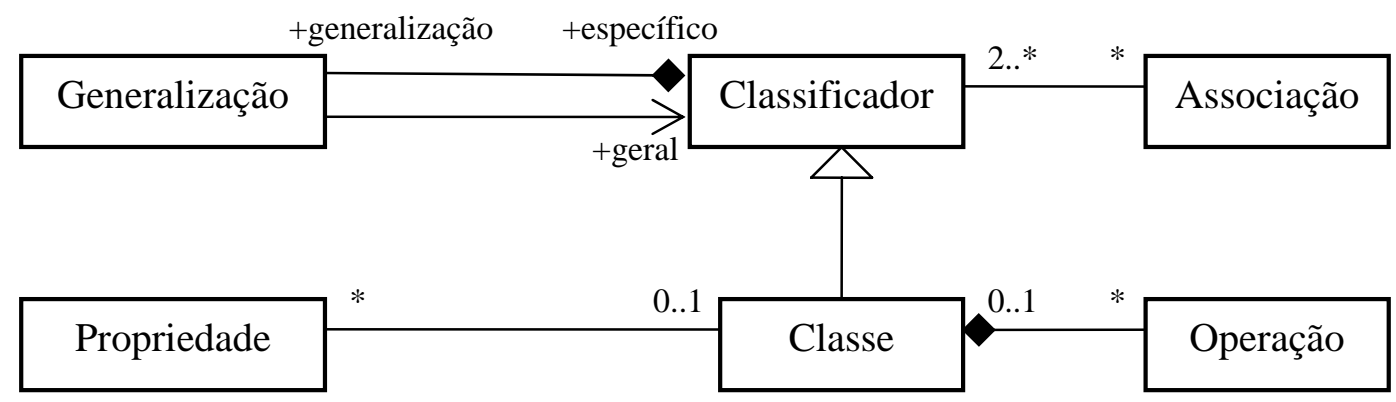

Figura 15: Subconjunto do meta-modelo da UML.

Nesse subconjunto observa-se que uma Classe pode ter diversas Operações e Propriedades, além de ser uma especialização de um Classificador, o que lhe possibilita ter muitas associações.

Além do meta-modelo fonte, é necessário o meta-modelo alvo. A linguagem Java possui um meta-modelo. Mais uma vez, para simplificar o exemplo, é utilizado apenas um subconjunto do meta-modelo. O subconjunto da linguagem Java é ilustrado na Figura 16, baseada em (INRIA, 2005).

O mapeamento mais simples de ser feito é o mapeamento de tipos, utilizando os meta-modelos apresentados. Os exemplos mostram mapeamentos de tipos entre os tipos Classe e Operação do meta-modelo da UML e os tipos ClasseJava e Método do meta-modelo da linguagem Java, respectivamente. Em seguida são apresentados exemplos de mapeamentos de subtipos e de valores de instâncias, e por fim, exemplos de mapeamentos de 
instâncias, utilizando marcas providas pelo mapeamento, por um perfil UML e por um modelo de marcas.

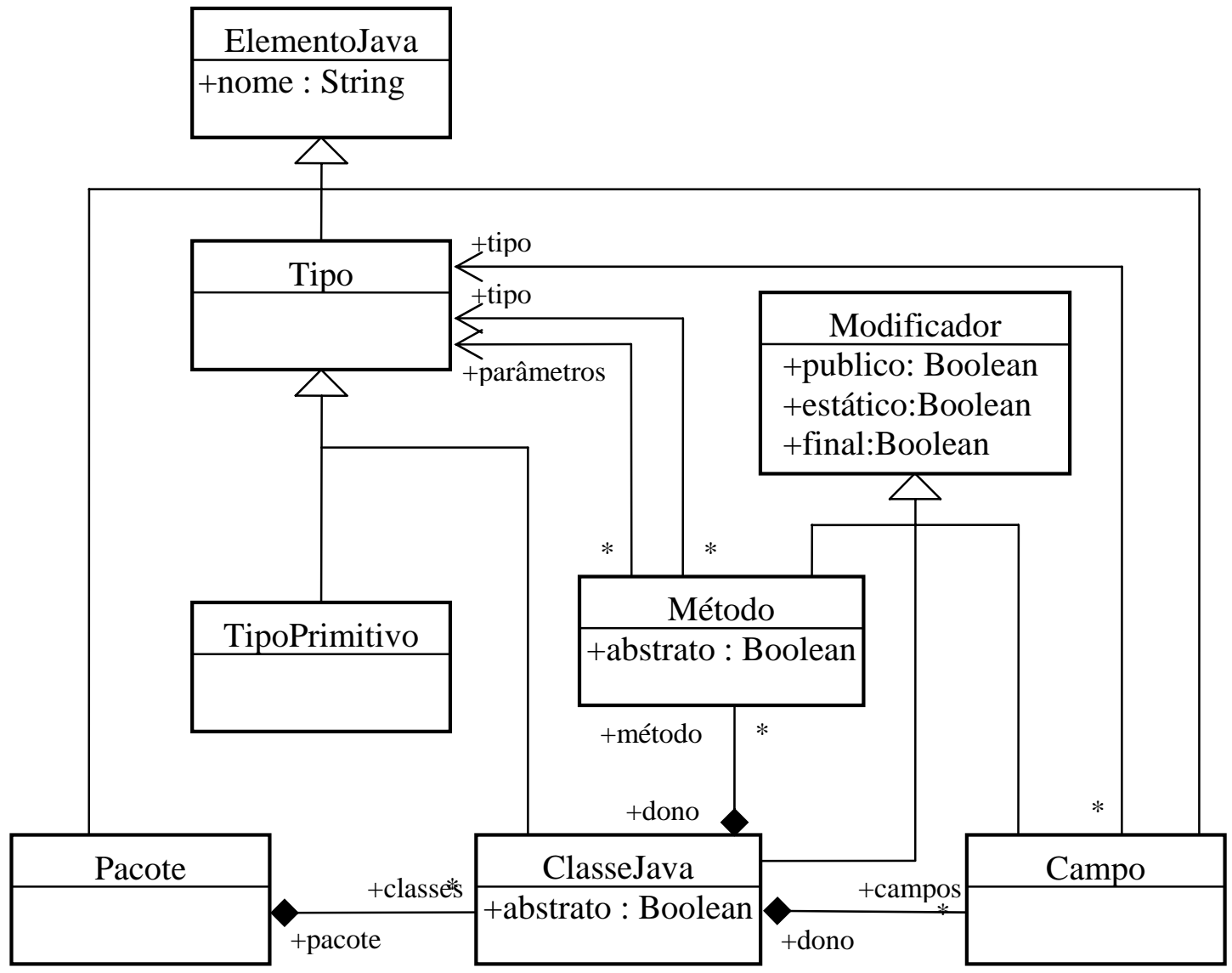

Figura 16: Subconjunto do meta-modelo da linguagem Java.

Nas seções 2.3.1, 2.3.2, 2.3.3 e 2.3.4 são apresentadas algumas opções de mapeamentos que a MDA oferece. Para ilustrar alguns dos mapeamentos, será utilizado o problema de uma determinada fonte ser mapeada de maneiras diferentes e exclusivas. Uma situação que explora a necessidade destes mapeamentos é tentar mapear o tipo Classe do meta-modelo da UML a uma classe Java normal ou a uma classe Java que cuja instanciação seja restrita a 
uma instância. Restringir uma classe a ter apenas uma instância é facilmente implementado utilizando o padrão de projetos Singleton (GAMMA, 1995).

\subsubsection{Exemplos de mapeamento de tipos}

O primeiro exemplo será mapear o tipo Classe do meta-modelo da UML ao tipo ClasseJava do meta-modelo da linguagem Java. Criar essa regra de mapeamento significa que instâncias do tipo Classe existentes no modelo de entrada corresponda, semanticamente, a instâncias do tipo ClasseJava em um programa Java. O mapeamento é ilustrado na Figura 17. A Tabela 2 explica os estereótipos usados nas Figuras 17 a 24.

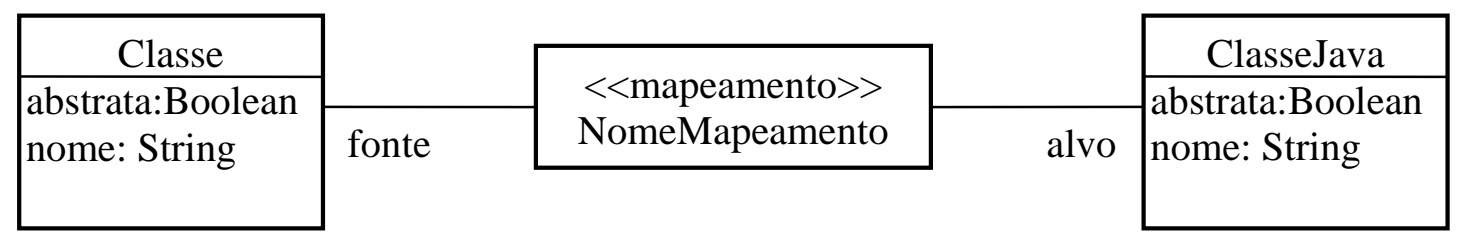

Figura 17: Exemplo de mapeamento de tipos.

Nesse mapeamento, vale a pena ressaltar que o tipo Classe do metamodelo da UML possui um atributo nome e um atributo abstrata, e o tipo ClasseJava também possui um atributo nome e um atributo abstrata. $\mathrm{O}$ mapeamento pode estabelecer que os valores dos atributos nome e abstrata das instâncias de Classe sejam designados para os atributos nome e abstrata, respectivamente, das instâncias de ClasseJava.

Outro exemplo é a regra de mapeamento do tipo Operação para o tipo Método. Essa regra significa que operações modeladas em UML são semanticamente equivalentes a métodos em um programa Java. Esses tipos possuem atributos que podem ter seus valores designados assim como 0 mapeamento anterior. Essa regra é mostrada na Figura 18 de maneira simplificada. O mapeamento final pode incluir as duas regras. 
Tabela 2: Estereótipos usados nas Figuras 17 a 24.

\begin{tabular}{|c|c|c|}
\hline Tipo de Nó & Notação & Referência \\
\hline Estereótipo & $<<$ mapeamento $>>$ & $\begin{array}{l}\text { Denota que um elemento corresponde } \\
\text { semanticamente a outro elemento. }\end{array}$ \\
\hline Estereótipo & <<stateless $>>$ & $\begin{array}{l}\text { Denota que um elemento corresponde } \\
\text { semanticamente a um EJB stateless session } \\
\text { bean }^{2} \text {. }\end{array}$ \\
\hline Estereótipo & $<<$ statelessJava $>>$ & $\begin{array}{l}\text { Denota que um elemento é uma classe Java } \\
\text { que implementa um EJB stateless session } \\
\text { bean }^{2} \text {. }\end{array}$ \\
\hline Estereótipo & $<<$ normal $>>$ & $\begin{array}{l}\text { Denota que um elemento corresponde } \\
\text { semanticamente a uma classe simples da } \\
\text { linguagem de programação do PSM. }\end{array}$ \\
\hline Estereótipo & <<único>> & $\begin{array}{l}\text { Denota que um elemento corresponde } \\
\text { semanticamente à implementação do padrão } \\
\text { de projetos Singleton (GAMMA, 1995). }\end{array}$ \\
\hline
\end{tabular}

\begin{tabular}{|c|c|c|c|c|}
\hline Operação & fonte & $<<$ mapeamento $>>$ & alvo & Método \\
\hline & & NomeMapeamento & & \\
\hline
\end{tabular}

Figura 18: Outro exemplo de mapeamento de tipos.

\footnotetext{
${ }^{2}$ EJB stateless representam um cliente no servidor JEE que não mantém um estado conversacional. Um estado conversacional é um estado de um objeto que mantém interações com um cliente do objeto. O estado de um objeto consiste dos valores das suas variáveis. (SUN, 2006).
} 


\subsubsection{Exemplo de mapeamento de subtipos}

Mapeamentos de subtipos são mapeamentos em que a fonte e/ou o alvo de um mapeamento são subtipos dos tipos do PIM e/ou PSM. Mapeamentos de subtipos possibilitam que um determinado tipo, como Classe, seja mapeado de maneiras diferentes e exclusivas.

A situação descrita anteriormente em que é necessário mapear de maneira exclusiva o tipo Classe do meta-modelo da UML a uma classe Java normal ou a uma classe Java que implementa um Singleton pode ser resolvida utilizando subtipos. Utilizando apenas tipos, é impossível criar um mapeamento onde o elemento fonte é o mesmo e não se quer utilizar ambos os mapeamentos.

Uma possível solução utilizando subtipos é mapear o tipo Classe para a classe Java normal e criar um subtipo de Classe mapeando este subtipo para uma classe Java que implementa o padrão de projetos Singleton. Esse mapeamento é ilustrado na Figura 19.

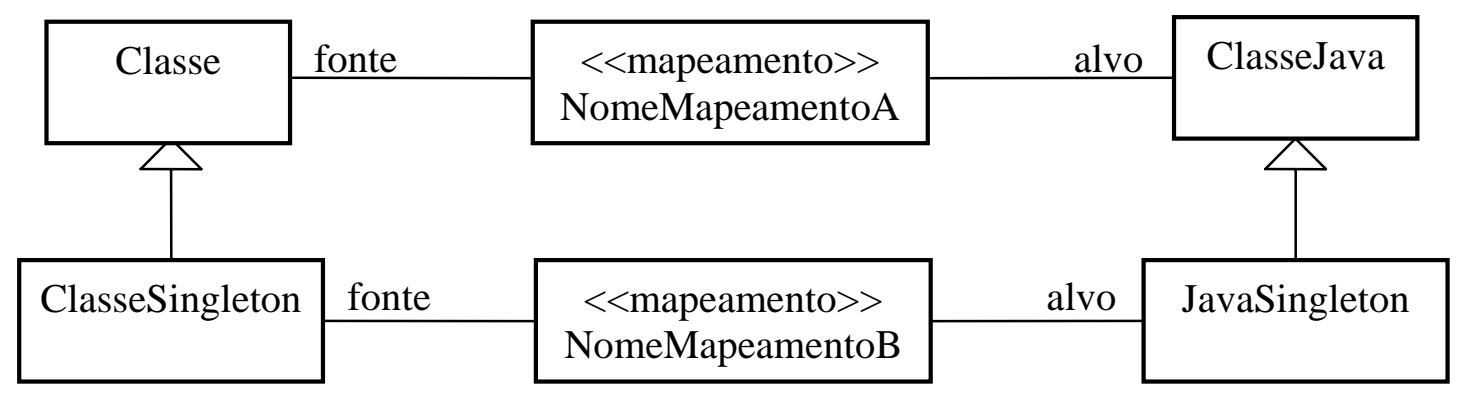

Figura 19: Exemplo de mapeamento de subtipos.

Na Figura 19 observa-se que Classe possui um subtipo chamado ClasseSingleton e que ClasseJava possui um subtipo JavaSingleton. O subtipo JavaSingleton implementa o padrão de projetos Singleton. No exemplo, continua existindo a regra de mapeamento de Classe para ClasseJava, mas além dela existe uma outra regra de mapeamento que faz a correspondência de 
ClasseSingleton a JavaSingleton. Desse modo, é necessário utilizar o metamodelo da UML estendido do subtipo ClasseSingleton como meta-modelo do PIM, além de utilizar o mapeamento mostrado na Figura 19. Ao se criar o PIM, deve-se criar elementos cujo tipo seja ClasseSingleton para todos os casos em que se queira que sejam criadas classes Java cuja instanciação seja restrita a uma instância no código.

\subsubsection{Exemplo de mapeamento de tipos com valores de instâncias}

Outra possibilidade para se resolver o problema de mapear um determinado tipo da UML de maneiras diferentes e exclusivas é utilizar mapeamentos de valores de instâncias. Para resolver o problema proposto, em que é necessário mapear o tipo Classe do meta-modelo da UML a uma classe Java normal, ou a uma classe Java que implementa um Singleton, basta criar um mapeamento que tenha como fonte o tipo Classe e especifique como saída ClasseJava ou JavaSingleton, dependendo do valor designado a um atributo de Classe nas suas instâncias.

Na Figura 20 é ilustrado uma possível solução do problema utilizando um atributo chamado único. O mapeamento é feito com uma regra fazendo a correspondência do tipo Classe aos tipos ClasseJava e JavaSingleton, e definindo qual das duas saídas deve ser utilizada pela verificação do valor do atributo único. Se o valor de único for true, será usado JavaSingleton como saída, e se o valor de único for false, será usada a saída ClasseJava. Todas as instâncias de Classe que se queira que sejam transformadas em JavaSingleton deverão ter o valor de seus atributos único alterados para true.

Esse método possui a vantagem de não precisar alterar o meta-modelo fonte, como o mapeamento de subtipos faz. Apesar disso, é necessário definir um atributo para o tipo a ser mapeado, e é necessário atribuir o valor deste 
novo atributo a todas as instâncias do tipo que se queira transformar de maneira diferente.

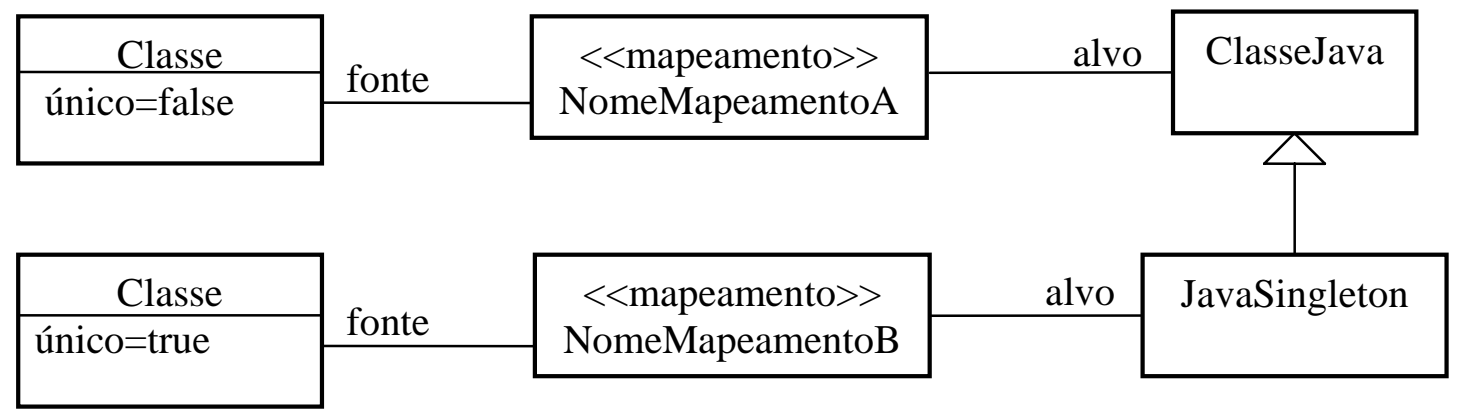

Figura 20: Exemplo de mapeamento de tipos com valores de instâncias.

\subsubsection{Exemplo de mapeamento de instâncias}

Mapeamentos de instâncias definem marcas, que representam conceitos no PSM. As marcas devem ser utilizadas para anotar elementos do modelo fonte para que estes possam ser transformados de maneiras diferentes. Mapeamentos de instâncias diferem de mapeamentos de tipos e seus derivados, por não se basear em tipos para definir a fonte do mapeamento e sim em anotações feitas com marcas nos elementos do modelo.

Marcas são comumente usadas para mapear determinados elementos do PIM a estruturas que representam conceitos referentes à plataforma. Um exemplo seria o mapeamento de um elemento do modelo a um EJB stateless session bean, como ilustrado na Figura 21.

\begin{tabular}{|c|c|c|c|c|}
\hline \multirow{2}{*}{$\begin{array}{c}<<\text { stateless }>> \\
\text { Classe }\end{array}$} & fonte & \multirow{2}{*}{$\begin{array}{l}<<\text { mapeamento }>> \\
\text { NomeMapeamento }\end{array}$} & alvo & \multirow{2}{*}{$\begin{array}{c}<<\text { statelessJava }>> \\
\text { ClasseJava }\end{array}$} \\
\hline & & & & \\
\hline
\end{tabular}

Figura 21: Exemplo de mapeamento de instâncias. 
O mapeamento é feito com uma regra que corresponde um elemento como fonte, anotado com a marca <<stateless>>, à estrutura necessária para criar um stateless session bean no PSM. Por exemplo, se a plataforma escolhida for Java utilizando EJB 3.0 (SUN, 2006) na implementação do servidor de aplicações JBoss (JBOSS, 2006) e a transformação for direta para código, o alvo do mapeamento seria uma classe Java marcada com a anotação ${ }^{3} @$ Stateless (JBOSS, 2006).

No entanto, algumas marcas podem necessitar que o elemento marcado possua um determinado tipo para que o mapeamento possa gerar a saída. No exemplo anterior, para gerar um stateless session bean é necessário que o elemento marcado possua um nome e operações que o bean deverá prover. Um tipo que possui tais atributos, e normalmente é usado para criar mapeamentos para EJB, é Classe da UML. Dada essa necessidade, é preciso que o uso da marca <<stateless $>>$ seja restrito a elementos do tipo Classe no PIM.

O uso de marcas também possibilita a solução do problema proposto de mapear uma determinada fonte do mapeamento a diferentes saídas de maneira exclusiva, no entanto existe o empecilho de marcas mapearem apenas elementos do modelo marcados e, assim como no caso de mapeamentos de tipos com valores de instâncias, é necessário marcar todas as instâncias a serem transformadas dessa maneira. Para resolver o problema, basta criar duas marcas, uma sendo mapeada para ClasseJava e a outra para JavaSingleton. Na Figura 22 é ilustrada essa solução com as marcas <<normal>> e <<único>> sendo mapeadas para ClasseJava e JavaSingleton respectivamente.

\footnotetext{
${ }^{3}$ Anotações em Java são informações extras associadas a pontos do código que é usado por um programa para gerar código extra automaticamente (SUN, 2006).
} 
Outra possibilidade é utilizar um mapeamento híbrido, com tipos e instâncias. Seria criado um mapeamento do tipo Classe para ClasseJava e um mapeamento de uma marca <<único>> para um JavaSingleton. Esse mapeamento híbrido está ilustrado na Figura 23.

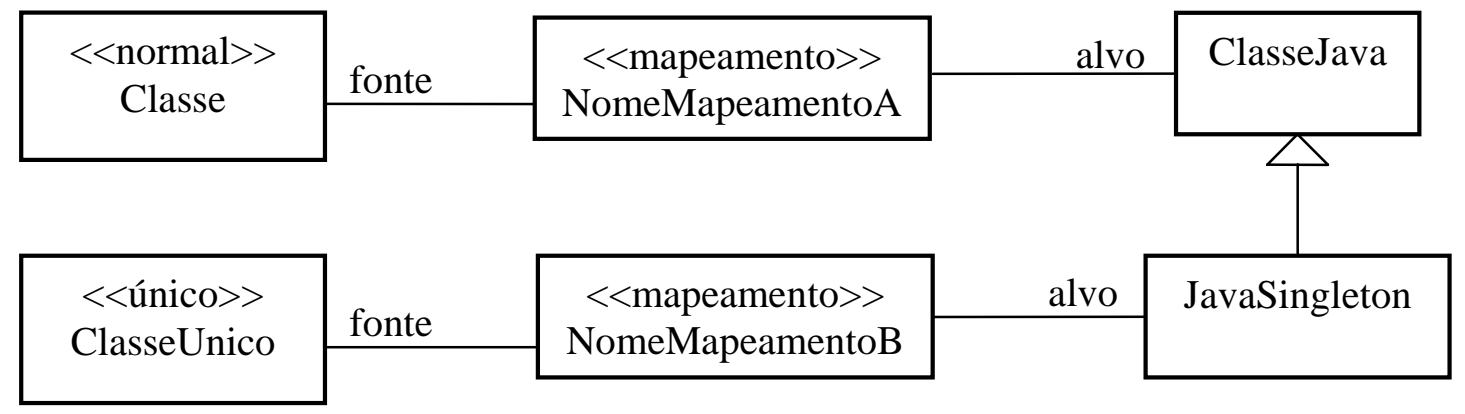

Figura 22: Exemplo de mapeamento de instâncias utilizando marcas.

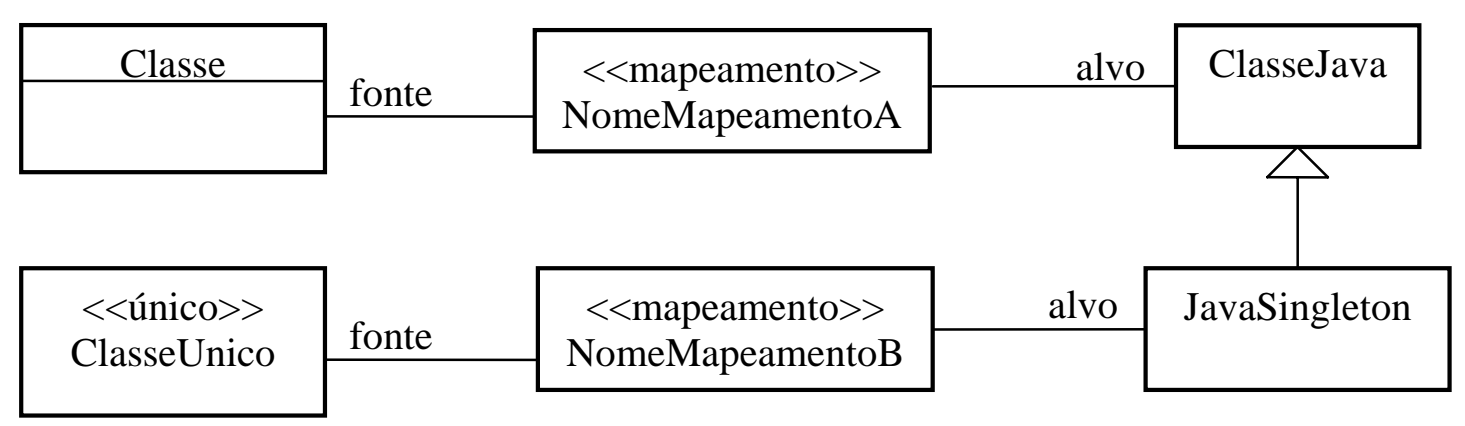

Figura 23: Exemplo de mapeamento híbrido de tipos e instâncias.

Na solução proposta para o problema, as marcas podem ser providas pelo mapeamento, por um perfil UML ou por um modelo de marcas. Em qualquer um desses casos, a solução não se altera. 


\subsubsection{Exemplo de transformação}

Como definido anteriormente, uma transformação é a execução de um mapeamento. Pode-se utilizar o mapeamento proposto na seção 2.3.4, ilustrado na Figura 23, que possui duas regras, uma para mapear o tipo Classe ao tipo ClasseJava (referenciada como regra 1 ) e outra regra para mapear a marca <<único>> a JavaSingleton (referenciada como regra 2). Como entrada para esse mapeamento, é utilizado um PIM simplificado, ilustrado na Figura 26.

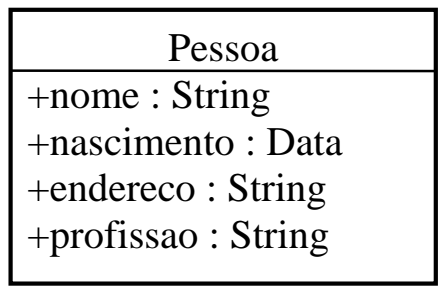

\begin{tabular}{|c|}
\hline$<<$ único $>>$ \\
Papa \\
\hline +nome : String \\
+nascimento : Data \\
+endereco : String \\
+profissao : String \\
\hline
\end{tabular}

Figura 24: PIM simplificado usado como entrada no exemplo da transformação.

A transformação deve ler o modelo de entrada e verificar as regras do mapeamento para descobrir qual regra deve ser executada para cada elemento. Nesse exemplo, a regra 2 é aplicada ao elemento Papa, pois a regra estabelece que elementos anotados com a marca <<único>> deverão ser transformados segundo esta regra, e a regra 1 é aplicada ao elemento Pessoa, pois ele é do tipo Classe, fonte desta regra. Deve-se observar que a regra 2 é aplicada antes da regra 1, pois mapeamentos de marcas são feitos para transformar elementos de maneira diferente, e se a regra de tipos for aplicada primeiro, isso não acontecerá. A saída da transformação serão duas classes Java, uma para cada elemento de entrada. As saídas das regras 1 e 2 são listadas nas Figuras 25 e 26, respectivamente.

A MDA também especifica que a transformação deve gerar, além do PSM, um registro da transformação, indicando qual regra do mapeamento foi aplicada a qual elemento do PIM e qual saída foi gerada para cada um dos 
elementos. Para esse exemplo, o registro da transformação pode seguir a definição XML apresentada na Figura 27.

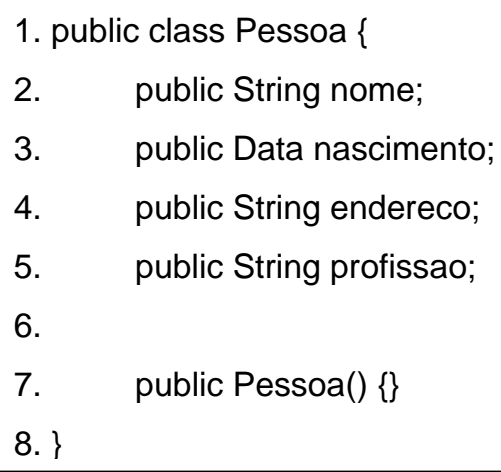

Figura 25: Código gerado pela regra 1 para a classe Pessoa.

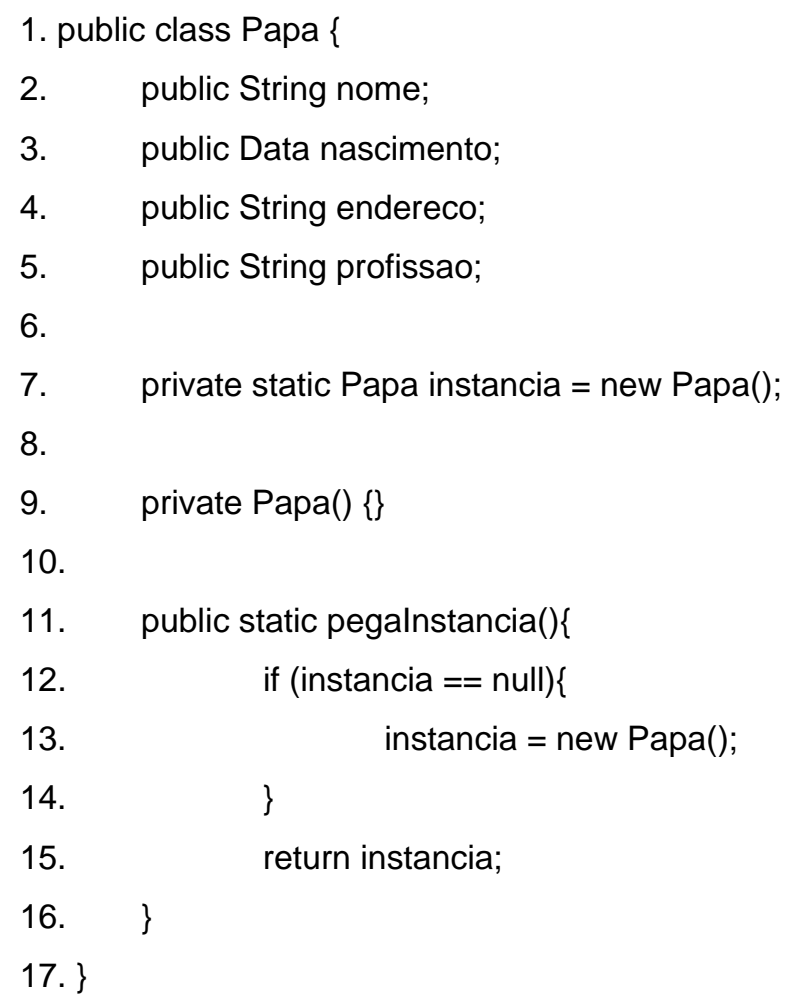

Figura 26: Código gerado pela regra 2 para a classe Papa. 
Página 40

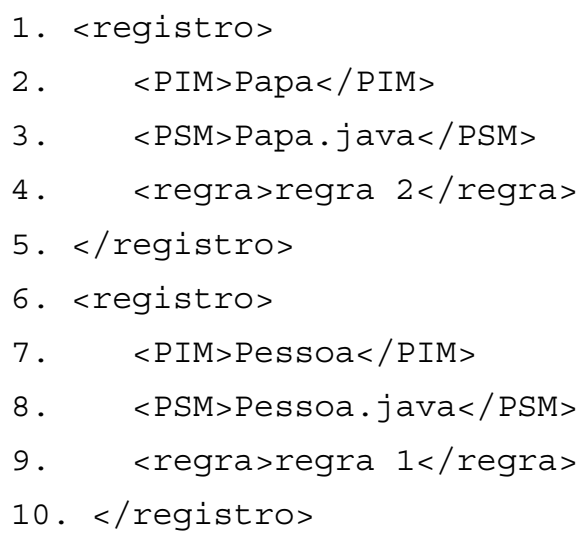

Figura 27: Exemplo de registro da transformação. 


\section{Analise de três ferramentas MDA}

Este capítulo descreve três ferramentas MDA com foco nos seguintes tópicos: a implementação dos conceitos da MDA e a abordagem destas ferramentas para as transformações de PIM para PSM ou código. As três ferramentas são OptimalJ (COMPUWARE, 2006), AndroMDA (ANDROMDA, 2006) e ArcStyler (ARCSTYLER, 2006).

A OptimalJ e ArcStyler foram escolhidas por serem as duas ferramentas mais bem cotadas segundo (TARIQ, 2005), e a AndroMDA foi escolhida porque é uma ferramenta de código aberto. A OMG recomenda o uso de UML ao modelar o sistema e as três ferramentas seguem essa recomendação. Além disso, em nenhuma ferramenta é necessário criar os mapeamentos, todas elas provêm mapeamentos.

\subsection{Descrição das ferramentas}

Esta seção descreve os principais conceitos das três ferramentas e a aderência destes conceitos em relação aos conceitos como preconizados pela MDA.

A descrição é relativamente detalhada, procurando apresentar as principais decisões dos projetos das ferramentas para o suporte às recomendações da MDA quanto a transformações e mapeamentos.

\subsubsection{OptimalJ}

A descrição geral da ferramenta OptimalJ se baseia em (COMPUWARE, 2006) e na análise da ferramenta realizada para o presente trabalho. 


\subsubsection{Descrição Geral}

A OptimalJ utiliza um subconjunto da UML como linguagem de modelagem e o MOF como meta-meta-modelo. A OptimalJ divide o desenvolvimento de um sistema em três etapas, cada uma com seu modelo: Modelo de Domínio, Modelo de Aplicação e Modelo de Código.

Segundo a OptimalJ, o Modelo de Domínio define a funcionalidade e a estrutura, sem detalhes específicos de tecnologia. O Modelo de Domínio é dividido em três diagramas: um diagrama de classes para modelar a estrutura do sistema com as classes de domínio e suas associações; outro diagrama de classes para modelar a informação comportamental na forma de declarações de serviços de domínio e operações de domínio (fornecem os dados necessários aos componentes dos serviços de domínio para que implementem o comportamento desejado); e um diagrama de atividade, que modela o processo de um fluxo de trabalho na forma de atividades que podem invocar serviços de domínio, operações dos serviços de domínio, ou chamadas de processo para executar suas atividades.

O modelo seguinte é o Modelo de Aplicação, que descreve a funcionalidade, baseado em determinada tecnologia ou subsistema sendo dividido em módulos que representam unidades de implementação, todos representados por diagramas de classes. Os módulos incluem a camada de persistência, a de acesso aos dados, a de lógica de negócios e a camada de apresentação do sistema. A OptimalJ ainda provê um Modelo de Integração que possibilita a aplicação conectar-se a aplicações e componentes externos. $\mathrm{O}$ Modelo de Aplicação adiciona não somente a tecnologia ao sistema, mas também a arquitetura. Quando o Modelo de Domínio é transformado em Modelo de Aplicação, uma arquitetura de camadas, como camada de apresentação e camada de negócios, é aplicada ao sistema.

Por fim, existe o Modelo de Código, que provê uma implementação do sistema descrito nos modelos anteriores. Contém o código fonte, descritores e scripts SQL. A OptimalJ automaticamente cria código implementando padrões 
de projeto (GAMMA, 1995), incluindo padrões de projeto J2EE, assim como padrões de projeto criados pelo usuário.

Para a OptimalJ, os mapeamentos da transformação do Modelo de Domínio para o Modelo de Aplicação são feitos baseados em regras que mapeiam tipos do modelo fonte a tipos do modelo alvo. A ferramenta também disponibiliza algumas regras de mapeamento de tipos baseados em valores de instâncias do modelo, em que os elementos são transformados de maneira diferente do mapeamento do seu tipo. Esses mapeamentos de tipos com valores de instâncias são disponibilizados como configurações que podem ser feitas em propriedades dos elementos do modelo.

Outro mecanismo de auxílio às transformações que a OptimalJ disponibiliza é a criação de novas meta-classes baseadas no MOF para os modelos de domínio e aplicação. As novas meta-classes são criadas para que possam ser utilizadas na modelagem, possibilitando a criação de outros mapeamentos.

A linguagem de mapeamento utilizada pela OptimalJ é Java. Devem ser construídos algoritmos para as regras do mapeamento em métodos Java, nos quais os parâmetros de entrada descrevem o tipo e/ou gabarito esperado do Modelo de Domínio. O retorno do método é o resultado da transformação, isto é, um novo elemento do Modelo de Aplicação.

A OptimalJ permite que seja escolhida um estilo arquitetônico para o código da aplicação na criação do projeto. A escolha do estilo arquitetônico influi na transformação de PIM para PSM, determinando quais mapeamentos serão usados, para escolher os gabaritos que vão gerar o PSM. Alguns exemplos de estilo arquitetônico possíveis são: arquitetura em três camadas, arquitetura em duas camadas, arquitetura em duas camadas baseada em serviços, etc.

A versão analisada neste estudo foi a OptimalJ Edição de Arquitetura 4.0.00 (COMPUWARE, 2006). 


\subsubsection{Conceitos da MDA na OptimalJ}

A OptimalJ não utiliza modelos independentes de computação, o CIM da MDA. O modelo inicial do desenvolvimento na OptimalJ, chamado pela ferramenta de Modelo de Domínio, define a funcionalidade e a estrutura sem detalhes específicos de tecnologia e, por isso, é classificado como o PIM. O modelo seguinte, denominado Modelo de Aplicação descreve a funcionalidade, baseado em determinada tecnologia ou subsistema, e por isso,descrever o sistema e a plataforma utilizada, deve ser classificado como o PSM da MDA. O Modelo de Código desta ferramenta equivale ao código.

O processo definido pela OptimalJ, utilizando os termos da MDA, se resume a criar o modelo PIM de acordo com as regras da ferramenta, transformá-lo em um PSM que pode ser editado de acordo com as necessidades e, por fim, transformar o PSM em código. A OptimalJ não permite que o PIM seja transformado diretamente em código. Ao transformar o PIM em PSM, a OptimalJ também adiciona um estilo arquitetônico ao modelo. A MDA define que uma transformação do PIM para PSM deve adicionar uma plataforma ao sistema e, na definição da MDA, uma plataforma não inclui um estilo arquitetônico. Portanto, a inserção de um estilo arquitetônico na aplicação durante a transformação do PIM para PSM é uma característica da ferramenta OptimalJ, e não uma definição da MDA.

Um resumo de como os modelos da OptimalJ são relacionados aos modelos da MDA é mostrado na Tabela 3.

Tabela 3: Cobertura de modelos MDA com modelos da OptimalJ.

\begin{tabular}{|l|l|}
\hline \multicolumn{1}{|c|}{ MDA } & \multicolumn{1}{c|}{ OptimalJ } \\
\hline CIM & Não implementa \\
\hline PIM & Modelos de Domínio \\
\hline PSM & Modelos de Aplicação \\
\hline Código & Modelo de Código \\
\hline
\end{tabular}


Os mapeamentos da OptimalJ podem ser feitos com regras que mapeiam tipos, subtipos e tipos com valores de instâncias do modelo fonte a tipos e gabaritos do modelo alvo. Isso significa que a OptimalJ utiliza os mapeamentos de tipos da MDA nas suas transformações, como descrito no capítulo 2. Na OptimalJ, os mapeamentos mais comuns são mapeamentos de tipos, baseados nos meta-modelos fonte e alvo. As transformações da OptimalJ podem ser classificadas como transformações de meta-modelos, já que todos os modelos da OptimalJ são baseados no MOF, e transformações de modelos, pois apesar das transformações utilizarem principalmente meta-modelos como base, elas também podem usar subtipos.

Como a OptimalJ não possui mapeamentos de instâncias, utiliza apenas mapeamentos de tipos, ela não possui marcas, como descrito na seção 2.2.2.3. Como a OptimalJ não usa marcas, ela não utiliza o PIM marcado como entrada para a transformação de PIM para PSM. Um registro de transformação é gerado após a transformação de PIM para PSM, em que cada elemento do modelo guarda uma lista dos elementos a partir dos quais ele foi criado e/ou uma lista dos elementos criados a partir dele.

Do processo definido pela MDA, a OptimalJ cobre a criação do PIM, a transformação para PSM, edição do PSM e transformação para código, além de gerar o registro da transformação.

\subsubsection{AndroMDA}

A descrição geral da ferramenta AndroMDA se baseia em (ANDROMDA, 2006) e na análise da ferramenta realizada para o presente trabalho.

\subsubsection{Descrição Geral}

AndroMDA é um arcabouço de código aberto que implementa transformações da MDA (ANDROMDA, 2006). Ela é divida em núcleo e plugins, 
chamados de cartuchos, que são adicionados ao núcleo para realizar as transformações. Cartuchos são componentes que contém um mapeamento para uma determinada plataforma.

A linguagem de modelagem dessa ferramenta é a UML. A AndroMDA utiliza apenas um modelo, usado como entrada para as transformações e geração direta de código. Esse modelo é chamado de PIM do sistema, e a AndroMDA especifica que ele não pode conter qualquer tipo de dado específico de plataforma nos seus elementos, apenas tipos de dados genéricos. O modelo utiliza diagramas de casos de uso, diagramas de classes e diagramas de atividade da UML.

Para garantir que os tipos de dados corretos sejam usados, a AndroMDA desenvolveu um perfil UML que deve ser incluído como parte do modelo. Esse perfil UML contém todos os tipos de dados, estereótipos e valores anotados genéricos que devem ser utilizados com a ferramenta e todos os seus cartuchos. O modelo deve ser construído utilizando os tipos de dados genéricos definidos no perfil UML, e os elementos do modelo podem ser anotados com os estereótipos para que eles sejam transformados de maneira diferente.

Para gerar o código a partir do PIM do sistema, o modelo deve ser usado como entrada para a ferramenta e os cartuchos necessários devem ser escolhidos. Os cartuchos contêm o mapeamento para as plataformas, então a escolha dos cartuchos deve ser baseada na plataforma na qual se quer que o sistema seja construído. Desse modo, a escolha dos cartuchos define a plataforma do sistema. Mapeamentos na AndroMDA são feitos utilizando regras de mapeamento, as quais declaram os elementos do PIM do sistema esperados como entrada na regra e os elementos ou gabaritos alvos.

As regras de mapeamento da AndroMDA definem entradas baseadas em três possibilidades: tipos dos elementos, valores de propriedades ou estereótipos, e saídas baseadas em gabaritos. Os tipos e os estereótipos estão presentes no perfil UML. Os elementos do modelo de entrada são analisados 
pelas regras e, ao encontrar elementos cujos tipos, valores de propriedades ou estereótipos sejam os requeridos por uma determinada regra, ela é aplicada. O gabarito definido na regra e os valores do elemento de entrada são passados para um gerador de gabaritos (ou máquina de gabaritos), que irá gerar o código seguindo o padrão descrito e utilizando os valores recebidos para preencher o os valores necessários do gabarito. O gerador de gabaritos Velocity acompanha a ferramenta, mas pode ser substituída por outro gerador, de acordo com a necessidade. Os mapeamentos são descritos em XML e interpretados pela ferramenta utilizando a linguagem Java.

O primeiro passo para utilizar a AndroMDA é criar um modelo do sistema utilizando o perfil UML que ela dispõe. Em seguida, um projeto deve ser criado, escolhendo os cartuchos e um estilo arquitetônico para o código da aplicação. O estilo arquitetônico escolhido afeta a transformação de PIM para código, determinando os mapeamentos e gabaritos que serão usados para gerar o código. Alguns exemplos de estilos arquitetônicos possíveis são: arquitetura em três camadas, arquitetura em duas camadas, arquitetura em duas camadas baseada em serviços, etc. Por fim, o modelo, as configurações e os cartuchos devem ser utilizados como entrada para a transformação de PIM para código da ferramenta. O resultado deve ser o código esperado.

A versão da AndroMDA analisada foi a AndroMDA 3.2 (ANDROMDA, 2006).

\subsubsection{Conceitos da MDA na AndroMDA}

A AndroMDA trabalha com apenas um modelo chamado PIM do sistema, que não contém qualquer tipo de dado específico de plataforma nos seus elementos e, por isso, é equivalente ao PIM da MDA. Seguindo uma das recomendações da MDA, a ferramenta transforma o PIM diretamente em código, ela não possibilita a criação de um PSM. Apesar de esse ser o comportamento normal da AndroMDA, é possível criar um perfil UML em que os 
tipos de dados são específicos de uma plataforma, e utilizar estes tipos na modelagem, podendo trabalhar-se com um PSM ao invés do PIM.

Um resumo de como os modelos da MDA são relacionados aos modelos da AndroMDA é mostrado na Tabela 4.

Tabela 4: Cobertura de modelos MDA com modelos da AndroMDA.

\begin{tabular}{|l|l|}
\hline \multicolumn{1}{|c|}{ MDA } & \multicolumn{1}{c|}{ AndroMDA } \\
\hline CIM & Não implementa \\
\hline PIM & PIM do sistema \\
\hline PSM & Não implementa \\
\hline Código & Código \\
\hline
\end{tabular}

A AndroMDA define uma plataforma como sendo uma tecnologia ou arcabouço. O processo da AndroMDA também é simples, resumindo-se a transformar o PIM em código baseado na plataforma escolhida. No entanto, não é gerado o registro da transformação, como é determinado pela MDA (seção 2.1.2).

A ferramenta utiliza mapeamentos de tipos e de instâncias, fazendo uso de marcas como principal mecanismo nas transformações. Os mapeamentos de tipos da MDA são implementados na AndroMDA por regras de mapeamento, que especificam determinados tipos de dados como entrada ou valores de instâncias. Os mapeamentos de instâncias da MDA são feitos através de marcas, implementadas na ferramenta como estereótipos de um perfil UML. Os elementos do PIM podem receber valores em algumas de suas propriedades para que sejam transformados de modo diferente do mapeamento estipulado para o tipo do elemento. De modo equivalente, as marcas são usadas para anotar determinados elementos do modelo para que sejam transformados de uma maneira particular. As marcas providas no perfil UML são utilizadas em diferentes mapeamentos. 
Apesar de a definição do PIM dada pela ferramenta coincidir com a definição da MDA, o PIM do sistema da AndroMDA possui marcas, e a MDA faz diferença entre um PIM e um PIM adicionado de marcas (seção 2.2.2.3). O PIM adicionado de marcas é o primeiro passo em uma transformação de PIM para PSM ou código em que existem mapeamentos de instâncias. Com isso, concluise que o PIM do sistema da AndroMDA é o PIM marcado.

\subsubsection{ArcStyler}

A descrição geral da ferramenta ArcStyler se baseia em (ARCSTYLER, 2006) e na análise da ferramenta realizada para o presente trabalho.

\subsubsection{Descrição Geral}

A ArcStyler (ARCSTYLER, 2006) é outra ferramenta comercial, mas assim como a AndroMDA, ela trabalha utilizando plugins, aqui também chamados de cartuchos. Os cartuchos são pacotes que contêm todos os elementos e mecanismos necessários para automatizar, configurar, modelar e gerenciar várias atividades de desenvolvimento. Nos cartuchos podem estar incluídas regras de transformação, gabaritos para formatação, modelos de padrões, tipos de dados, estereótipos, etc. A escolha dos cartuchos também define a plataforma na qual o sistema será construído, dado que os cartuchos possuem os mapeamentos para as plataformas.

A ArcStyler também utiliza a UML como linguagem de modelagem. Ela possui apenas um modelo, chamado de modelo de domínio, utilizado como entrada para as transformações e geração direta de código. Esse modelo é composto de diagramas de classes, de atividade e de componentes. Os diagramas de classes e componentes definem a estrutura do sistema, e o diagrama de atividade modela os processos do sistema. Para criar esse modelo, os cartuchos escolhidos disponibilizam tipos de dados e estereótipos 
que os cartuchos requerem para serem utilizados no modelo. Além de tipos de dados e estereótipos, os cartuchos também podem conter regras de modelagem que devem ser seguidas ao criar o modelo.

A ArcStyler pode transformar o modelo de entrada em outro modelo ou código. A norma é gerar código a partir do modelo, dado que é o cartucho que define se será gerado um modelo ou código, e a maioria dos cartuchos existentes faz mapeamento para código. Os mapeamentos da ferramenta são feitos nos cartuchos. As regras de mapeamento mapeiam tipos, valores de instâncias e estereótipos a gabaritos no modelo ou código a ser gerado. As transformações da ferramenta são baseadas principalmente em mapeamentos de instâncias. A linguagem na qual esses mapeamentos são escritos é JPython. JPython é uma implementação da linguagem Python completamente escrita em Java e integrada na plataforma Java (JYTHON, 2007).

Para utilizar a ArcStyler, primeiro deve-se definir quais cartuchos serão utilizados, e para definir os cartuchos é necessário saber qual a plataforma alvo. Além de definir os cartuchos, é necessário configurar a ferramenta para utilizar esses cartuchos. Com os cartuchos definidos e configurados, deve-se criar o modelo do sistema utilizando os tipos e estereótipos providos nos cartuchos escolhidos. Com o modelo pronto, basta executar as transformações que o código, ou um modelo, será gerado.

A ArcStyler utilizada neste trabalho foi a ArcStyler 5.5 (ARCSTYLER, 2006).

\subsubsection{Conceitos MDA na ArcStyler}

A ArcStyler utiliza apenas um modelo que pode ser classificado tanto como PIM quanto PSM, dependendo do aspecto analisado. A maior parte da modelagem é feita com tipos independentes de plataforma, mas existem alguns casos em que tipos específicos de plataforma são usados como, por exemplo, a 
modelagem de componentes EJB. A ferramenta permite isso, pois alguns cartuchos provêm tipos de dados específicos de plataforma que podem ser utilizados para que os mapeamentos possam ser realizados. Dessa maneira, a ArcStyler viola uma das principais idéias da MDA que é a separação do sistema e da plataforma que fornece suporte a algumas de suas transformações. Apesar disso, é possível criar um cartucho MDA em que existem apenas tipos independentes de plataforma, tornando o modelo da ferramenta aderente ao PIM da MDA. A MDA prega que o PSM deve ser gerado a partir do PIM, portanto, o modelo de entrada da ArcStyler pode ser classificado como PIM com alguns aspectos de PSM, pois ele é usado como o modelo de entrada para as transformações. Um resumo de como os modelos da MDA são relacionados aos modelos da ArcStyler é mostrado na Tabela 5.

Tabela 5: Cobertura de modelos MDA com modelos da ArcStyler.

\begin{tabular}{|l|l|}
\hline \multicolumn{1}{|c|}{ MDA } & \multicolumn{1}{c|}{ ArcStyler } \\
\hline CIM & Não implementa \\
\hline PIM & Modelo de domínio \\
\hline PSM & Não implementa \\
\hline Código & Código \\
\hline
\end{tabular}

A ArcStyler define uma plataforma como sendo uma tecnologia ou arcabouço, assim como a AndroMDA. A ArcStyler pode transformar o PIM diretamente em código ou em outro modelo. Essa transformação é baseada na plataforma escolhida. Nessa ferramenta também não é gerado registro da transformação, como preconizado pela MDA.

$\mathrm{Na}$ ArcStyler são utilizados mapeamentos de tipos, subtipos, tipos com valores instâncias e de instâncias de modo equivalente à AndroMDA. Os tipos utilizados na modelagem são mapeados pelas regras de mapeamento para tipos ou gabaritos no modelo alvo. A ArcStyler possibilita o uso de 
mapeamentos de tipos com valores de instâncias através de propriedades em cada elemento do modelo que podem ser configuradas com os valores necessários.

Além de mapeamentos por tipos, são utilizados mapeamentos de instâncias. As marcas são providas pelo mapeamento incluso em um cartucho, e por isso são utilizadas em apenas um mapeamento. Para utilizá-las, o elemento escolhido deve ser anotado com um estereótipo, que irá marcar o elemento com as marcas associadas ao estereótipo. As marcas utilizadas na ferramenta possuem parâmetros cujos valores podem indicar valores de algumas propriedades do código, como descrito pela MDA. Esses parâmetros são configurados como propriedades, de mesma maneira que os valores de instâncias.

As transformações que a ArcStyler utiliza são as transformações baseadas em marcas, as transformações de meta-modelos, transformações de modelos e aplicação de padrões. A ferramenta executa todas as transformações de uma vez, não sendo feitas transformações incrementais. O produto é apenas o código. A ArcStyler realiza apenas a transformação do modelo PIM para o código ou para outro modelo, deixando de lado conceitos como registro da transformação ou CIM.

\subsection{Transformações e mapeamentos nas ferramentas}

A definição da MDA possibilita diferentes implementações de ferramentas, além de dispor mais de uma maneira de criar mapeamentos. Cada ferramenta pode criar suas transformações diferentemente, pode utilizar mapeamentos de tipos, subtipos, tipos com valores de instâncias e/ou mapeamentos de instâncias. Além disso, as marcas utilizadas nos mapeamentos de instâncias podem ser providas por diferentes repositórios, como perfis UML, modelos de marcas ou mesmo o próprio mapeamento. Outro 
fator é a linguagem na qual os mapeamentos são descritos, pois a MDA possibilita o uso de linguagens naturais, algorítmicas ou uma linguagem de mapeamento de modelos, como a proposta pela própria MDA, a QVT (OMG, 2005). Nesta seção mostra-se como cada uma das ferramentas lida com mapeamentos e transformações, descrevendo quais os mapeamentos possíveis, como eles são feitos, a linguagem utilizada e como realizar as transformações.

\subsubsection{OptimalJ}

O texto desta seção baseia-se em (COMPUWARE, 2006). Os exemplos e suas explicações foram produzidos para o presente trabalho.

A OptimalJ não possui mapeamentos de instâncias, permitindo apenas mapeamentos de tipos e suas variações: mapeamentos de subtipos e de tipos com valores de instâncias. A OptimalJ não utiliza mapeamentos de instâncias.

Para criar uma transformação, é necessário, primeiramente, criar um pacote no qual ela será armazenada. Criados o pacote e a transformação, é necessário adicionar regras de mapeamentos à transformação. Todas as regras de mapeamento da OptimalJ são feitas na linguagem de programação Java. A OptimalJ possui diversos componentes de criação (wizards) para facilitar a criação de transformações.

Cada regra de mapeamento é implementada por uma classe Java que possui métodos de configuração, métodos para especificar os modelos fonte e alvo e um método getChildClasses(...) que é a regra do mapeamento. O método especifica qual tipo dos elementos do modelo fonte será mapeado para qual tipo do modelo alvo. Nesse método, os parâmetros de entrada descrevem o tipo esperado do modelo fonte e o retorno do método descreve o tipo a ser criado no modelo alvo. Além do tipo, o método recebe como entrada o nome do elemento sendo mapeado, o elemento pai do elemento sendo mapeado e o pai 
do elemento a ser criado no modelo alvo. Esses outros parâmetros são necessários para especificar condições especiais e criar estruturas adicionais no modelo alvo. Estruturas adicionais no modelo alvo podem ser criadas fazendo chamadas a outras regras de mapeamento. Na Figura 28 é mostrado um exemplo do método getchildClasses(...).

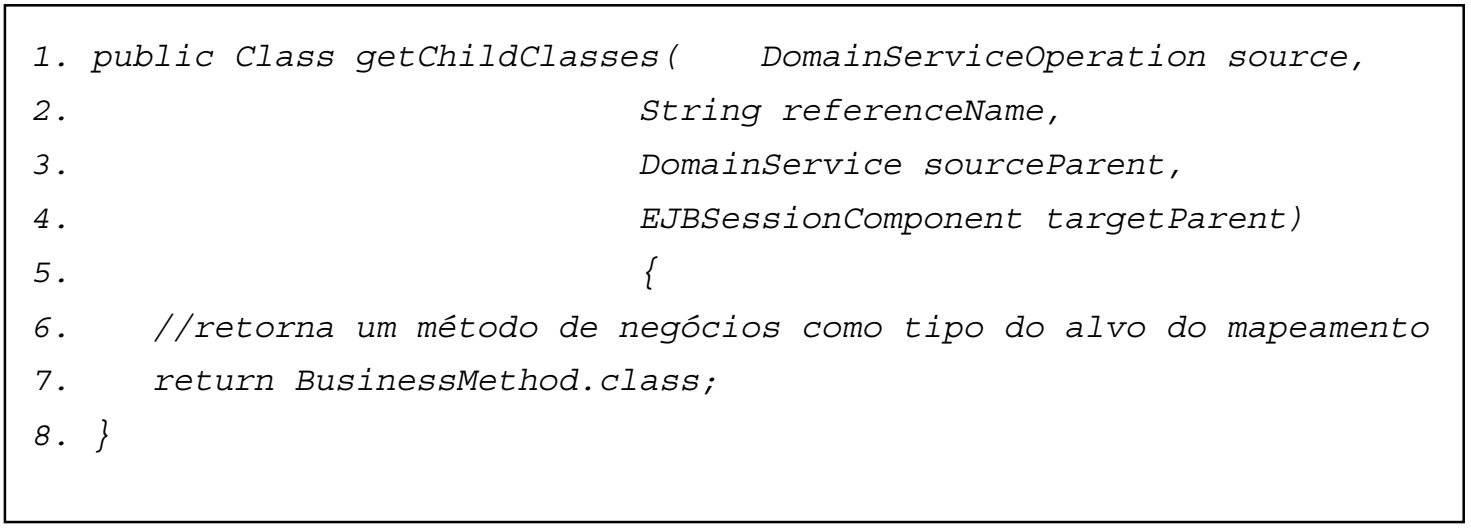

Figura 28: Exemplo do método getChildClasses(...).

Uma regra de mapeamento é ilustrada na Figura 28. Essa regra faz um mapeamento de tipo entre uma operação do diagrama de serviços do modelo PIM (DomainServiceOperation) para um método de negócios no PSM (BusinessMethod.class). O retorno do método getChildClasses(...) determina o tipo do elemento que será criado no PSM.

A OptimalJ possibilita o uso de mapeamentos com valores de instâncias. Para isso, basta adicionar código ao método getChildClasses(...) que verifique o valor do atributo desejado. Utilizando mapeamentos de tipos com valores de instâncias também é possível atribuir valores aos elementos do modelo alvo sendo criados. Para isso, a classe Java que implementa a regra de mapeamento deve ter um método copystructuralfeatures(...) que irá atribuir o valor desejado.

Mapeamentos de subtipos também são possíveis na OptimalJ. Ela disponibiliza wizards para a criação de novas meta-classes no meta-modelo da ferramenta ou para a criação de novos meta-modelos. Os meta-modelos 
criados podem ser exportados para serem utilizados por outras pessoas. Os meta-modelos da OptimalJ são definidos utilizando o MOF. Além de possibilitar a criação e edição de meta-modelos, também é possível alterar a interface com o usuário para facilitar o uso de novas meta-classes.

A OptimalJ requer que um PSM seja gerado a partir do PIM, e o código é gerado a partir do PSM. Portanto, a OptimalJ possui duas transformações, de PIM para PSM e de PSM para código. Para executar essas transformações, basta executar um comando da ferramenta. Antes de uma transformação ser executada, o modelo-fonte e o mapeamento são analisados para detectar inconsistências, e o modelo-alvo é analisado procurando por elementos já gerados. Se inconsistências no modelo-fonte ou no mapeamento forem encontradas, a transformação não é executada, e, se uma determinada regra do mapeamento já tiver sido aplicada, ela não será executada novamente sem um comando especial.

A OptimalJ gera o registro da transformação para todas as regras executadas. Os elementos do modelo-fonte e modelo-alvo são associados através de propriedades, que indicam quais elementos foram gerados a partir do elemento sendo analisado e quais elementos foram utilizados para gerar o elemento atual.

\subsubsection{Exemplos de mapeamento na OptimalJ}

Um exemplo de mapeamento de uma classe de negócios para uma entidade EJB pode ser visto na Figura 29. Essa regra faz um mapeamento de tipo entre uma classe do diagrama de domínio do modelo PIM (DomainClass) para um método no PSM, especificado pelo tipo do retorno (EJBEntityComponent.class). 


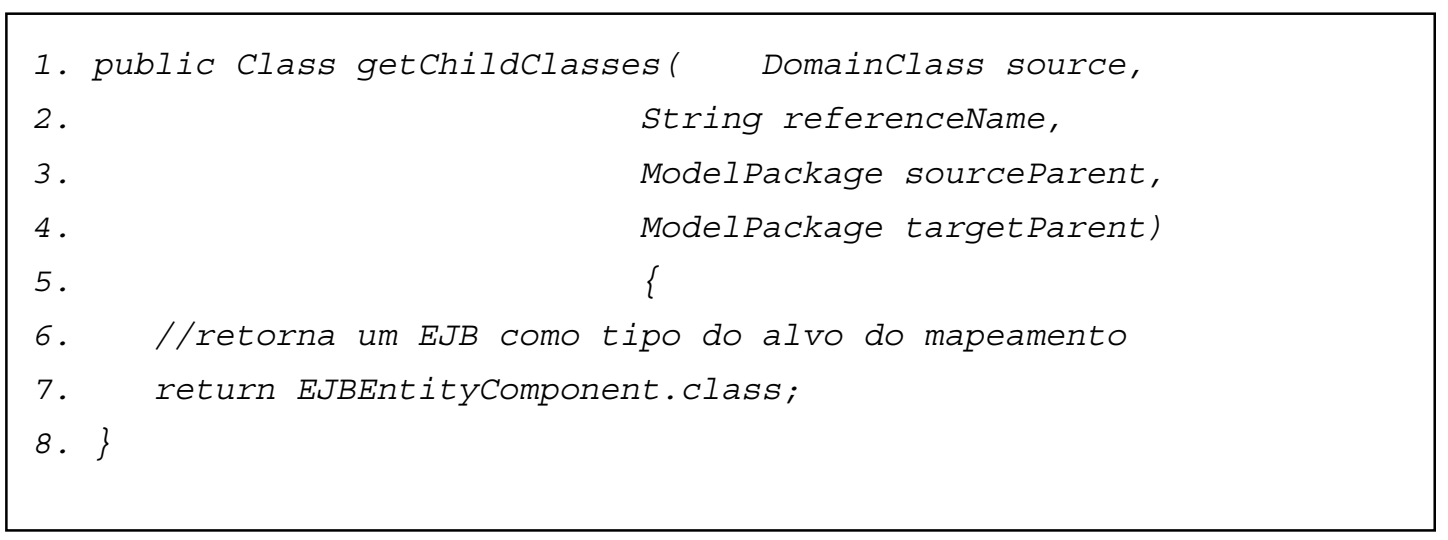

Figura 29: Exemplo de um mapeamento de tipos na OptimalJ.

Esse exemplo pode ser facilmente adaptado para ilustrar um exemplo de mapeamentos de tipos utilizando valores de instâncias, como visto na Figura 30. Nesse caso, se o atributo persistente for false, significa que a classe não deve ser persistida e o tipo do elemento criado seria uma simples classe de negócio (Businessclass.class). Se o atributo persistente for true, a classse deve ser persistida e o tipo criado para ela no PSM seria um EJB (EJBEntityComponent.class). Os atributos dos elementos são configurações que a ferramenta disponibiliza na sua interface para serem alteradas de acordo com as necessidades do modelador.

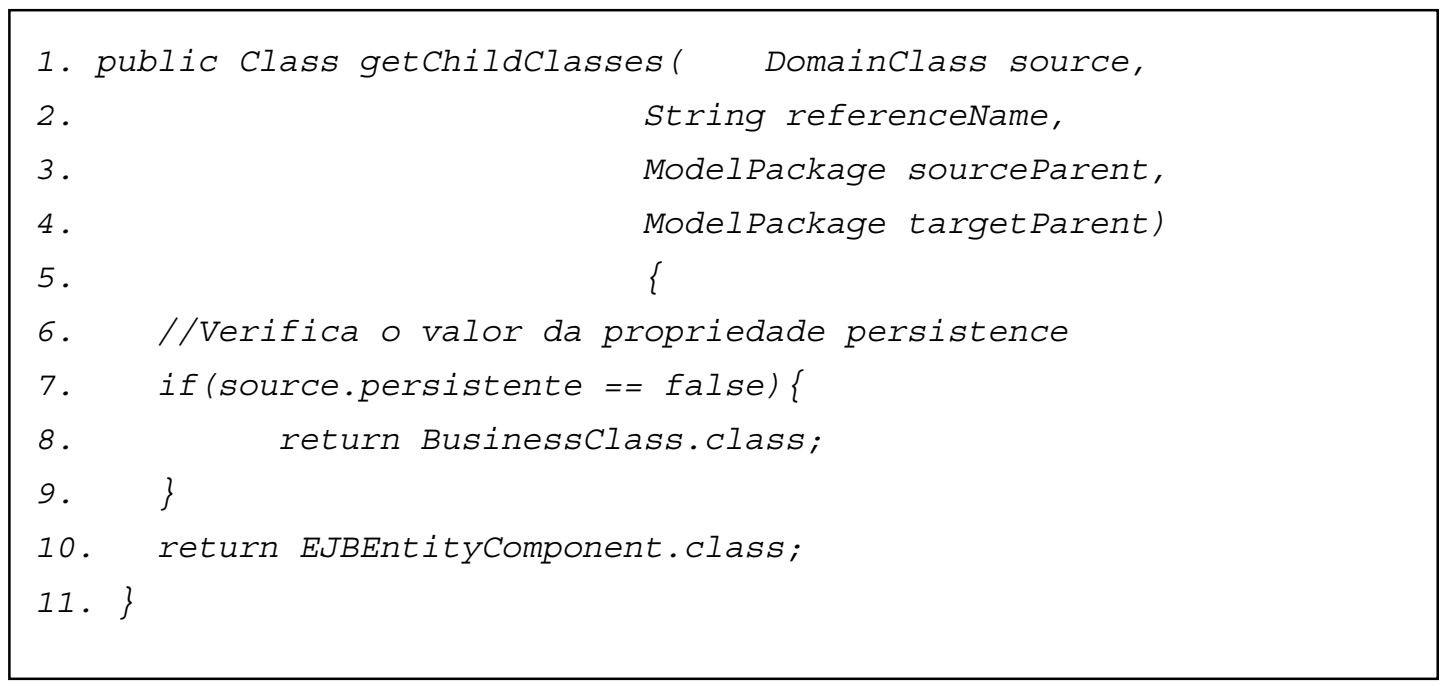

Figura 30: Exemplo de mapeamento de tipos com valores de instância na OptimalJ. 
Para ilustrar um exemplo de mapeamento de uso de subtipos, basta utilizar o mesmo exemplo do mapeamento de tipos, alterando o tipo que o método recebe. No exemplo ilustrado na Figura 31, o tipo DomainClassFi 1 ho recebido pelo método é um subtipo de DomainClass.

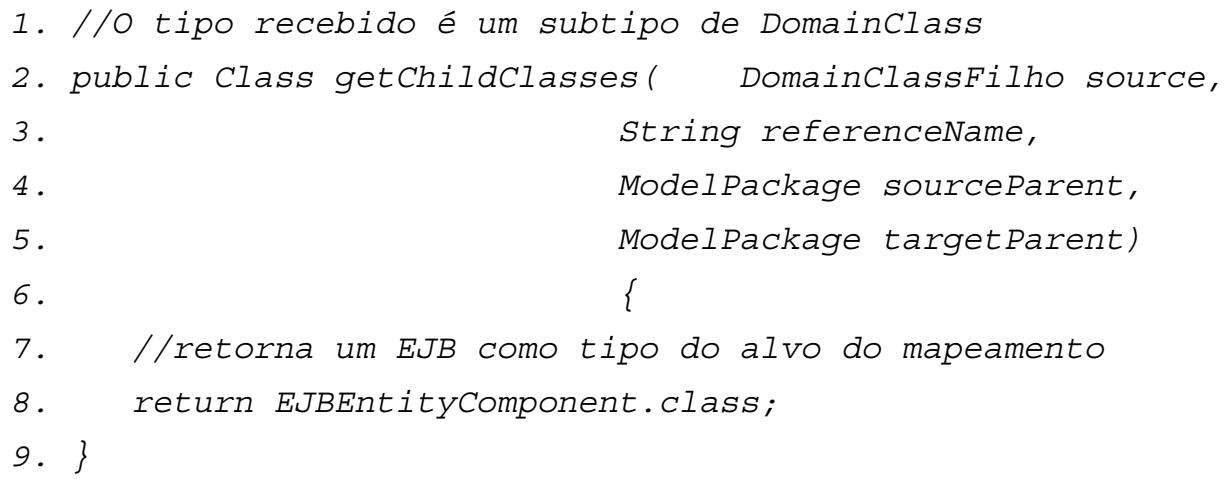

Figura 31: Exemplo de um mapeamento de subtipos na OptimalJ.

\subsubsection{AndromDA}

A AndroMDA possui mapeamentos de tipos, subtipos, tipos com valores de instâncias e de instâncias. Os mapeamentos de instâncias utilizam marcas. Esses mapeamentos podem ser usados em conjunto ou separadamente, mas são normalmente combinados para criar uma transformação.

$\mathrm{Na}$ AndroMDA, as transformações são armazenadas em arquivos XML que descrevem os mapeamentos, e a ferramenta utiliza outro arquivo XML como configuração de quais mapeamentos serão utilizados. A ferramenta permite que os mapeamentos sejam feitos de duas maneiras: utilizando arquivos de mapeamento ou descritores de cartuchos.

Os arquivos de mapeamentos são utilizados para mapear tipos de dados do modelo fonte a tipos de dados do modelo alvo, como por exemplo, mapear o tipo de dados Inteiro para um Integer da linguagem Java. Alguns mapeamentos 
de tipos de dados mais comuns são fornecidos. Os mapeamentos que acompanham a ferramenta são todos baseados em tipos de dados independentes de plataforma que devem ser utilizados para criar o PIM. A ferramenta disponibiliza diversos mapeamentos para esses tipos de dados, para diversas plataformas.

$\mathrm{O}$ arquivo de mapeamento deve conter uma etiqueta mappings com um atributo especificando o nome do mapeamento. As definições das regras de mapeamento estão aninhadas nessa etiqueta, utilizando etiquetas mapping que possuem, por sua vez, as etiquetas from e to, especificando qual o tipo de dado fonte e o tipo de dado alvo, respectivamente. Os mapeamentos têm a forma apresentada na Figura 32.

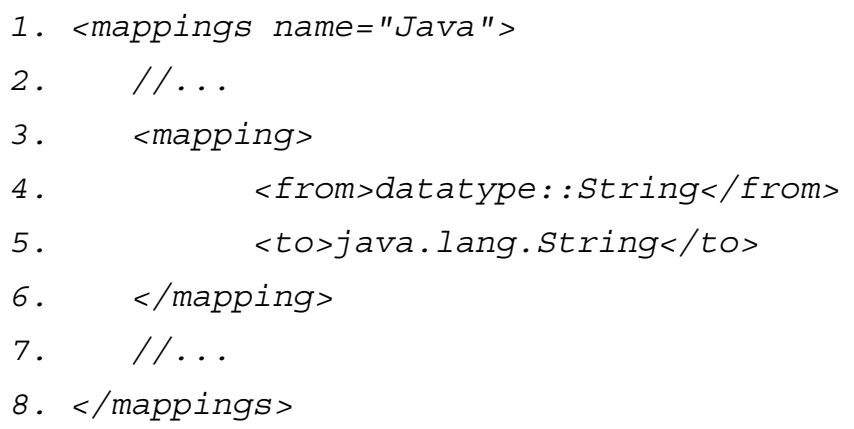

Figura 32: Exemplo de um mapeamento de tipos de dados na AndroMDA.

$\mathrm{Na}$ Figura 32 mostra-se um mapeamento de um tipo de dado datatype: : String para o tipo de dado java.lang.String da linguagem Java.

O outro tipo de mapeamento que a ferramenta dispõe é feito em descritores de cartuchos. Os mapeamentos feitos em descritores de cartuchos podem mapear tipos do meta-modelo fonte ou instâncias do modelo fonte a gabaritos especificando tipos ou estruturas no modelo alvo. Além de permitir 
mapeamentos de tipos e instâncias, os descritores de cartuchos também permitem o mapeamento de tipos com valores de instâncias. A Figura 33 apresenta desses mapeamentos.

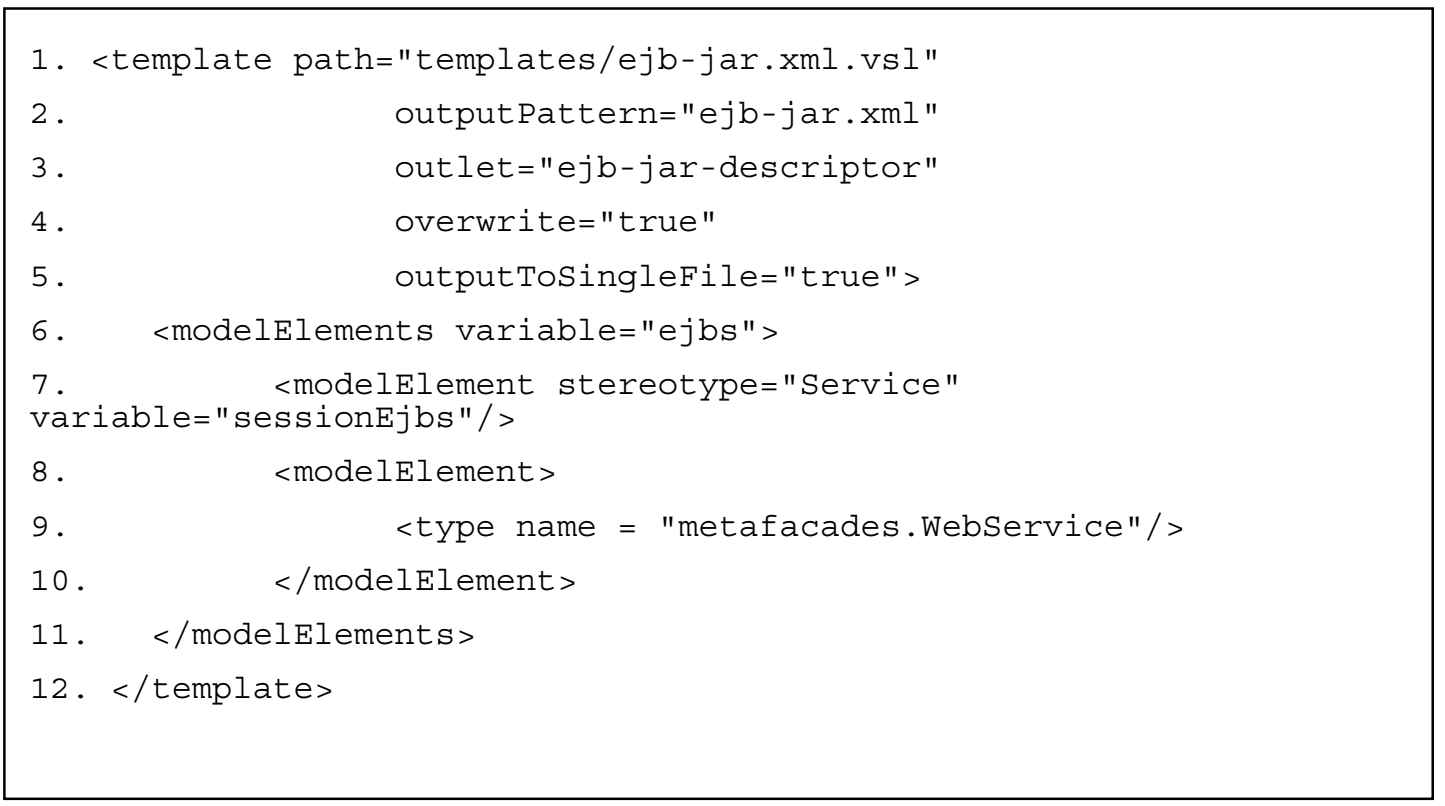

Figura 33: Exemplo de um mapeamento de descritores de cartuchos na AndroMDA.

Os mapeamentos do descritor de cartuchos são feitos com a etiqueta template. Essa etiqueta deve indicar o caminho do gabarito e o caminho do arquivo a ser gerado. Aninhada nessa etiqueta, deve ser definida uma etiqueta modelElements, e dentro de modelElements, a etiqueta modelElement, que define quais elementos do modelo fonte devem ser processados.

Para definir mapeamentos de instâncias, o mais comum da AndroMDA, é necessário atribuir o nome da marca ao atributo stereotype e o nome da variável a ser usada nos gabaritos ao atributo variable. Mapeamentos de tipos são definidos com uma etiqueta type, que deve estar aninhada em modelElement. Mapeamentos de subtipos também utilizam a etiqueta type. No escopo da etiqueta type pode ser definida uma etiqueta property, que especifica quais valores de propriedades do elemento fonte devem estar presentes para 
que esse elemento possa ser processado, e assim especificam mapeamentos de tipos com valores de instâncias.

$\mathrm{Na}$ AndroMDA, as marcas são providas por um perfil UML que deve ser adicionado à ferramenta de modelagem para que os tipos de dados independentes de plataforma e as marcas sejam disponibilizados na modelagem. As marcas são definidas em um arquivo XML, como mostrado na Figura 34.

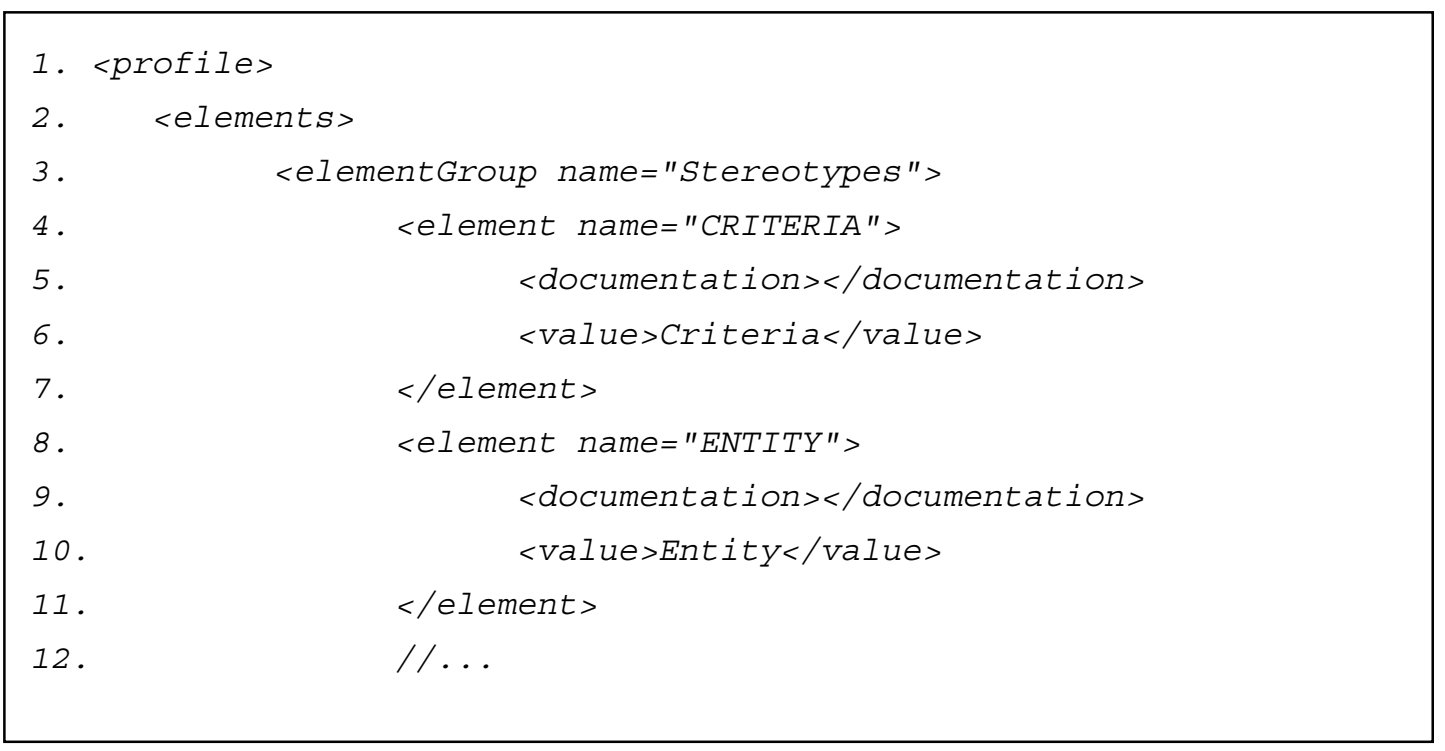

Figura 34: Exemplo de definição de marcas na AndroMDA.

As marcas são definidas em uma etiqueta elementGroup cujo atributo name é Stereotypes. Aninhada nessa etiqueta deve ser criada uma outra etiqueta element, e aninhada a ela uma etiqueta value cujo valor é o nome da marca.

Para criar uma transformação na AndroMDA, é necessário criar o mapeamento dos tipos de dados no arquivo de mapeamento e as regras de mapeamento no descritor de cartuchos, e depois devem ser adicionados a um 
cartucho. Por fim, esse cartucho deve ser incluído na transformação. A AndroMDA não gera registro de transformação.

\subsubsection{Exemplos de mapeamento na AndroMDA}

Para criar um mapeamento completo, é necessário criar o arquivo de mapeamentos, que mapeia tipos de dados, e criar o descritor de cartuchos, que descreve os mapeamentos de tipos e instâncias. A Figura 32 apresenta um exemplo de um mapeamento de um tipo de dado String independente de plataforma para um tipo de dado String da linguagem Java. A Figura 35 apresenta um exemplo de uma regra de mapeamento de tipos.

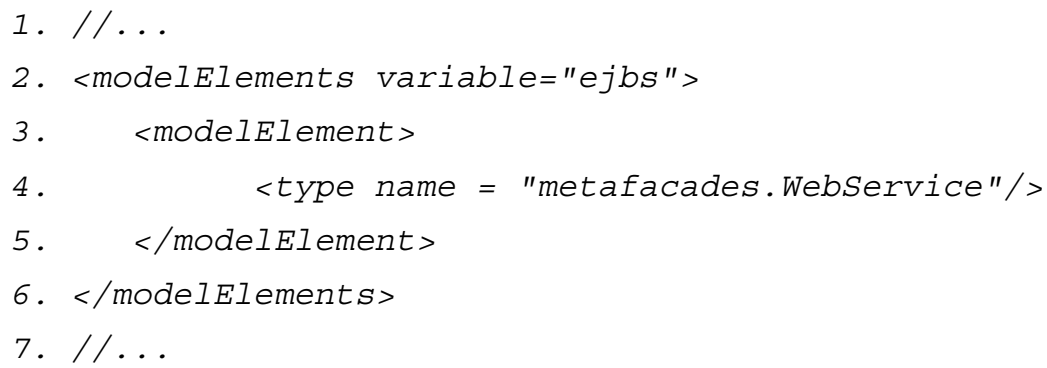

Figura 35: Exemplo de mapeamento de tipos na AndroMDA.

$\mathrm{Na}$ Figura 35 é mostrado um mapeamento de um tipo metafacades. WebService do modelo PIM para um gabarito identificado pela variável ejbs.

Para exemplificar o uso de regras de mapeamentos de subtipos pode-se usar a mesma estrutura do mapeamento de tipos da Figura 35, porém o atributo name da etiqueta type deve ser o caminho completo para o subtipo criado.

Na Figura 36 é mostrado um exemplo de uma regra de mapeamento de tipos utilizando valores de instâncias. 


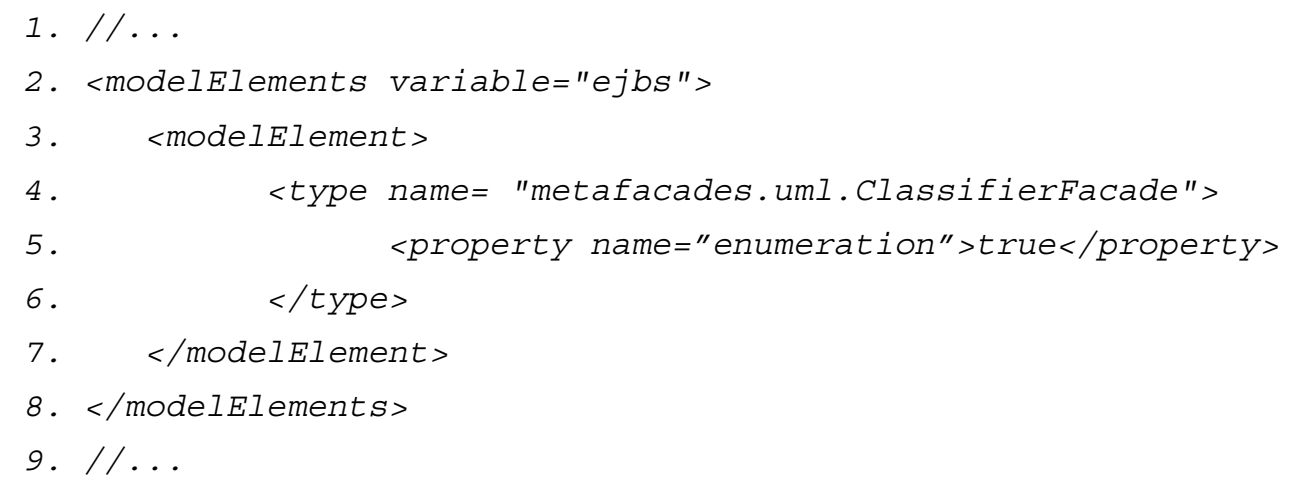

Figura 36: Exemplo de mapeamento de tipos com valores de instâncias na AndroMDA.

O mapeamento da Figura 36 corresponde um tipo metafacades.uml.ClassifierFacade do modelo PIM cujo valor da propriedade enumeration é true a um gabarito identificado pelo nome ejbs.

Por fim, a Figura 37 apresenta um exemplo de uma regra de mapeamento de instâncias utilizando a marca Entity, que pode ser definida como visto na Figura 34.

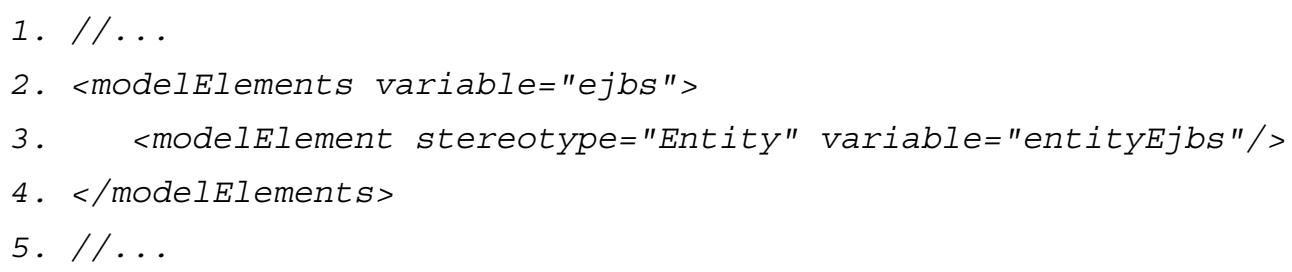

Figura 37: Exemplo de mapeamento de instâncias na AndroMDA.

Na Figura 37 é ilustrado um mapeamento entre elementos marcados com a marca Entity e um gabarito cujo nome é ejbs. A variável entityEjbs define como o elemento marcado será usado no gabarito 


\subsubsection{ArcStyler}

A ArcStyler é outra ferramenta que possui mapeamentos de tipos, tipos com valores de instâncias e mapeamentos de instâncias. Os mapeamentos são criados em cartuchos, e estes são criados ou editados na própria ferramenta. Os mapeamentos da ArcStyler são feitos da mesma maneira que um projeto de desenvolvimento normal, através de modelagem. Os mapeamentos são modelados com diagramas de classe que indicam, através de associações, quais os tipos fonte e os gabaritos alvo do mapeamento.

A ArcStyler lê os elementos do modelo-fonte através de um componente chamado Rootlterator. Os mapeamentos devem ser associados graficamente a ele em um diagrama de classes especial para que possam receber os elementos, analisá-los e transformá-los. O mapeamento irá receber todos os elementos do modelo fonte e deverá filtrá-los de acordo com sua necessidade. Para gerar a saída, os gabaritos devem ser associados ao mapeamento no mesmo diagrama. Essa estrutura é ilustrada na Figura 38.

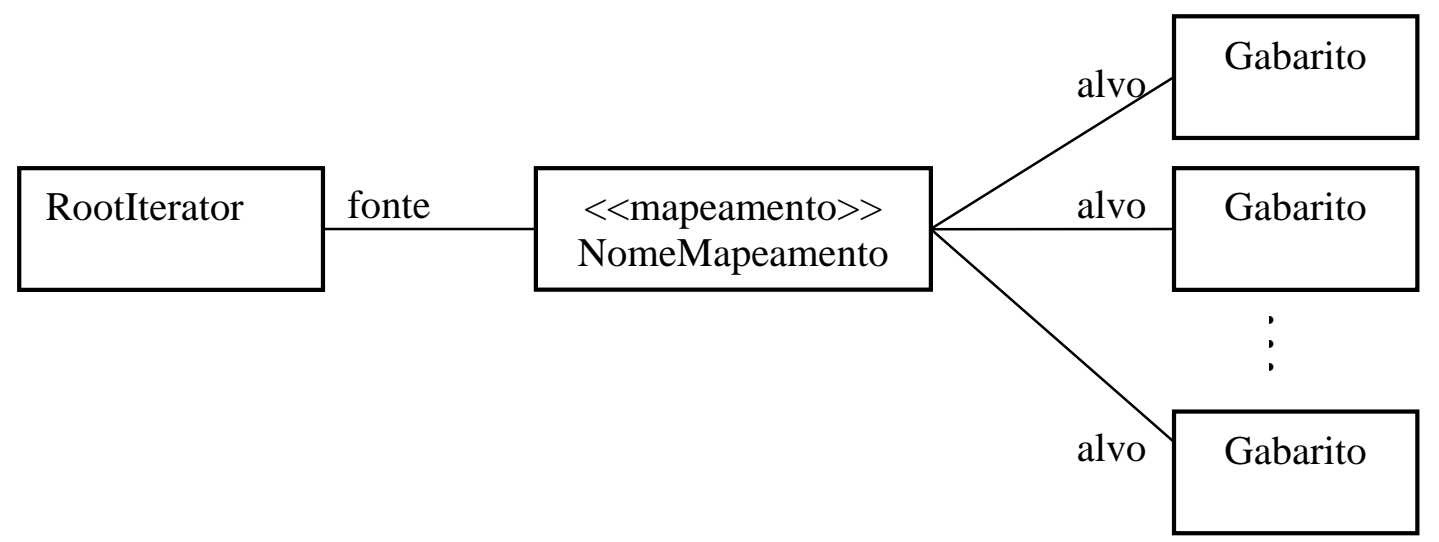

Figura 38: Estrutura dos mapeamentos da ArcStyler.

Após criar as associações entre os artefatos e os mapeamentos, é necessário editar o código destes. Os mapeamentos são escritos na linguagem JPython, como no exemplo da Figura 39. 


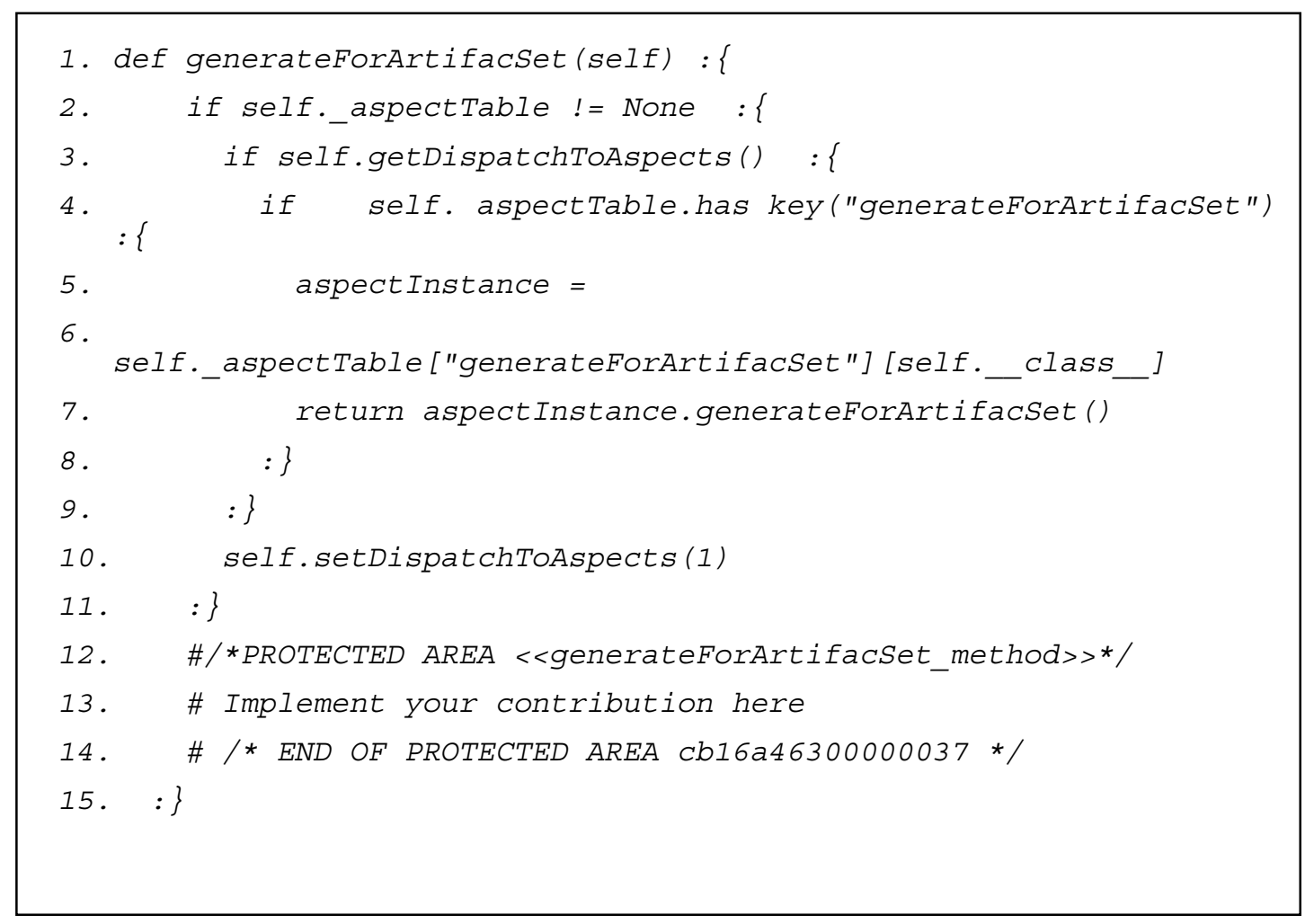

Figura 39: Exemplo de mapeamento da ArcStyler.

Os mapeamentos filtram os elementos do modelo-fonte que serão processados baseados no código, que pode verificar o tipo do elemento, valores da instância ou marcas associadas a ele. A ferramenta gera parte do código necessário, deixando um indicador de onde o resto do código deve ser escrito. No exemplo acima, o código deve ser inserido após o comentário "\# Implement your contribution here".

As marcas são definidas em cartuchos, utilizando diagramas de classes. As marcas devem ser criadas como atributos em classes que representam conjuntos de marcas, e estes conjuntos são associados aos elementos nos quais as marcas podem ser aplicadas. As marcas, atributos da classe, possuem tipos que indicam quais os valores possíveis para as marcas, como por exemplo, Integers ou Strings. 
Página 65

\subsubsection{Exemplos de mapeamento na ArcStyler}

Um exemplo de mapeamento de uma classe UML para uma classe Java pode ser visto nas Figuras 40 e 41 . O mapeamento inclui o diagrama de classes, o código do mapeamento e uma configuração para filtrar quais elementos do modelo fonte devem ser processados. Essa configuração é criada em propriedades dos elementos, no editor gráfico, e pode ser feita tanto para os gabaritos quanto para o mapeamento.

\begin{tabular}{|l|l|c|}
\hline RootIterator & fonte & $\begin{array}{c}<<\text { mapeamento }>> \\
\text { NomeMapeamento }\end{array}$ \\
\cline { 2 - 3 } & &
\end{tabular}

Figura 40: Exemplo de modelo de um mapeamento de tipos da ArcStyler.

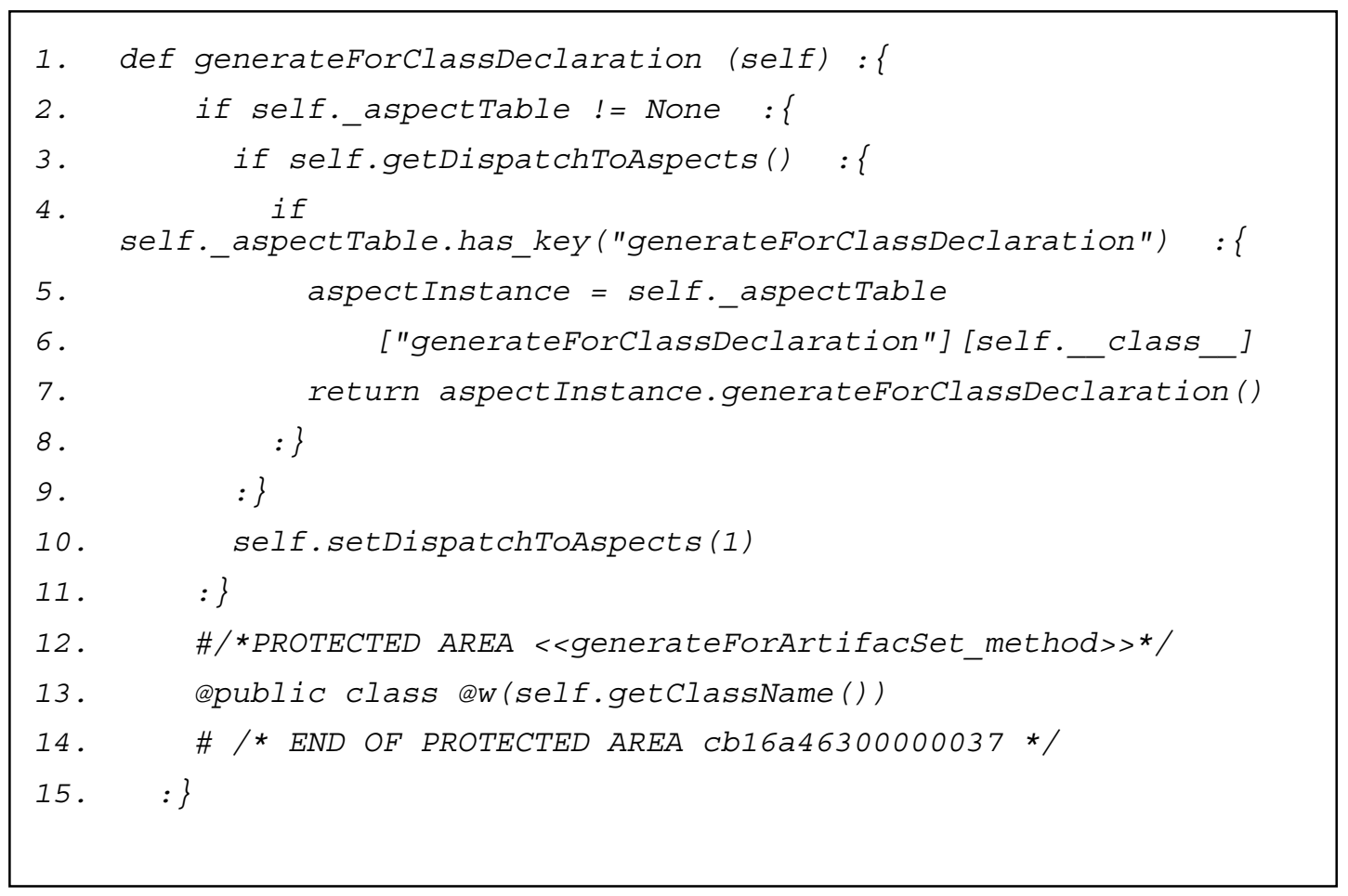

Figura 41: Exemplo de código de um mapeamento de tipos da ArcStyler. 
Página 66

A Figura 40 mostra que o Rootlterator irá processar os elementos do PIM, e o alvo do mapeamento será processado por uma classe Gabarito que contém o código da Figura 41. A Figura 41 mostra um mapeamento que mapeia um elemento do PIM a uma classe no PSM ou código. O tipo do elemento do PIM a ser mapeado é determinado pela configuração feita no editor gráfico. A linha 13 indica que o tipo a ser criado no PSM ou código é uma classe (class).

Para criar um mapeamento de subtipos, basta criar um subtipo e utilizar este subtipo em vez da Classe UML nas configurações de filtro. Mapeamentos de tipos com valores de instâncias e mapeamentos de instâncias são tratados da mesma maneira na ArcStyler, ambos o valor da propriedade e a marca são configurados como propriedades nos elementos do modelo. Para acessar essas marcas ou valores das instâncias, o código do mapeamento deve utilizar o método getMarkValue (... ) para acessar o valor delas. Um modelo, como o da Figura 40, indicando a classe com o código e o componente que deve ler os elementos do PIM também é necessário. Um exemplo de código de um mapeamento de instâncias é mostrado na Figura 42.

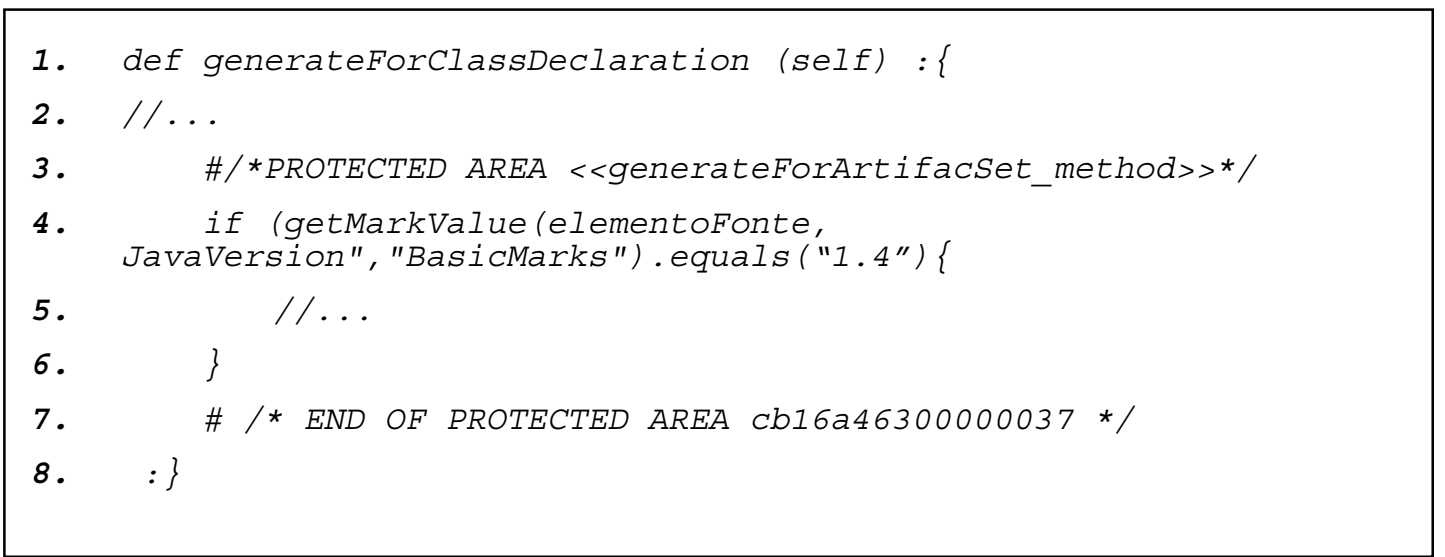

Figura 42: Exemplo de código de um mapeamento de instâncias da ArcStyler.

No exemplo da Figura 42, na linha 13, é verificado se o valor da marca JavaVersion do elemento elementoFonte do modelo fonte é igual a "1.4". 


\section{Estudo de caso}

Este capítulo descreve um estudo de caso feito com as ferramentas OptimalJ, AndroMDA e ArcStyler. O estudo de caso tem por principal objetivo analisar qualitativamente como os mapeamentos definidos pelas ferramentas são usados nas suas transformações. Além disso, verificam-se algumas das modificações necessárias ao modelo de entrada para as transformações devido a requisitos necessários por cada uma das ferramentas. Esses requisitos impõem limitações ou regras à modelagem do sistema. Apresentam-se essas limitações e regras e como foram resolvidas, provendo, dessa maneira, um breve guia de possíveis soluções para os problemas de modelagem encontrados.

O sistema foi criado para analisar aspectos da modelagem, das transformações e mapeamentos da MDA providos pelas ferramentas, e por isso, é apenas tão completo quanto foi necessário para fazer esta análise. Os diagramas apresentados neste capítulo são apenas parte da coleção de elementos dos modelos PIM das soluções completas.

\subsection{Preparação do Estudo de Caso}

\subsubsection{Requisitos do Sistema}

Para realizar o estudo de caso, primeiramente escolheu-se o domínio do problema e a plataforma para a qual a solução do sistema seria gerada. $\mathrm{O}$ domínio do problema é baseado em lojas de vendas de produtos pela Internet. O sistema é uma loja de venda de filmes pela Internet.

O sistema deve possibilitar o cadastro de clientes e possibilitar aos clientes procurar e comprar filmes. O sistema deve permitir também que 
administradores do sistema sejam criados, especificando todas as permissões para cada administrador. Os administradores podem cadastrar novos filmes, alterar dados dos filmes e remover filmes que não serão mais vendidos.

Além dos filmes, os administradores podem criar descontos para filmes individuais ou para compras sendo feitas, baseados no preço ou em quantidades, descontando por porcentagens ou por valores absolutos. Esses descontos são determinados com base em categorias de desconto atribuídas aos clientes por políticas de desconto. Novas categorias podem ser determinadas pelo número de compras, indicações, primeira compra, etc. As categorias devem ser facilmente adicionadas ao sistema e as políticas de desconto criadas para incluir novas maneiras de determinar a categoria de desconto.

Os administradores também devem poder criar relatórios baseados nos itens sendo vendidos, nas vendas feitas, clientes, descontos aplicados, e nos endereços de entrega.

Além dos requisitos do sistema, foi definida a plataforma alvo para as transformações. Foi escolhida a mesma plataforma alvo para as três ferramentas: Java com EJB (SUN, 2006) e Struts (APACHE, 2006). Além da plataforma alvo, na OptimalJ e na AndroMDA também foram configuradas a arquitetura da aplicação. Em ambas as ferramentas foi escolhida uma arquitetura de três camadas, implementando o padrão de projetos Controle Visão - Modelo (Model-View-Control - MVC) de (BURBECK, 1992).

\subsubsection{Modelagem do sistema}

Antes de começar a modelagem foi verificado o nível de abstração requerido pelas ferramentas para que o modelo do sistema pudesse ser processado. Isso foi necessário para saber quão completos os modelos deveriam ser. Todas as três ferramentas trabalham no nível de abstração 
próximo ao modelo de domínio clássico do projeto orientado a objetos (LARMAN, 2004).

Fez-se uma breve análise das ferramentas para verificar qual linguagem de modelagem e quais os diagramas deveriam ser utilizados no estudo de caso. A linguagem de modelagem utilizada nas três ferramentas é a UML e os diagramas utilizados são os diagramas de casos de uso, os diagramas de classes e os diagramas de atividade. Os diagramas de classes e atividades são usados nas três ferramentas. Como visto no capítulo 3, a AndroMDA é a única das três ferramentas que faz uso de diagramas de casos de uso.

Utilizando a UML, com os diagramas de classes e atividades aceitos no nível de abstração adequado às ferramentas, foi criado o modelo do sistema. $O$ diagrama de casos de uso é ilustrado na Figura $43^{4}$.

Nesse diagrama são ilustrados os principais requisitos de uso do sistema. Um cliente deve poder se cadastrar no sistema, alterar seu cadastro e comprar filmes. Para alterar seu cadastro em comprar filmes, o cliente deve estar identificado no sistema utilizando o login. Uma compra precisa ser paga e os filmes comprados precisam ser enviados ao cliente. A conta será paga utilizando um sistema de cobrança externo ao sistema, e os filmes serão enviados ao cliente através de outro sistema externo de envio. Os administradores também são cadastrados no sistema. Eles podem gerenciar as permissões de acesso aos relatórios e outras funcionalidades de administração do sistema. Além disso, os administradores podem gerenciar os filmes, isto é, cadastrar, procurar, alterar e remover os filmes. Também podem criar relatórios e gerenciar promoções. Não foi necessário detalhar os casos de uso, pois as ferramentas não os utilizam.

\footnotetext{
${ }^{4}$ Não se apresenta aqui a especificação do modelo de casos de uso, apenas o diagrama para fins ilustrativos.
} 


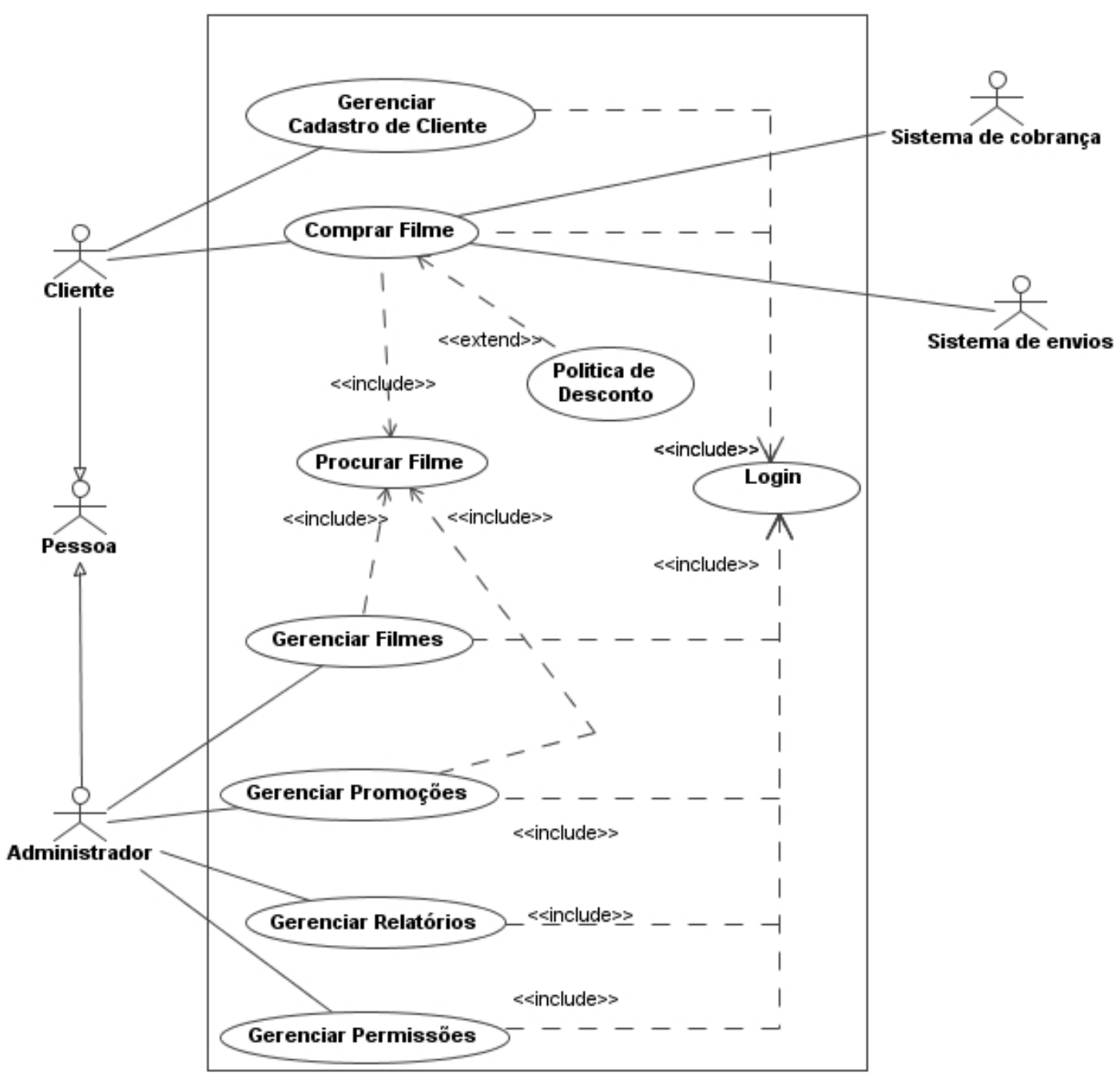

Figura 43: Diagrama de casos de uso do sistema.

O diagrama de classes do modelo é ilustrado na Figura 44. O diagrama de classes mostra a estrutura do sistema, as classes e seus relacionamentos. A interface DadoRelatório é usada para indicar quais as entidades do sistema que podem ser usadas para gerar relatórios. As classes que a realizam devem implementar os métodos que são chamados para gerar os dados dos relatórios. As entidades que podem receber desconto são realizações da interface Descontavel. A classe CompraCliente é uma classe de transporte de dados, 
criada para preencher relatórios mistos das entidades Compra e Cliente. CompraCliente implementa o padrão de projetos Objeto de Transporte de Dados (Data Transfer Object - DTO) definido em (FOWLER, 2002).

É importante notar no diagrama da Figura 44 o uso do padrão de projetos Estratégia (Strategy) definido em (GAMMA, 1995). O padrão de projetos Estratégia "define uma família de algoritmos, encapsula cada um, e os torna intercambiáveis. Estratégia permite que 0 algoritmo varie independentemente dos clientes que o usam" (GAMMA, 1995). Esse padrão de projetos é usado no sistema para possibilitar que diferentes estratégias sejam escolhidas ao calcular a estratégia de desconto de um cliente. O padrão de projetos Estratégia possui três tipos de participantes: a Estratégia, a Estratégia Concreta e o Contexto. A Estratégia declara a interface comum a todas as Estratégias Concretas. O Contexto usa essa interface para chamar Estratégias Concretas, e as Estratégias Concretas descrevem parte do comportamento. A Estratégia é a classe PoliticaDesconto, o Contexto é a classe Cliente e as Estratégias Concretas são as classes DescontoNormal, DescontoFuncionario e DescontoVIP, além de outras que poderiam ser adicionadas. Por serem apenas implementações de comportamentos, as classes que são Estratégias Concretas não devem ser persistidas.

As ferramentas utilizam o diagrama de atividade para descrever 0 comportamento dos casos de uso do sistema. Na Figura 45 é mostrado o diagrama de atividade que descreve o fluxo de eventos básico do caso de uso Compra Filme. Nesse processo, o cliente deve primeiramente adicionar um filme às suas compras. Em seguida, ele deve se identificar no sistema fazendo o login. O sistema vai processar quaisquer descontos aos quais o cliente seja elegível. Após isso, o cliente deve selecionar um endereço dentre os cadastrados para servir de endereço de entrega da compra e, finalmente, deve pagar pela compra. Por fim, o sistema providencia o envio dos filmes comprados para o cliente no endereço selecionado. 
Página 72

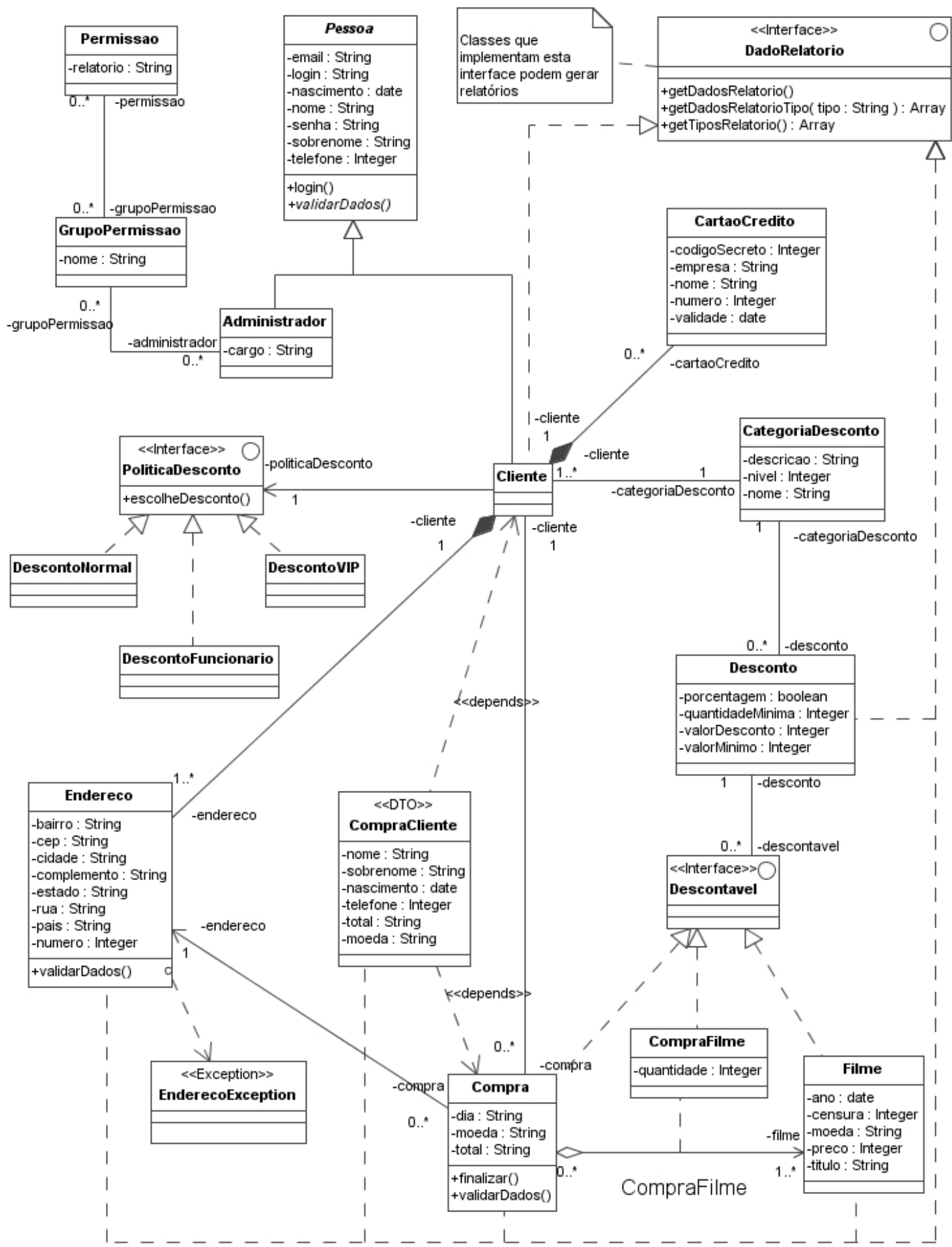

Figura 44: Diagrama de classes do sistema. 


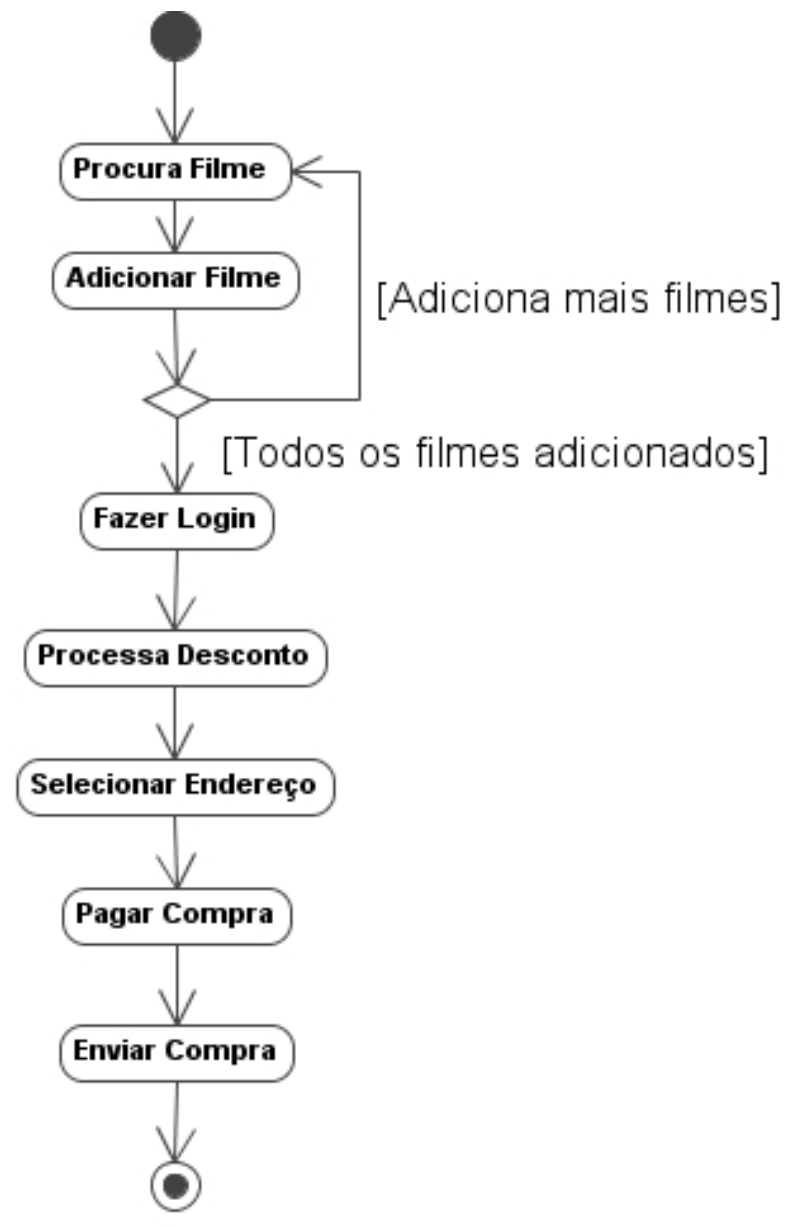

Figura 45: Diagrama de atividade descrevendo o caso de uso Comprar Filme.

\subsubsection{Requisitos de modelagem das ferramentas}

O modelo proposto na seção 4.1 .2 não é aceito integralmente pelas ferramentas. Cada ferramenta possui requisitos próprios de modelagem que exigem adaptações no modelo proposto. O modelo original foi adaptado de acordo com essas necessidades e três modelos diferentes foram gerados, um para cada ferramenta. Além das necessidades de modelagem, algumas configurações nas ferramentas tiveram de ser feitas. Nesta seção apresentam- 
se esses requisitos e o impacto destes no modelo proposto, mostrando o modelo adaptado para cada ferramenta.

\subsubsection{OptimalJ}

A OptimalJ interpreta apenas diagramas de classes e diagramas de atividades. Ela utiliza um diagrama de classes para declarar as entidades do sistema e outro para declarar os serviços do sistema. Os diagramas de classes da OptimalJ não aceitam alguns elementos da UML, como Classes de Associação (AssociationClass), Interfaces (Interface), e Tipo de Visibilidade (VisibilityKind). Uma classe de associação é um elemento que possui propriedades tanto de uma classe quanto de uma associação (OMG, 2006c). Para resolver a falta de Classes de Associação, a Classe de Associação CompraFilme foi removida e substituída por uma classe de mesmo nome associada tanto a Compra quanto a Filme. Um subconjunto do diagrama de classes adaptado para a ferramenta OptimalJ que mostra essa solução pode ser visto na Figura 46.

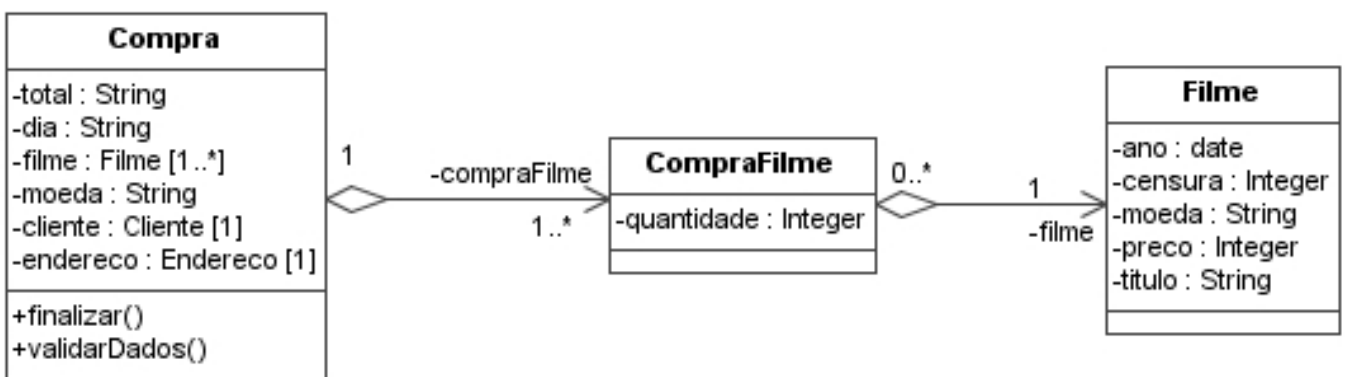

Figura 46: Subconjunto do diagrama de classes substituindo a Classe de Associação.

Por não trabalhar com interfaces, as interfaces do diagrama tiveram que ser substituídas por classes abstratas. As interfaces PoliticaDesconto e Descontavel foram substituídas por classes abstratas homônimas, mas a 
interface DadoRelatorio não pode seguir a mesma solução pois existem classes que implementam ambas as interfaces Descontavel e DadoRelatorio, criando herança múltipla, não existente nem na ferramenta e nem na plataforma alvo escolhida (Java). Portanto, a interface DadoRelatório foi removida e seus métodos integrados nas classes que a implementavam para poder prover a mesma funcionalidade. A OptimalJ também não possui Tipo de Visibilidade para seus elementos, a ferramenta gera, como padrão, métodos de acesso para todos os atributos, tornando-os públicos. Para alterar este comportamento é necessário configurar algumas propriedades dos atributos.

Outra particularidade encontrada na modelagem foi o fato de a ferramenta OptimalJ prover o controle de acesso às páginas de internet do sistema por meio de configurações no PSM. Podem ser configurados os usuários do sistema, a quais os grupos de acesso eles pertencem e quais as páginas que cada grupo pode acessar. Com isso, a modelagem de permissão de acesso foi desnecessária.

A classe CompraCliente foi removida, pois a OptimalJ não necessita da modelagem desta classe para criar um relatório extra. Os relatórios extras são feitos no PSM através da criação de métodos de acesso e páginas de internet do sistema. A classe CompraException também foi removida, pois a ferramenta não aceita a modelagem de exceções para métodos. O diagrama de classes final da OptimalJ pode ser visto na Figura 47.

A OptimalJ exige que seja construído um diagrama de classes especificando os serviços e operações que o sistema irá disponibilizar, bem como o comportamento de acesso a métodos e classes de negócio do sistema. Como o sistema não disponibiliza serviços a outros sistemas, e as políticas de acesso a métodos e classes de negócio não precisam de configuração, este diagrama não precisou ser gerado. 
Página 76

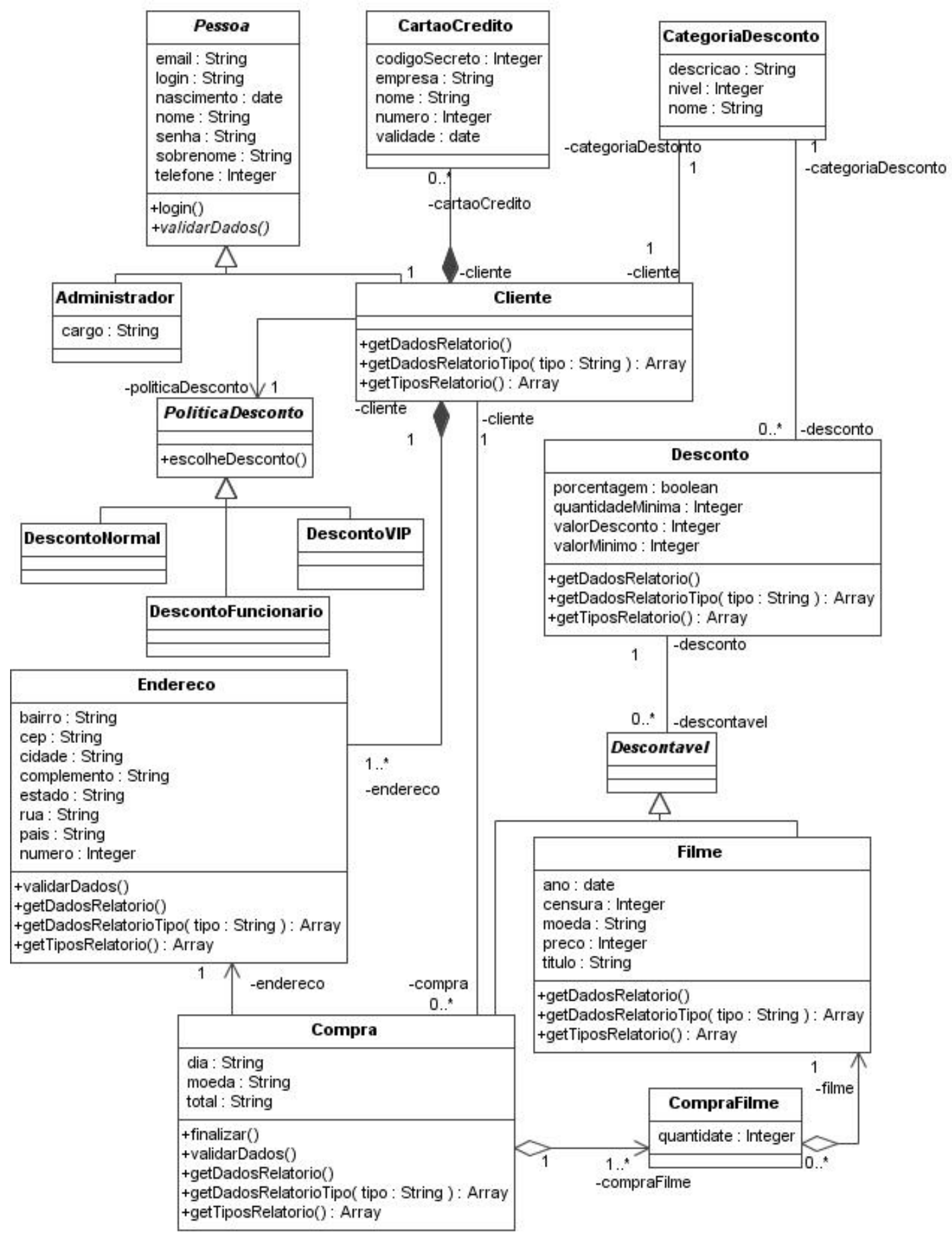

Figura 47: Diagrama de classes do sistema para a ferramenta OptimalJ. 
Quanto aos diagramas de atividade, a OptimalJ define que as atividades modeladas sejam abrangentes, de modo que os passos específicos de cada atividade e suas interfaces sejam definidos no PSM. A ferramenta requer que o objeto que está sendo passado de uma atividade para outra seja especificado nos fluxos. A OptimalJ utiliza Pontos de Decisão (DecisionNodes) apenas para decisões resolvidas por algoritmos no processamento do servidor da aplicação. Por isso, o Ponto de Decisão do diagrama de atividade original foi removido. O diagrama de atividade do caso de uso Compra Filme adaptado para a OptimalJ é ilustrado na Figura 48.

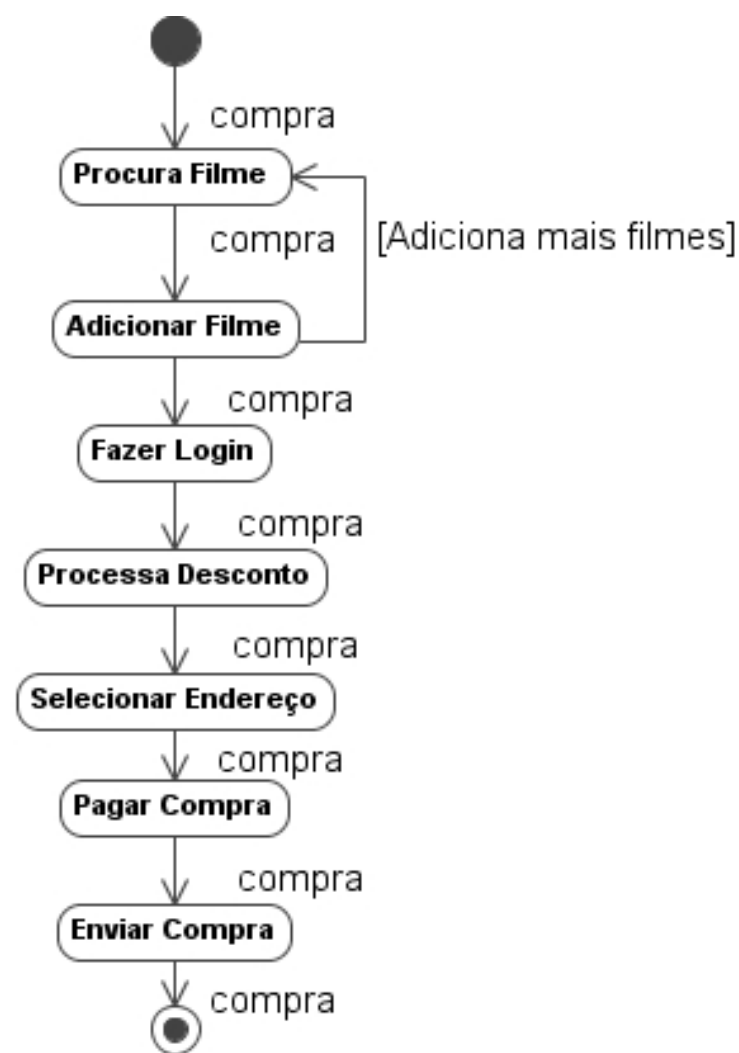

Figura 48: Diagrama de atividades do caso de uso Compra Filme para a ferramenta OptimalJ. 
Página 78

\subsubsection{AndroMDA}

A AndroMDA possibilita a geração do código do sistema utilizando arquiteturas de camadas. Ela recomenda que entidades de negócio não possam ser acessadas pela camada de apresentação do sistema, que a camada de negócios deve empacotar a informação necessária em objetos e transferi-los para a camada de apresentação. Esses objetos de transporte são chamados Objetos de Valor (Value Objects - VO), também conhecidos como objetos de transferência de valores (Data Transfer Objects - DTO) descrito em (FOWLER, 2002). Por esse motivo, ela requer que sejam modeladas classes de transporte para todas as entidades do sistema. As classes de transporte são modeladas em outro diagrama de classes, e as respectivas entidades devem ter uma associação de dependência com estes Objetos de Valor.

A AndroMDA exige que listas de elementos do modelo sejam criados para que o sistema possa utilizar estas listas. A ferramenta não habilita o uso de listas automaticamente. Por exemplo, um método que tem como tipo de retorno um vetor de ClienteVO, Objetos de Valor da classe Cliente, não pode declarar este retorno diretamente. O vetor deve ser modelado, criando um novo elemento ClienteVO [] no diagrama de Objetos de Valor. É possível utilizar tipos de conjuntos genéricos, como Array ou Collection, ao invés de listas dos objetos. Um pequeno subconjunto do diagrama de classes dos Objetos de Valor é mostrado na Figura 49.

A AndroMDA não interpreta elementos do tipo Classe de Associação (AssociationClass) da UML. No diagrama de classes de negócio, a única alteração necessária é a substituição da classe de associação CompraFilme por uma classe CompraFilme associada tanto a Compra quanto a Filme. A solução utilizada é a mesma descrita para a OptimalJ e pode ser vista na Figura 46.

A AndroMDA também requer que seja criado um diagrama de classes para modelar os serviços do sistema. Esse diagrama deve expor os serviços providos pelo sistema, assim como operações internas como, por exemplo, um 
método de procura por filmes.
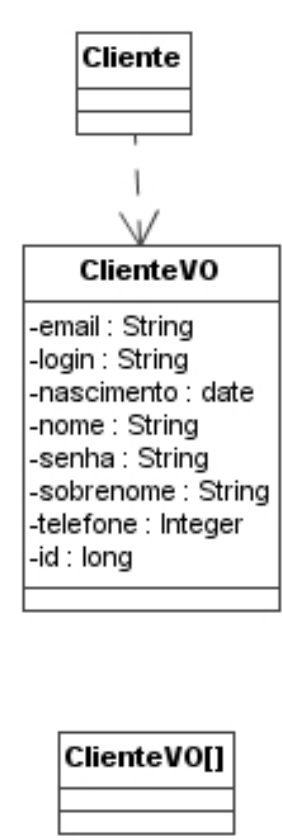
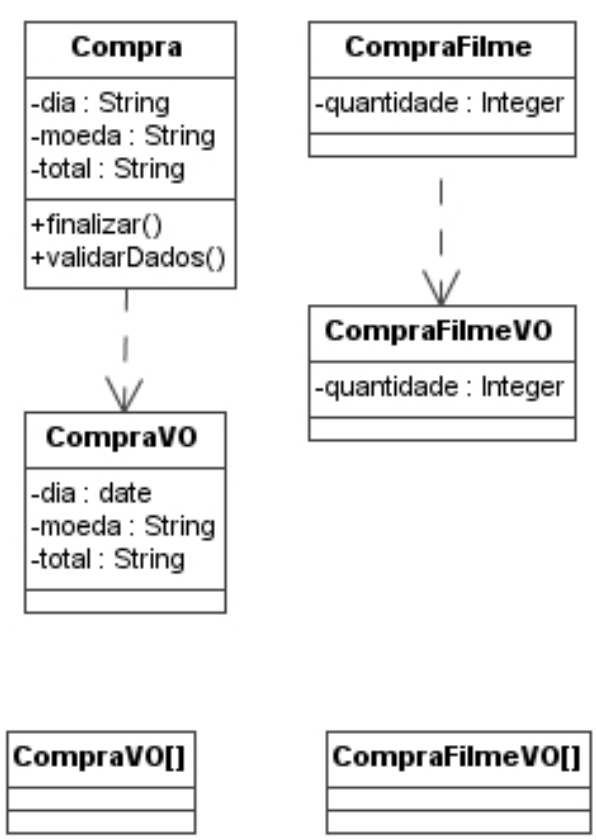
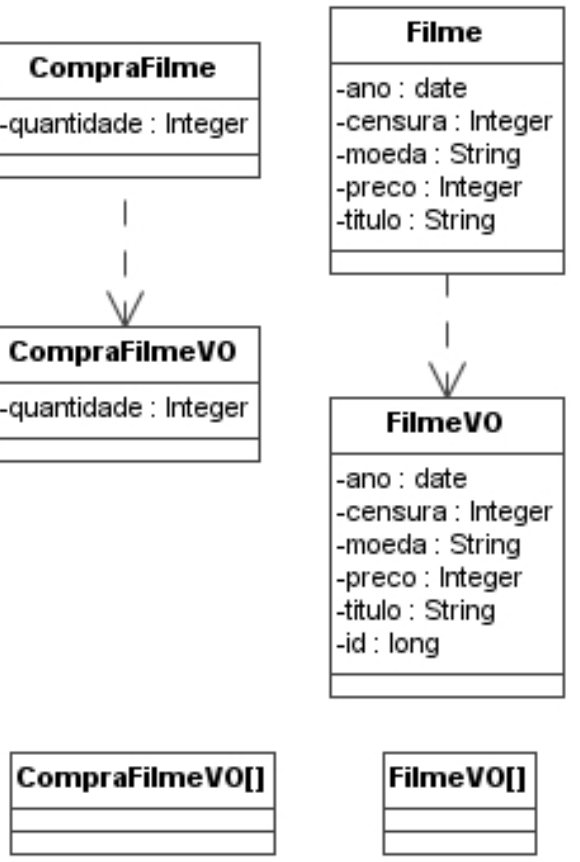

FilmeVo[]

Figura 49: Subconjunto do diagrama de classes de Objetos de Valor da AndroMDA.

Esta ferramenta também necessita de um diagrama de casos de uso. A modelagem do diagrama de casos de uso deve ser feita levando em consideração que os casos de uso modelados serão implementados em diagramas de atividade e, por isso, devem ser funcionalmente decompostos o máximo possível. Por exemplo, um caso de uso Gerenciar Filmes deve ser dividido em casos de uso Cadastrar Filme, Remover Filme e Atualizar Filme. Em suma, a ferramenta requer uma decomposição funcional dos casos de uso, tornando-os casos de uso não aderentes à UML. O diagrama de casos de uso pode apenas utilizar associações entre os atores e casos de uso, não podendo usar associações como <<includes>> ou <<extends>>. O diagrama de casos de uso adaptado para a ferramenta AndroMDA pode ser visto na Figura 50. Observam-se os efeitos da decomposição funcional no aumento significativo dos casos de uso. 


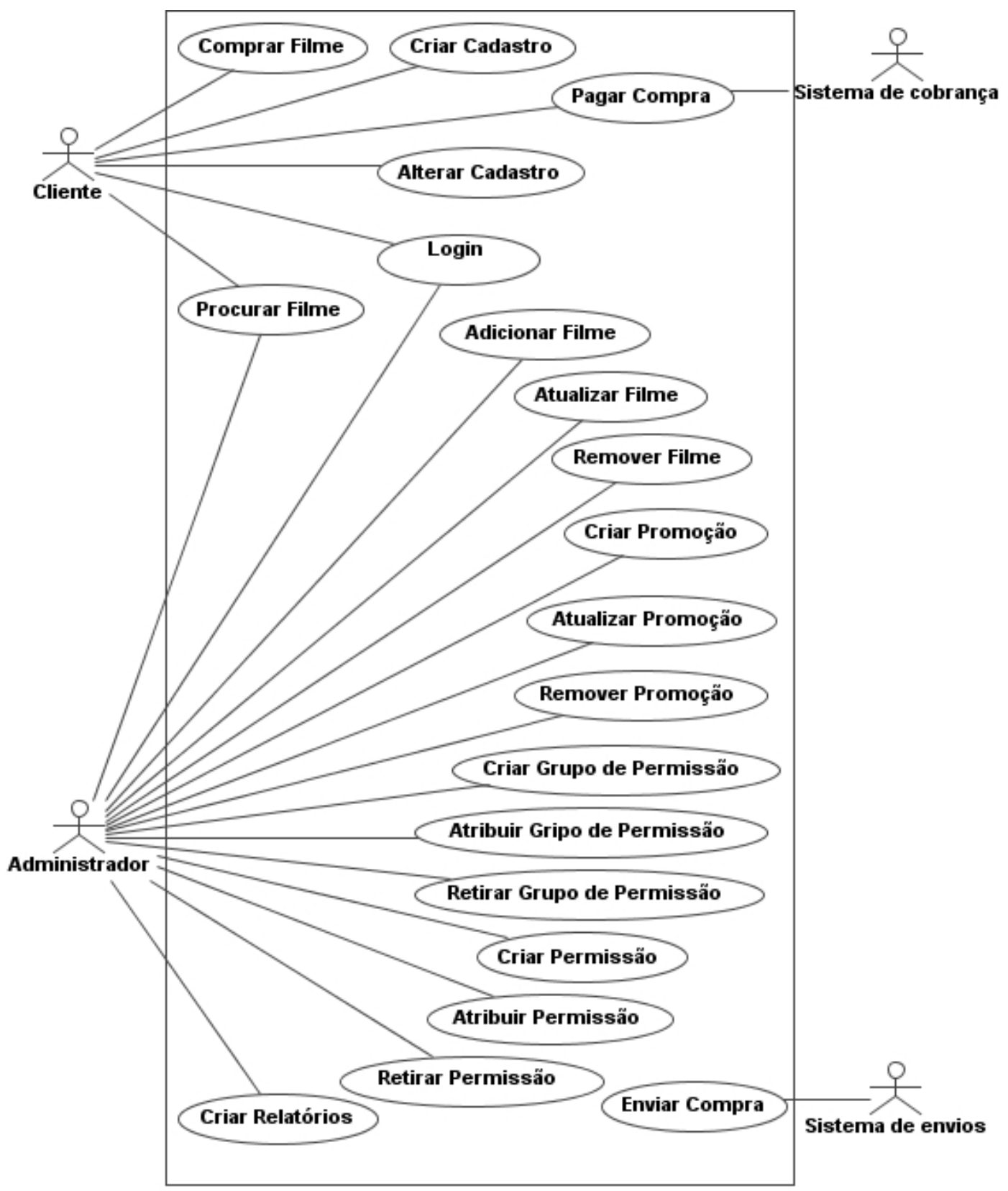

Figura 50: Diagrama de casos de uso do sistema adaptado para a AndroMDA.

Outro requisito imposto pela ferramenta é que atividades em diagramas de atividades precisam ser divididas e especificado quem as realiza. Para a AndroMDA, atividades podem ser realizadas pelo usuário do sistema ou pelo 
servidor. Por isso, todas as atividades descritas no diagrama da Figura 45 que envolvem ações do usuário do sistema e do servidor tiveram que ser divididas em duas. Por exemplo, a atividade Selecionar Endereço teve de ser dividida em uma atividade Selecionar Endereço, realizada pelo usuário do sistema, na qual ele seleciona um dos endereços previamente cadastrados, e outra atividade Atribuir Endereço realizada pelo servidor, que valida o endereço, calcula a taxa de entrega e associa o endereço selecionado pelo usuário à compra efetivada, designando-o como o endereço de entrega.

Além disso, a AndroMDA não interpreta nós de decisão (DecisionNodes) dos diagramas de atividade. Os nós de decisão são substituídos por fluxos saindo da atividade requerida, gerando possibilidades de navegação para o usuário do sistema. Outro fator é que os fluxos devem conter os dados que são passados quando a próxima atividade é uma interface com o usuário do sistema e devem conter a chamada do método quando a atividade seguinte é uma chamada ao servidor. O diagrama de atividade adaptado para a ferramenta AndroMDA é ilustrado na Figura 51.

\subsubsection{ArcStyler}

A ArcStyler utiliza os diagramas de classes e diagramas de atividade para a modelagem do sistema. Para ser adaptado para a ArcStyler, o diagrama de classes deve sofrer apenas uma alteração. A ArcStyler, assim como a OptimalJ e a AndroMDA, não interpreta Classes de Associação (AssociationClass) da UML. No diagrama de classes de negócio, é necessário substituir a classe de associação CompraFilme por uma classe CompraFilme associada tanto a Compra quanto a Filme. A solução utilizada é a mesma descrita para a OptimalJ e pode ser vista na Figura 46. 


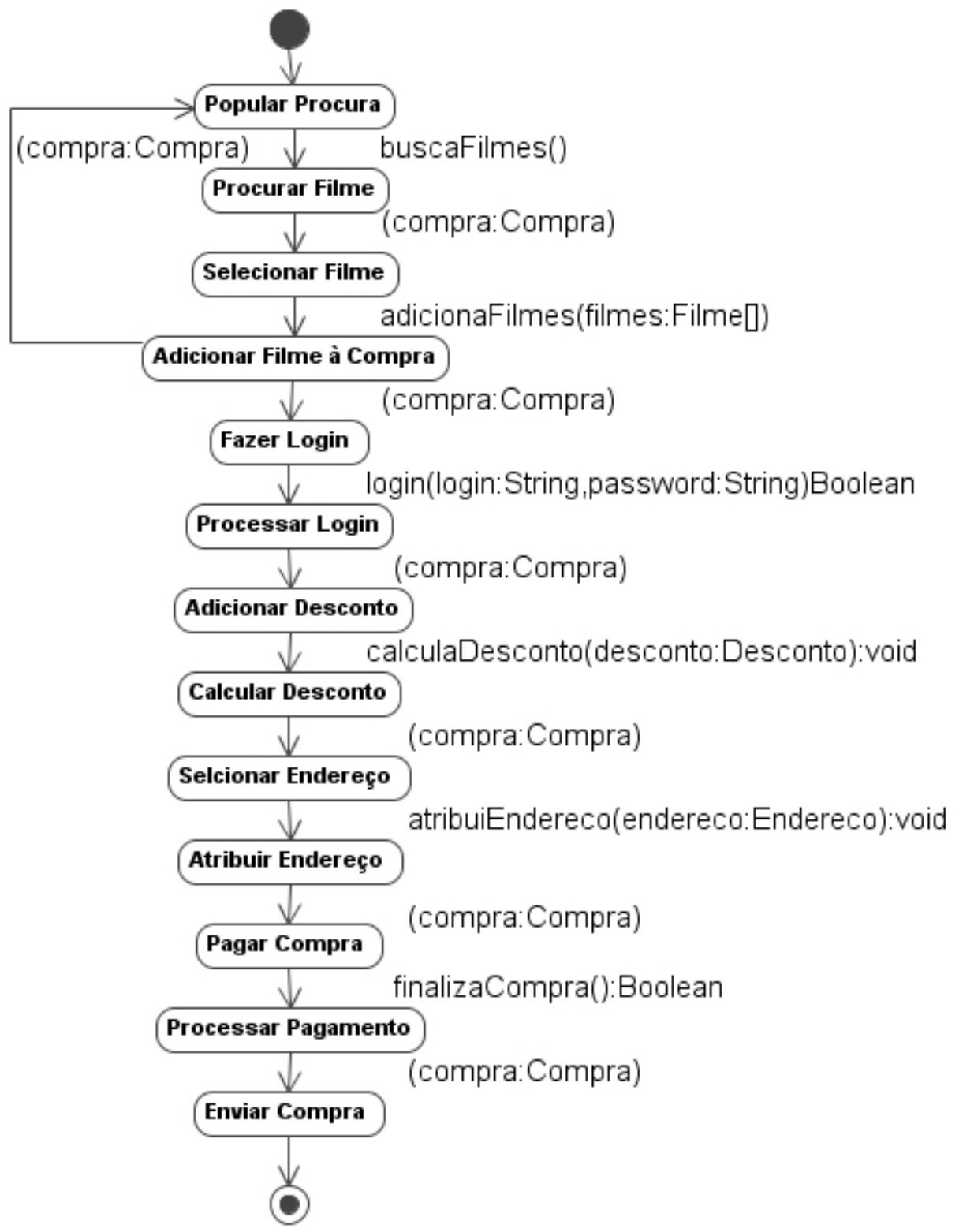

Figura 51: Diagrama de atividades do caso de uso Comprar Filme adaptado para a AndroMDA.

$\mathrm{Na}$ ArcStyler, os diagramas de atividade são usados para modelar o comportamento geral do sistema. A ArcStyler utiliza uma estratégia parecida com a da AndroMDA ao tratar diagramas de atividade como modelos de 
comportamento e atividades como páginas de internet. Cada atividade anotada com o estereótipo $<<V i e w S t a t e>>$ é uma página de Internet do sistema, na qual o usuário entra com dados e escolhe o próximo passo, e os fluxos servem para transportar os dados e chamar os métodos a serem executados. Para passar os dados entre as atividades, a ferramenta requer que sejam modelados objetos de transporte seguindo o padrão de projeto Objeto de Transferência de Dados (Data Transfer Object - DTO). Esses objetos de transporte devem possuir o estereótipo <<DataTransferObject>> e ser devidamente associados às atividades que os usam através de associações com o estereótipo $<<$ DataFlow $>>$. Como objeto de transporte, foi adicionado o elemento CompraDTO. As classes nas quais esses objetos de transporte se baseiam podem ser modeladas em um diagrama de classes separado, que irá conter apenas essas classes.

Foi necessário remover a atividade Enviar Compra, pois ela trata apenas de um processamento do servidor, e as atividades modeladas na ferramenta são interfaces com o usuário do sistema. Outra alteração foi a remoção do Ponto de Decisão (DecisionNode) do diagrama. Ele foi removido, pois Pontos de Decisão não são usados para representar escolhas feitas pelos usuários do sistema, e sim por resultados de processamento. O diagrama de atividades para o caso de uso Compra Filme adaptado para a ArcStyler é ilustrado na Figura 52.

Para realizar chamadas de métodos a partir das páginas geradas pelo diagrama de atividades, é necessário modelar um diagrama de classes com a classe cujo método será executado. No diagrama de classes, deve-se associar o método a ser chamado a uma classe que representa os fluxos do diagrama de atividade através de uma associação de dependência. Por exemplo, a atividade AdicionarFilme é associada a um diagrama de classes chamado AdicionarFilme. Nesse diagrama de classes estão a classe Cliente, e uma classe que representa o fluxo fazerLogin. O método login() de Cliente está 
associado à classe fazerLogin por uma associação de dependência. Esse diagrama de classes é mostrado na Figura 53.

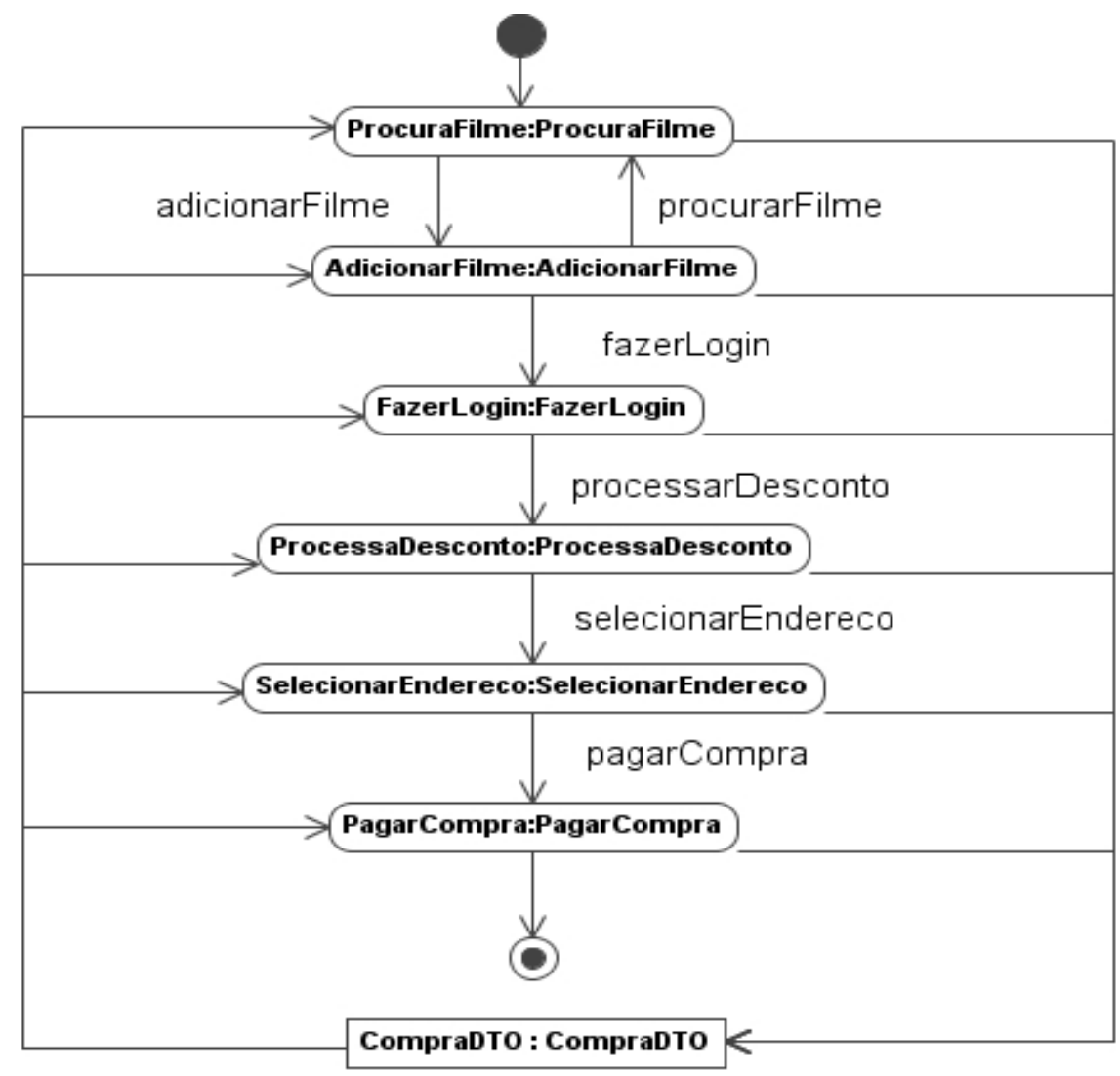

Figura 52: Diagrama de atividades para o caso de uso Compra Filme adaptado para a ArcStyler.

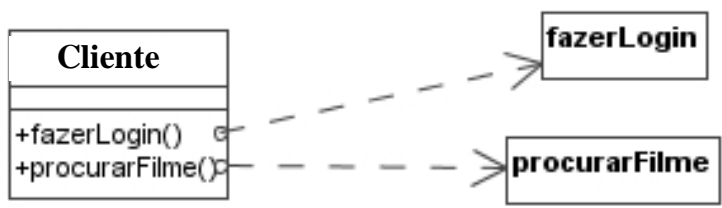

Figura 53: Diagrama de classes para a atividade AdicionarFilme. 


\subsubsection{Marcas no PIM}

Após adaptar o PIM a cada uma das ferramentas, o próximo passo foi marcá-los, para criar o PIM marcado usado como entrada nas transformações. A OptimalJ não utiliza marcas e, por isso, este passo não foi necessário para a ferramenta.

\subsubsection{AndroMDA}

A AndroMDA provê marcas através de um perfil UML. As marcas são estereótipos do perfil UML. As transformações da AndroMDA são amplamente baseadas em marcas, e exigem que quase todos os elementos do modelo sejam marcados.

No diagrama de casos de uso, cada caso de uso que possui interação com usuários do sistema deve ser marcado com o estereótipo $<<$ FrontEndUseCase>>. Indicando que é um caso de uso que interage com o usuário. Essa marca faz parte de um mapeamento que faz a correspondência entre um caso de uso a uma estrutura que possibilita interação com o usuário do sistema às atividades do diagrama de atividade associado a este caso de uso e também a um link na página de menu do sistema. A marca $<<$ FrontEndApplication $>>$ indica qual caso de uso deve ser utilizado como página inicial do sistema. Essa marca está mapeada à página inicial do sistema. A marca <<FrontEndRegistration>> indica qual caso de uso é a página de registro de usuários do sistema. Essa marca corresponde a uma página de redirecionamento, chamada para levar usuários não autorizados no sistema para a página inicial do processo de autorização. O diagrama de casos de uso adaptado para a ferramenta AndroMDA e adicionado de marcas está ilustrado na Figura 54. 


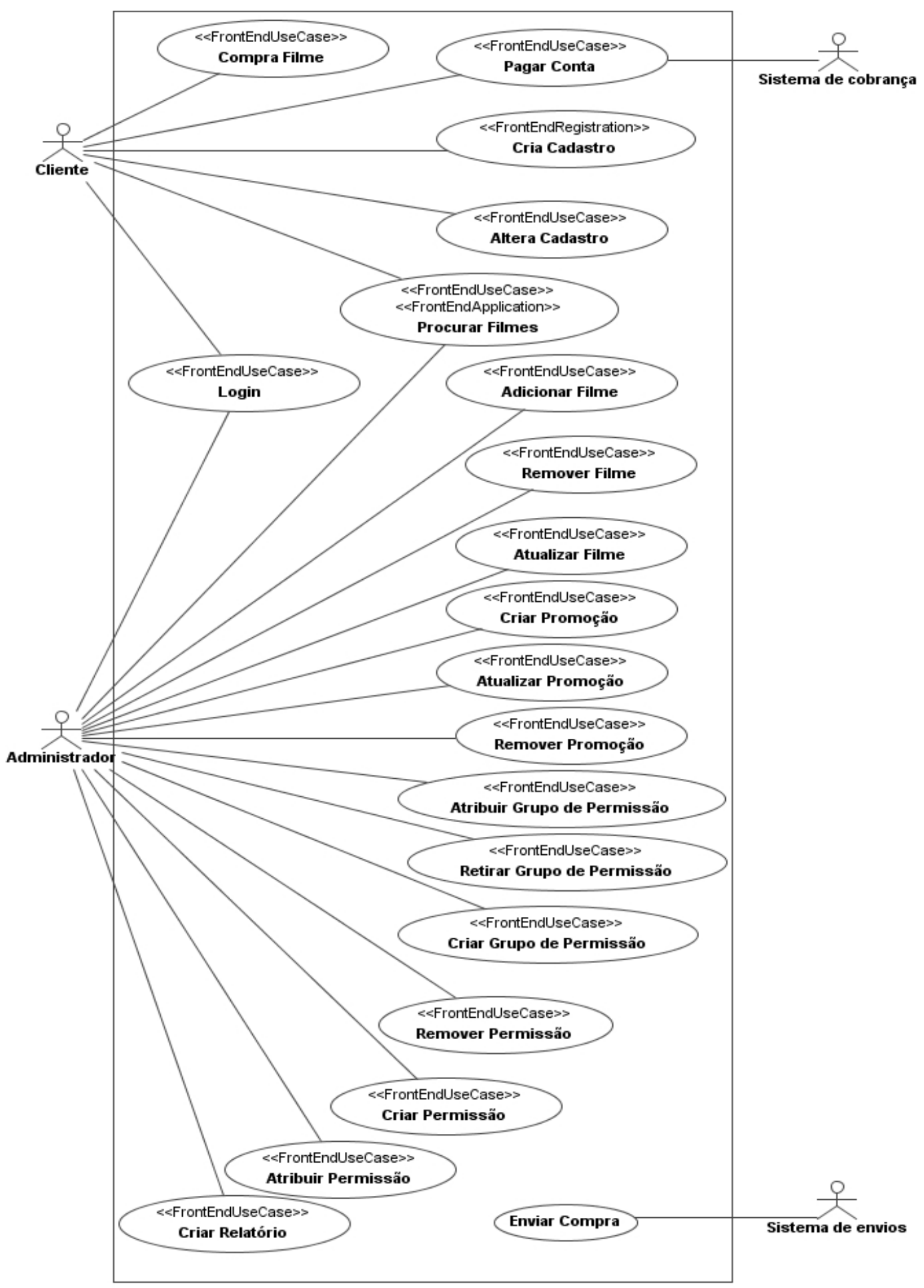

Figura 54: Diagrama de casos de uso adaptado para a ferramenta AndroMDA e marcado. 
O diagrama de classes deve ser marcado para indicar quais classes são entidades do sistema, quais são exceções e quais são classes de transferência de dados. A marca <<Entity $>>$ deve ser usada para marcar as classes do diagrama que representam entidades do sistema. Essa marca cria uma correspondência entre os elementos marcados e toda a estrutura necessária para a criação de uma entidade da plataforma alvo controlada pelo servidor. No caso, o alvo desse mapeamento inclui a classe Java de implementação de um EJB de entidade, a classe de interface remota e local, o roteiro (script) de criação de tabela(s) do banco de dados e informação no descritor de implantação (deployment descriptor).

A marca $<<$ ValueObject $>$ é usada para indicar que um elemento do diagrama é um objeto de transferência de dados. Essa marca cria uma correspondência entre a classe marcada e uma classe Java comum contendo todos os atributos e métodos declarados na classe marcada. A marca <<ApplicationException>> indica que uma classe é uma exceção da aplicação, podendo ser passada para o usuário do sistema para que ele possa decidir como prosseguir após ocorrer o erro. A marca vai corresponder a uma classe Java, que estende uma Exception em Java, e em código que repassa a exceção desde o método marcado até a interface com o usuário do sistema para que ela possa ser tratada ali. O diagrama de classes adaptado e marcado para a AndroMDA é mostrado na Figura 55.

O diagrama de atividades da AndroMDA também deve ser marcado. Nele, a marca <<FrontEndView>> deve ser aplicada a uma atividade para indicar que esta é uma interface com o usuário do sistema. Essa marca mapeia a atividade a uma página de internet do sistema. O diagrama de atividades do caso de uso Compra Filme adaptado e marcado para a AndroMDA, é ilustrado na Figura 56. 


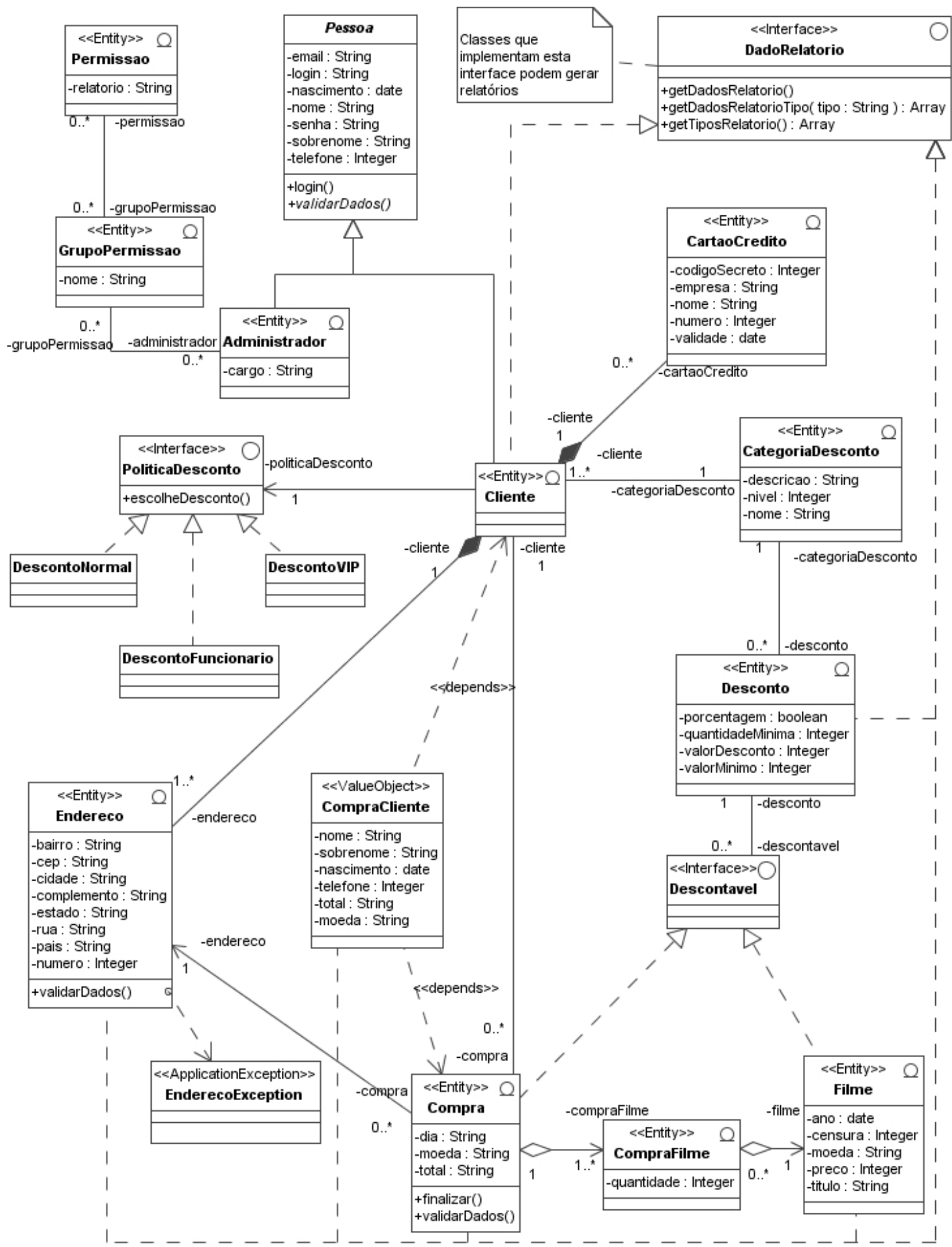

Figura 55: Diagrama de classes adaptado para a ferramenta AndroMDA e marcado. 
Página 89

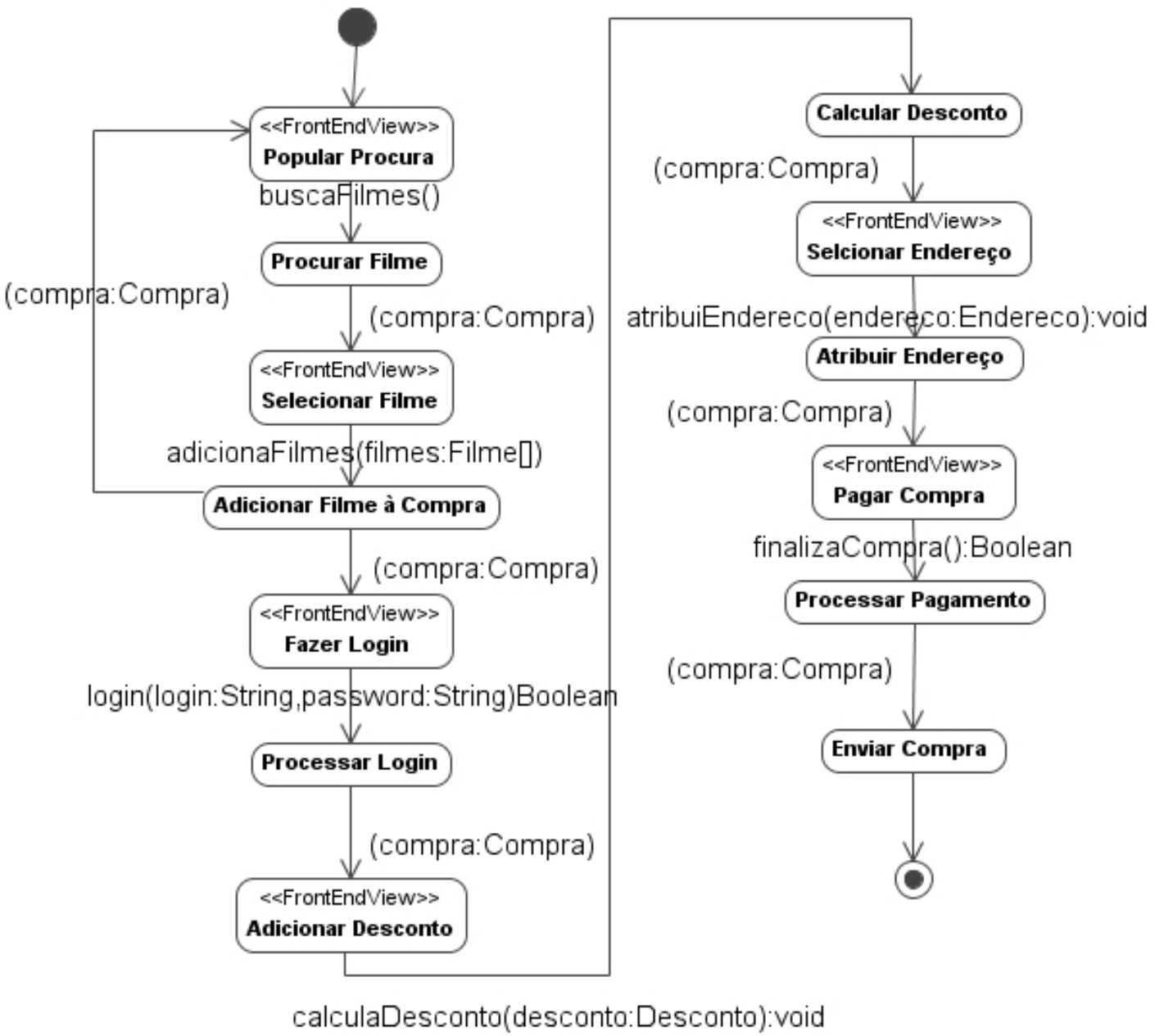

Figura 56: Diagrama de atividades do caso de uso Compra Filme adaptado para a ferramenta AndroMDA e marcado.

\subsubsection{ArcStyler}

As marcas da ArcStyler são providas pelos mapeamentos contidos nos cartuchos escolhidos. Para marcar o diagrama de classes de domínio, foi necessário utilizar a marca $<<$ ComponetSegment $>>$ para marcar as classes 
que representam entidades de negócio. As classes anotadas com essa marca serão mapeadas para um EJB de entidade. Esse mapeamento pode gerar a classe Java de implementação do EJB, a classe de interface remota e local, o roteiro (script) de criação de tabela(s) do banco de dados e informação no descritor de implantação (deployment descriptor). O diagrama de classes adaptado e marcado para a ArcStyler é ilustrado na Figura 57.

Na Figura 58 é mostrado o diagrama de atividade adaptado e marcado para o processo de comprar filme. As atividades do diagrama foram marcadas com a marca <<ViewState>> para indicar que são páginas do sistema e gerar a interface com o usuário. Para indicar que CompraDTO deveria ser utilizada como um objeto de transferência de dados entre as atividades, foi necessário marcá-lo com <<DataTransferObject $>>$. A marca $<<$ ViewState $>>$ estabelece a correspondência de uma atividade ao código de uma página e a marca <<DataTransferObject>> a uma classe Java comum e às alterações de código necessárias às páginas associadas ao elemento marcado, para que as páginas possam trabalhar com o objeto.

Os diagramas de classes criados para indicar os métodos a serem chamados pelas atividades também precisam ser marcados. A marca <<signal>> teve de ser adicionada às classes que representam os fluxos do diagrama de atividades. Com isso, essas classes serão mapeadas para trechos de código nas páginas indicando qual página do sistema deve seguir a chamada de qual método a ser executado.

A Figura 59 mostra o diagrama de classes para a atividade AdicionarFilme, visto na Figura 53, adicionado de marcas.

\subsubsection{Observações gerais sobre configurações adicionais e o código gerado}

Nesta seção comentam-se, sucintamente, algumas das configurações adicionais necessárias às ferramentas e as saídas das três ferramentas para 
uma mesma classe, para apontar algumas diferenças de código. A classe Cliente é escolhida por ser o foco central do sistema e por estar diretamente associada a alguns dos problemas encontrados na modelagem.

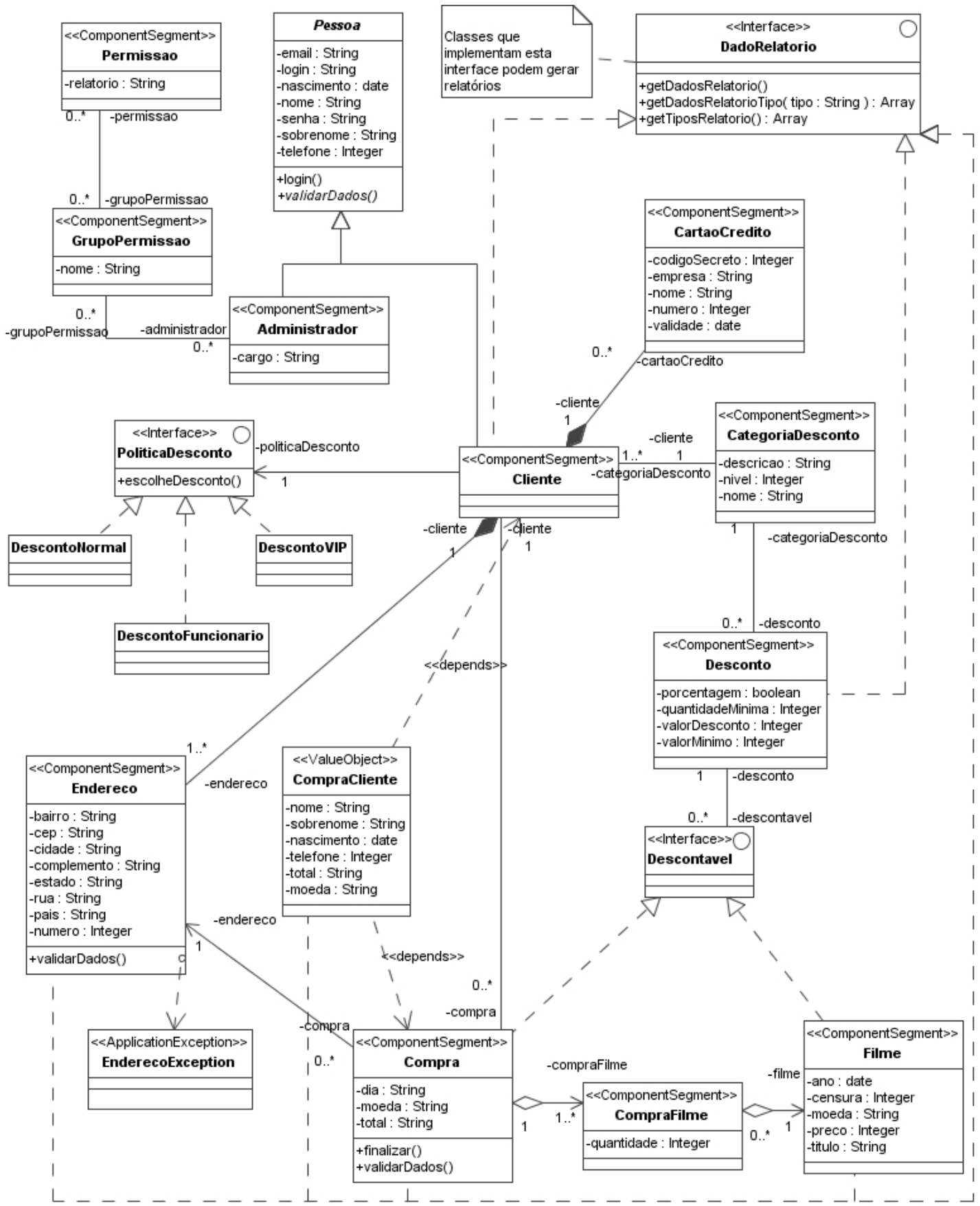

Figura 57: Diagrama de classes adaptado e marcado para a ferramenta ArcStyler. 
Página 92

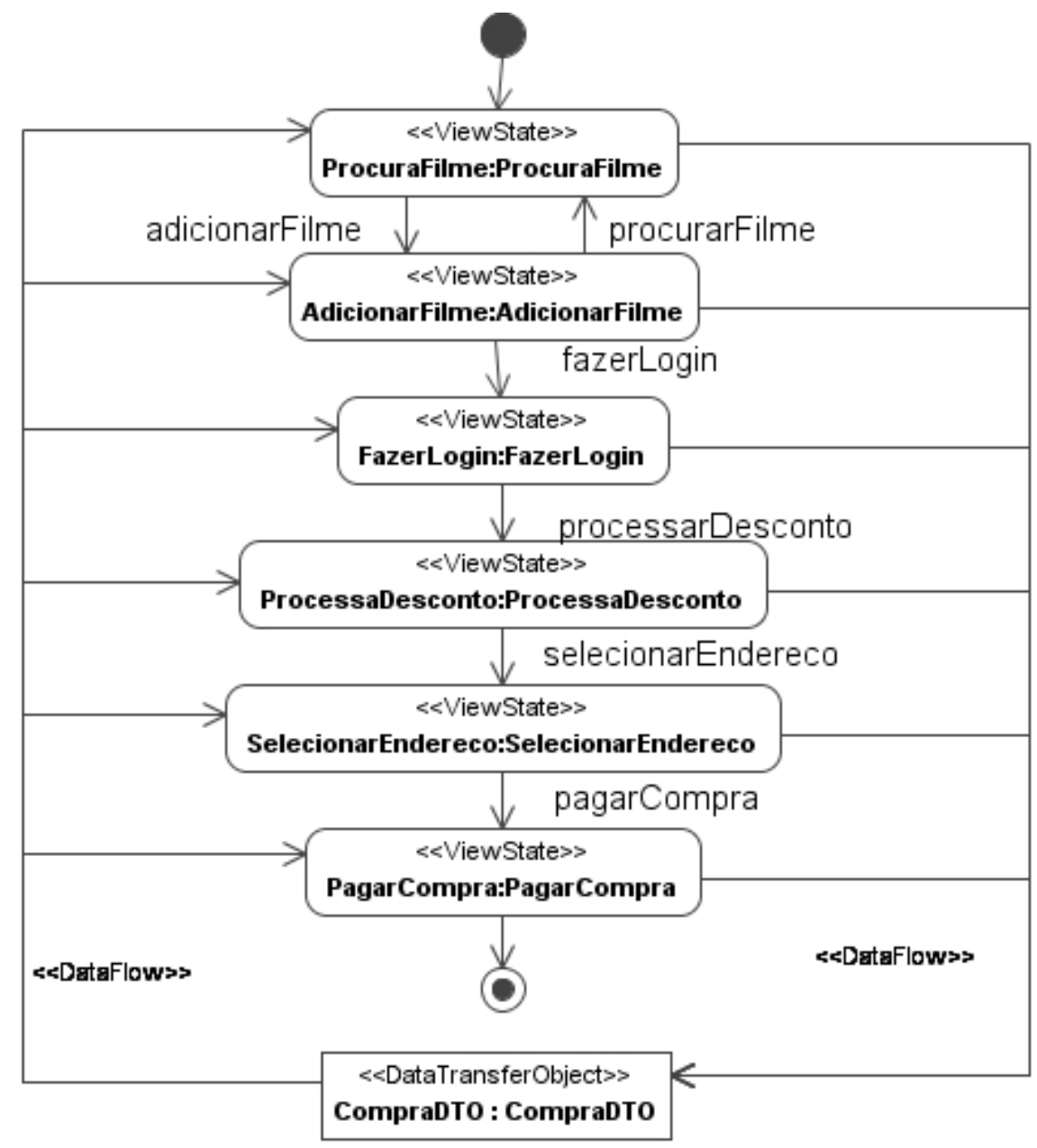

Figura 58: Diagrama de atividades para o caso de uso Comprar Filme adaptado para a ferramenta ArcStyler e marcado.

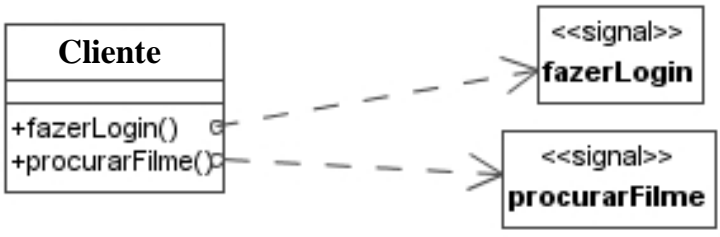

Figura 59: Diagrama de classes marcado para a atividade AdicionarFilme. 
A OptimalJ, antes de gerar o código, exige que seja gerado e configurado o PSM. A execução da transformação de PIM para PSM é feita com um único comando. No PSM é necessário configurar as políticas de acesso, as páginas de procura de Filmes e os métodos chamados por estas páginas. A política de acesso é configurada na própria ferramenta, criando grupos de acesso, atribuindo direitos de acesso a estes grupos e adicionando membros a estes grupos. Também é necessário modificar as páginas de acesso a alguns objetos como ClienteCompra, que teve de ser removido do PIM, devendo ser configurado no PSM. É necessário criar a classe, criar uma página que acesse a classe e codificar o método de procura pelos dados de Cliente e Compra.

Em ambas as ferramentas AndroMDA e ArcStyler, é necessária a codificação manual de alguns métodos. As ferramentas se concentram em gerar a estrutura do sistema e os principais métodos de acesso. Mas métodos mais complexos, como por exemplo, fazerLogin(), não são gerados automaticamente.

Nos Apêndices A, B e C são mostrados fragmentos do código EJB gerados para a classe Cliente para as ferramentas OptimalJ, AndroMDA e ArcStyler, respectivamente.

\subsection{Transformações e mapeamentos utilizados}

Utilizando as transformações definidas na seção 2.2.3 e os mapeamentos definidos na seção 2.2.2 resumem-se, nesta seção, as transformações aplicadas pelas três ferramentas para o estudo de caso.

A OptimalJ utiliza principalmente mapeamentos de tipos nas suas transformações. No estudo de caso, todos os mapeamentos usados são de tipos e as transformações são transformações de meta-modelos. A OptimalJ 
gera um registro da transformação utilizando propriedades dos elementos do modelo. Cada elemento e cada diagrama possuem uma propriedade chamada applicationElement, que armazena todos os elementos gerados a partir do elemento atual e outra propriedade chamada domainElement que indica qual elemento foi utilizado para gerar o elemento atual. Por exemplo, para a classe Cliente do PIM, a propriedade applicationElement indica que os elementos Cliente do pacote de negócios e Cliente do pacote de banco de dados do PSM foram gerados. Para o elemento Cliente do pacote de negócios, a propriedade domainElement indica que a classe Cliente do PIM foi o elemento da qual ela foi gerada.

A AndroMDA possui mapeamentos de tipos e instâncias. No estudo de caso, existem elementos marcados e elementos sem marcas. Os elementos sem marcas são transformados por mapeamentos de tipos, e os elementos marcados por mapeamentos de instâncias, portanto, as transformações aplicadas são transformações de meta-modelos e marcas. Por exemplo, a classe DescontoNormal não foi marcada, e foi transformada seguindo um mapeamento de tipo, gerando uma classe Java simples. A classe Cliente, anotada com a marca <<Entity >>, apesar de ser do mesmo tipo que a classe DescontoNormal, não foi transformada da mesma maneira. A classe Cliente foi transformada em um EJB de entidade, seguindo o mapeamento da marca $<<$ Entity $>$. A AndroMDA não gera registro da transformação.

A ArcStyler também utiliza mapeamentos de tipos e instâncias. No modelo do estudo de caso, os elementos marcados são transformados de acordo com os mapeamentos de instâncias em que as marcas se encaixam, e os elementos sem marca são transformados de acordo com seus tipos por mapeamentos de tipos. As transformações utilizadas nessa ferramenta são transformações de meta-modelos e marcas. Assim como na AndroMDA, a classe DescontoNormal não foi marcada, e seguindo um mapeamento de tipo, gerou uma classe Java simples. A classe Cliente, marcada com a marca 
$<<$ Entity >>, seguiu um mapeamento de instância e gerou um EJB de entidade. A ArcStyler não gera registro da transformação.

\subsection{Conclusões gerais da análise qualitativa das ferramentas}

Seguem algumas conclusões do estudo de caso. Para analisar quais os tipos de mapeamentos definidos pela MDA estão sendo usados pelas ferramentas utilizam-se as Tabelas 6 e 7. A Tabela 6 resume os tipos de mapeamentos possíveis em cada uma das ferramentas, e a Tabela 7 resume os tipos de mapeamentos utilizados durante o estudo de caso.

Tabela 6 - Tipos de mapeamentos possíveis em cada ferramenta.

\begin{tabular}{|l|l|l|l|}
\hline Mapeamentos & OptimalJ & AndroMDA & ArcStyler \\
\hline Tipos & Sim & Sim & Sim \\
\hline Tipos com valores de instâncias & Sim & Sim & Sim \\
\hline Subtipos & Sim & Sim & Sim \\
\hline Instâncias (Marcas) & Não & Sim & Sim \\
\hline
\end{tabular}

Tabela 7 - Tipos de mapeamentos utilizados por cada ferramenta no estudo de caso.

\begin{tabular}{|l|l|l|l|}
\hline Mapeamentos & OptimalJ & AndroMDA & ArcStyler \\
\hline Tipos & Sim & Sim & Sim \\
\hline Tipos com valores de instâncias & Não & Não & Não \\
\hline Subtipos & Não & Não & Não \\
\hline Instâncias (Marcas) & Não & Sim & Sim \\
\hline
\end{tabular}


Com as informações das Tabelas 6 e 7, observa-se que nem todos os mapeamentos possíveis foram utilizados no estudo de caso. Nota-se que o estudo de caso não exigiu a utilização de variações de mapeamentos de tipos, isto é, mapeamentos de tipos com valores de instâncias e mapeamentos de subtipos. Em particular, a OptimalJ utilizou apenas mapeamentos de tipos no estudo de caso. As outras duas ferramentas utilizaram marcas, além de mapeamentos de tipos.

Além dos tipos de mapeamentos utilizados, também foram estudados outros mecanismos de auxílio às transformações. A OptimalJ e a AndroMDA utilizam configurações para determinar uma arquitetura para o código da aplicação. A arquitetura utilizada é a arquitetura de camadas.

Outro ponto observado foram as alterações necessárias aos modelos para que as ferramentas os aceitassem. As Tabelas 8, 9 e 10 resumem essas alterações, dando uma idéia das diferenças entre as ferramentas em termos dos elementos requeridos para a aceitação do modelo PIM do estudo de caso.

Os números apresentados nas tabelas foram retirados das soluções completas utilizadas nas ferramentas. Os diagramas apresentados no presente trabalho são apenas parte da coleção de elementos dos modelos PIM submetidos às ferramentas. Por exemplo, os diagramas de atividade apresentados dizem respeito apenas ao caso de uso Comprar Filme.

A Tabela 8 apresenta a contagem do número de diagramas de caso de uso e seus elementos, utilizados no PIM proposto e nas soluções de cada ferramenta. Essa tabela mostra que o diagrama de casos de uso foi utilizado apenas na AndroMDA, mas sofreu significativas alterações, aumentando o número de casos de uso e suas associações. Como a ferramenta não aceita inclusões, extensões e nem generalizações neste diagrama, estes elementos 
foram removidos. Por exemplo, o ator Pessoa presente no PIM proposto (Figura 43) foi removido (Figura 50).

Tabela 8 - Contagem dos diagramas de casos de uso e seus elementos nos modelos.

\begin{tabular}{|l|c|c|c|c|}
\hline $\begin{array}{l}\text { Diagrama de casos de } \\
\text { uso }\end{array}$ & $\begin{array}{c}\text { PIM } \\
\text { proposto }\end{array}$ & OptimalJ & AndromDA & ArcStyler \\
\hline Diagramas & 1 & 0 & 1 & 0 \\
\hline Atores & 5 & - & 4 & - \\
\hline Casos de uso & 9 & - & 20 & - \\
\hline Associações & 8 & - & 23 & - \\
\hline Inclusões & 8 & - & 0 & - \\
\hline Extensões & 1 & - & 0 & - \\
\hline Generalizações & 2 & - & 0 & - \\
\hline
\end{tabular}

A OptimalJ e a ArcStyler não fizeram uso deste diagrama, por isso o número de diagramas listado na Tabela 8 para estas ferramentas é 0 . Como elas não possuem diagramas de caso de uso, não houve contagem dos elementos deste diagrama para essas ferramentas, fato representado pelo símbolo "_" na Tabela.

A Tabela 9 apresenta a contagem do número de diagramas de classes e seus elementos utilizados no PIM proposto e nas soluções de cada ferramenta.

A OptimalJ necessita que sejam modelados um diagrama de classes para gerar a estrutura do sistema e outro para os serviços. Além disso, foi necessário adaptar o diagrama de classes representando a estrutura do sistema, removendo as interfaces, adicionando classes e métodos, etc. 
Tabela 9 - Contagem dos diagramas de classes e seus elementos nos modelos.

\begin{tabular}{|l|c|c|c|c|}
\hline Diagrama de classes & $\begin{array}{c}\text { PIM } \\
\text { proposto }\end{array}$ & OptimalJ & AndroMDA & ArcStyler \\
\hline Diagramas & 1 & 2 & 3 & 9 \\
\hline Classes & 16 & 15 & 40 & 39 \\
\hline Interfaces & 3 & 0 & 3 & 3 \\
\hline Classes de Associação & 1 & 0 & 0 & 0 \\
\hline Atributos & 45 & 37 & 91 & 91 \\
\hline Métodos & 9 & 21 & 10 & 9 \\
\hline Associações & 10 & 10 & 12 & 12 \\
\hline Generalizações & 2 & 7 & 2 & 2 \\
\hline Realizações & 12 & 0 & 12 & 12 \\
\hline Dependências & 2 & 0 & 13 & 22 \\
\hline
\end{tabular}

A AndroMDA precisa de três diagramas de classes, um para a estrutura do sistema, um para as classes de transporte de dados e outro para os serviços. O diagrama de classes que gera a estrutura do sistema sofreu apenas uma alteração. O diagrama de classes com os serviços do sistema continha apenas um método, mas a inclusão do diagrama de classes modelando as estruturas de transporte quase dobrou o número de atributos.

A ArcStyler necessita que seja modelado um diagrama de classes para cada diagrama de atividade, pois devem ser modeladas as dependências dos métodos executados em cada atividade com os fluxos das atividades. Classes 
são usadas para representar os fluxos nos diagramas de classes das atividades. Isso causou um aumento significativo no número de classes.

A Tabela 10 apresenta a contagem do número de diagramas de atividade e seus elementos utilizados no PIM proposto e nas soluções de cada ferramenta.

Tabela 10 - Contagem dos diagramas de atividades e seus elementos nos modelos.

\begin{tabular}{|l|c|c|c|c|}
\hline Diagrama de atividades & $\begin{array}{c}\text { PIM } \\
\text { proposto }\end{array}$ & OptimalJ & AndroMDA & ArcStyler \\
\hline Diagramas & 7 & 2 & 20 & 20 \\
\hline Atividades & 25 & 11 & 68 & 50 \\
\hline Decisões & 4 & 0 & 0 & 0 \\
\hline Fluxos & 43 & 15 & 109 & 91 \\
\hline
\end{tabular}

Na OptimalJ, todo o código de leitura, criação, atualização e remoção de dados é criado automaticamente. Apenas os casos de uso mais complexos como compra de filmes e criação dos relatórios necessitaram de um diagrama de atividade. Na AndroMDA, cada caso de uso deve ter um diagrama de atividade. Cada atividade por sua vez, precisou ser dividida entre atividade realizada pelo usuário do sistema e atividade realizada pelo servidor. A ArcStyler não faz divisão entre atividades do usuário do sistema e do servidor. No entanto, ela utiliza os diagramas de atividades para criar as páginas da mesma maneira que a AndroMDA.

Como a análise realizada no presente trabalho é puramente qualitativa, não houve o estabelecimento de critérios quantitativos para, por exemplo, determinar a escolha mais apropriada de uma ferramenta para uma 
determinada classe de problemas. No entanto, a observação das Tabelas 9 e 10 mostra algumas diferenças relevantes.

Por exemplo, como apresentado na Tabela 9, o número de classes requerido para a solução na ferramenta OptimalJ (15) é praticamente o mesmo do PIM proposto (16). Este número sobe para 40 na solução requerida pela AndroMDA e 39 pela ArcStyler. O número de diagramas também apresenta uma variação razoável: 1 diagrama para o PIM proposto, 2 para a OptimalJ, 3 diagramas para a AndroMDA e 9 para a ArcStyler.

Quanto à Tabela 10, observa-se que há uma variação significativa no número de diagramas de atividade: 7 para o PIM proposto, 2 para a OptimalJ, 20 para a AndroMDA e 20 para a ArcStyler. Outra observação é a variação significativa no número de atividades em todos os diagramas de atividade: o PIM proposto possui 25 atividades, A OptimalJ totalizou 11 atividades, a AndroMDA ficou com 68 atividades e a ArcStyler com 50 atividades no total. 


\section{Conclusão e trabalhos futuros}

No presente trabalho apresentaram-se alguns dos conceitos relacionados com mapeamentos e transformações da MDA, e como três ferramentas lidam com estes conceitos. Analisaram-se, do ponto de vista estritamente qualitativo, as implementações feitas para mapeamentos e transformações, e seu uso prático através de um estudo de caso.

Verifica-se, neste trabalho, que as três ferramentas implementam parte dos conceitos da MDA. Nenhuma das três ferramentas dá suporte ao CIM, todas implementam o PIM e apenas a OptimalJ faz uso do PSM. A Tabela 9 apresenta um resumo, mostrando quais os modelos da MDA implementados em cada uma das ferramentas.

Tabela 11 - Modelos da MDA e suas implementações nas ferramentas.

\begin{tabular}{|l|l|l|l|}
\hline $\begin{array}{l}\text { Modelos I } \\
\text { Ferramentas }\end{array}$ & OptimalJ & AndroMDA & ArcStyler \\
\hline CIM & Não & Não & Não \\
\hline PIM & Sim & Sim & Sim \\
\hline PSM & Sim & Não & Não \\
\hline
\end{tabular}

A MDA especifica três transformações: de CIM para PIM, de PIM para PSM e PSM para código. A MDA também especifica que as transformações de PIM para PSM e de PSM para código podem ser substituídas por uma transformação do PIM diretamente para código, sem criar o PSM. Quanto às transformações implementadas pelas ferramentas, a AndroMDA e a ArcStyler implementam a transformação de PIM diretamente para código e a OptimalJ 
implementa a transformação de PIM para PSM e de PSM para código. Sob esse aspecto, as implementações das ferramentas para as transformações condizem com a especificação da MDA. No entanto, apenas a OptimalJ cria um registro da transformação como especificado pela MDA. A falta do registro da transformação implica na incapacidade de rastrear as transformações e na falta de sincronização entre o PIM e PSM do modo especificado pela MDA.

A MDA permite que mapeamentos de tipos e/ou mapeamentos de instâncias sejam usados nas transformações. A OptimalJ utiliza apenas mapeamentos de tipos e suas variações, mapeamentos de subtipos e mapeamentos de tipos com valores de instâncias. A AndroMDA e a ArcStyler utilizam mapeamentos de instâncias, mapeamentos de tipos e as variações de mapeamentos de tipos. A AndroMDA e a ArcStyler especificam marcas para serem usadas no modelo. A AndroMDA fornece suas marcas através de perfis UML e a ArcStyler, através dos mapeamentos. Ambos enfoques são previstos na MDA.

Um mecanismo de auxílio às transformações implementado pelas ferramentas OptimalJ e AndroMDA é a escolha do estilo arquitetônico do código da aplicação através de configurações. A escolha do estilo arquitetônico influencia as transformações de PIM para PSM na OptimalJ e de PIM para código na AndroMDA, especificando quais mapeamentos serão usados nas transformações.

As adaptações feitas no PIM para cada ferramenta, descritas no capítulo 4, ilustram que o PIM adaptado de uma ferramenta não pode ser utilizado em outra ferramenta. Isso significa que os modelos PIM usados como entrada para as transformações são dependentes do estilo de modelagem imposto pelas ferramentas, mostrando a falta de uma padronização para o estilo de modelagem do PIM.

As transformações e mapeamentos implementados pelas ferramentas têm o mesmo problema de falta de padronização. As ferramentas utilizam tipos 
diferentes de mapeamento e transformações, além de criarem implementações diferentes para eles. Outra observação feita é que não existe um padrão para marcas - cada ferramenta utiliza seu próprio conjunto de marcas, aumentando a dependência do PIM com a ferramenta.

A MDA, apesar de ser um padrão de desenvolvimento, ainda não possui padrões definidos para o uso de seus conceitos. A MDA permite que o desenvolvimento do software se torne dependente da ferramenta ao permitir que as ferramentas adotem seus próprios estilos de modelagem, organização e configurações de modelos e seus elementos.

Os trabalhos futuros vislumbrados incluem:

- Criação de critérios para comparações baseados em análises quantitativas entre as ferramentas, para a determinação da melhor escolha de ferramenta em determinados cenários de utilização de ferramentas MDA;

- Criação de um estudo de caso para analisar não apenas o uso que as ferramentas fazem dos mapeamentos mas também a geração de mapeamentos e transformações nas ferramentas;

- Realizar uma análise comparativa entre a geração automática de código utilizando mapeamentos de tipos e mapeamentos de instâncias, utilizando marcas, para verificar qual o grau de automatização de cada mapeamento.

- Criação de um meta-modelos de marcas, o que poderia ajudar a padronizar o uso de marcas. Modelos de marcas são definidos pela MDA como independentes de mapeamentos, e as ferramentas, ao adotar um mesmo meta-modelo de marcas, facilitariam a equivalência de modelos de marcas. 


\section{Referências Bibliográficas}

ALMEIDA, J. P.; DIJKMAN, R.; SINDEREN, M. V.; PIRES, L. F. On the Notion of Abstract Platform in MDA Development. Edoc, pp. 253-263. Enterprise Distributed Object Computing Conference, Eighth IEEE International (EDOC'04), 2004.

ALMEIDA, J. P.; DIJKMAN, R.; SINDEREN, M. V.; PIRES, L. F. Platformindependent Modeling in MDA: supporting abstract platforms. Model Driven Architecture: European MDA Workshops: Foundations and Applications, MDAFA 2004, 2004.

ANDROMDA. AndroMDA 3.2 documentation. 2006. Disponível em: $<$ http://galaxy.andromda.org/docs-3.2/>

APACHE SOFTWARE FOUDATION. Apache Struts. http://struts.apache.org/

ARCSTYLER. ArcStyler 5.5 Modeling Guide. 2006. Disponível em:

<http://www.interactive-objects.com/products/arcstyler/support-documentation>

BÉZIVIN, J.; HAMMOUDI, S.; LOPES, D.; JOUAULT, F. Applying MDA approach for Web service platform. Enterprise Distributed Object Computing Conference, 2004. EDOC 2004. Proceedings. Eighth IEEE International, 2004.

BROWN, A. W. Model driven architecture: Principles and practice. Software and Systems Modeling, v. 3, n. 4, p. 314-327, 2004.

BURBECK, S. Applications Programming in Smalltalk-80(TM): How to use Model-View-Controller (MVC). 1987, revisado me 1992. Disponível em: <http://st-www.cs.uiuc.edu/users/smarch/st-docs/mvc.html>

CALIARI, G. SILVA, P. S. M. An experiment on modeling persistence with MDA tools. XII Jornadas de Ingeniería del Software y Bases de Datos, 2007.

COMPUWARE. OptimalJ 4.0 User Guide. 2006. Disponível em:

<http://frontline.compuware.com/javacentral/members/doc/default.asp>

DELANOTE, G.; STEEGMANS, E. Concepts for Abstracting away Object Reification at the level of Platform Independent Models (PIMs). ModelBased Development of Computer-Based Systems and Model-Based 
Methodologies for Pervasive and Embedded Software, 2006

EUROPEAN SOFTWARE INSTITUTE. Enriched PIM with Project

Management Information. MASTER-2003-D3.1-V1.0-PUBLIC, 09/2003.

FOWLER, M. Patterns of Enterprise Application Architecture. AddisonWesley Professional, 2002.

FOWLER, M. UML Distilled: A Brief Guide to the Standard Object Modeling Language. 3a. edição. Addison-Wesley, 2004.

GAMMA, E. HELM, R. JOHNSON, R. VLISSIDES J. Design Patterns:

Elements of Reusable Object-Oriented Software. Addison-Wesley

Professional; $1^{\text {st }}$ edition. 01/1995.

GARCIA, A B.; MANSELL, J.; SELLIER, D. From Customer Requirements to PIM: necessity and reality. Workshop in Software Model Engineering. 2002.

HUANG, J.; VOETEN, J.; VENTEVOGEL, A.; BOKHOVEN, L. V. Platformindependent design for embedded real-time systems. Proceedings of Forum on specification and Design Languages, Frankfurt, Germany. 09/2003.

INRIA. ATL Transformation Example - UML to JAVA. 2005. Disponível em: $<$ http://www.eclipse.org/m2m/atl/at/Transformations/UML2Java/ExampleUML2J ava[v00.01].pdf>.

JBOSS.ORG. JBoss Application Server Guide. 2006. Disponível em: < http://labs.jboss.com/jbossas/docs>

JYTHON. Jython User Guide. 2007. Disponível em:

<http://www.jython.org/Project/userguide.html>

KLEPPE, A.; WARMER J.; BAST W. MDA Explained - The Model Driven Architecture: Practice and Promise. Addison-Wesley. 2003.

LANGLOIS B.; EXERTIER, D.; ROUX, X. L. PIM Definition and Description. First European Workshop on Model Driven Architecture with Emphasis on Industrial Application. 03/2004.

LARMAN, C. Applying UML and Patterns: An Introduction to ObjectOriented Analysis and Design and the Unified Process. 3a edição. Prentice Hall. 2004.

LOPES, D.; HAMMOUDI, S.; BÉZIVIN, J.; JOUAULT, F. Mapping Specification in MDA: from Theory to Practice. Proceedings of the First 
International Conference on Interoperability of Enterprise Software and Applications (INTEROP-ESA'2005). 2005.

MELLOR, S. J. MDA Distilled - Principles of Model Driven Architecture. Addison-Wesley. 2004.

MENS, T.; CZARNECKI, K. GORP, P. V. A Taxonomy of Model

Transformations. International Workshop on Graph and Model Transformation, Tallinn, Estonia. 09/2005.

OMG; Model Driven Architecture (MDA) - Document number ormsc/200107-01. Architecture Board ORMSC1. 2001. Disponível em:

<http://www.omg.org/cgi-bin/doc?ormsc/2001-07-01>

OMG; MDA Guide Version 1.0.1. 2003. Disponível em:

<http://www.omg.org/docs/formal/03-06-01.pdf>

OMG. Meta Object Facility (MOF) 2.0 Query/View/Transformation Specification - Final Adopted Specification. 2005. Disponível em: <http://www.omg.org/docs/formal/05-11-01.pdf>

OMG. Meta Object Facility (MOF) Core Specification - Version 2.0. 2006. Disponível em: <http://www.omg.org/docs/formal/06-01-01.pdf>.

OMG. Unified Modeling Language: Infrastructure - version 2.0. 2006.

Disponível em: <http://www.omg.org/docs/formal/05-07-05.pdf>.

OMG. Unified Modeling Language: Superstructure - version 2.1.1. 2006. Disponível em: < http://www.omg.org/cgi-bin/apps/doc?formal/07-02-05.pdf>.

SELIC, B. The pragmatics of model-driven development. IEEE Software, v. 20, n. 5, p. 19-25. 2003.

SUN. Enterprise JavaBeans Technology. http://java.sun.com/products/ejb/

TARIQ N. A.; AKHTER N. Comparison of Model Driven Architecture (MDA) based tools. 13th Nordic Baltic Conference (NBC). 2005.

VARRÓ, D.; PATARICZA A. UML action semantics for model transformation 
systems. Periodica Politechnica. 2003.

WAMPLER D. The Role of Aspect-Oriented Programming in OMG's ModelDriven Architecture. Aspect Programming, Inc. 2003. 


\section{Apêndice A - Código da classe Cliente gerado pela ferramenta OptimalJ}

Este apêndice apresenta alguns fragmentos do código resultante das transformações da ferramenta OptimalJ para a classe Cliente.

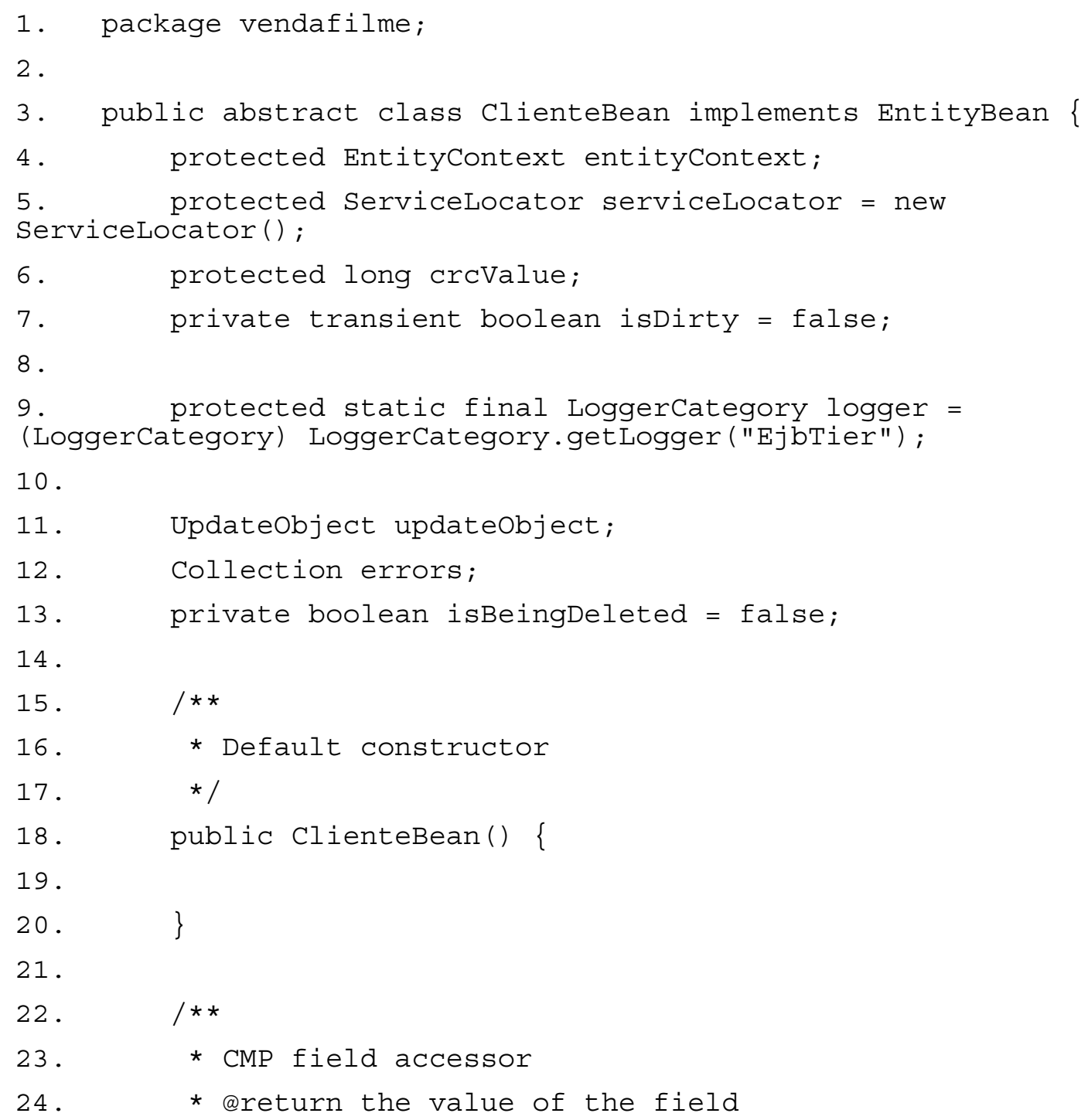




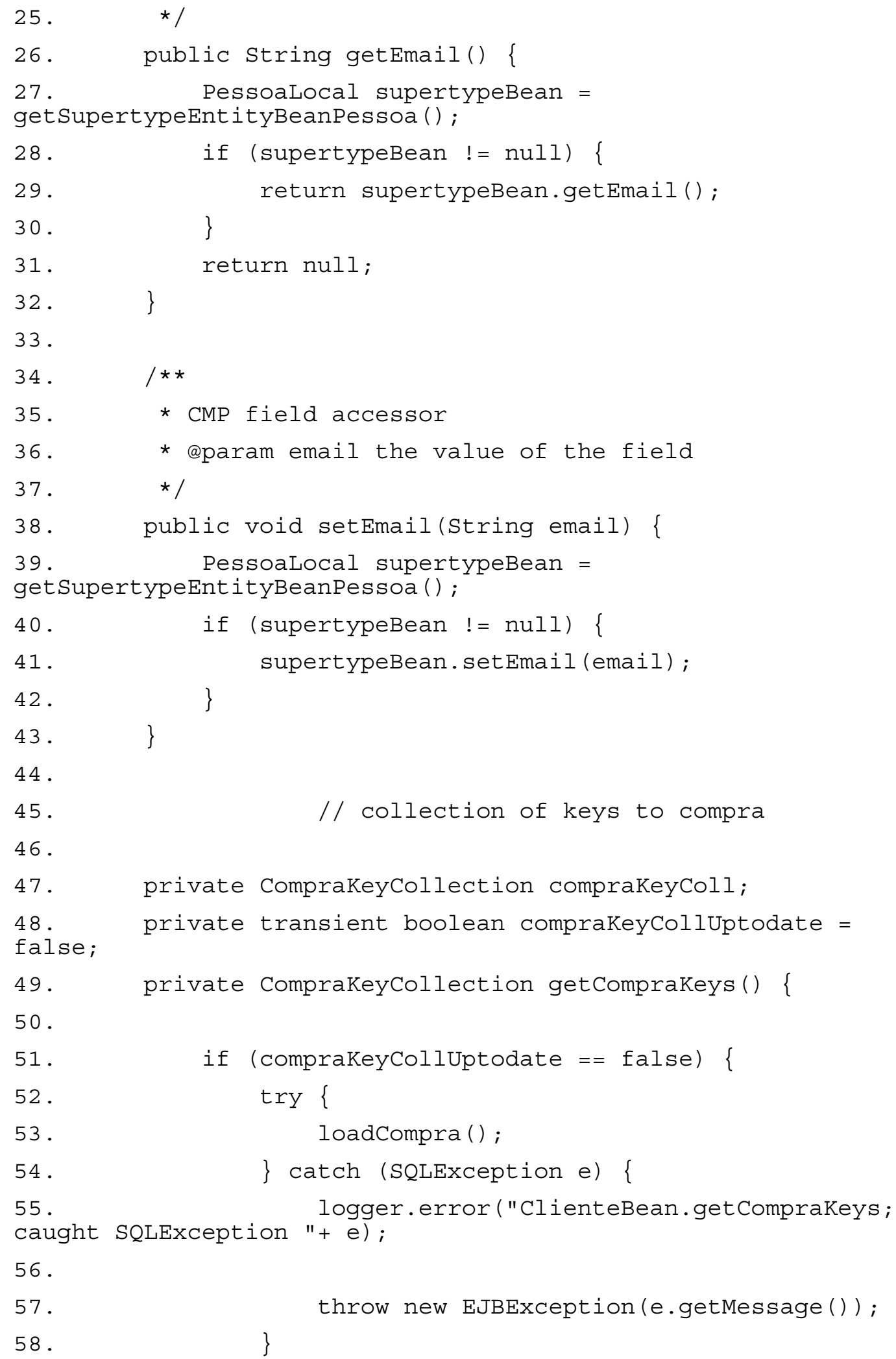




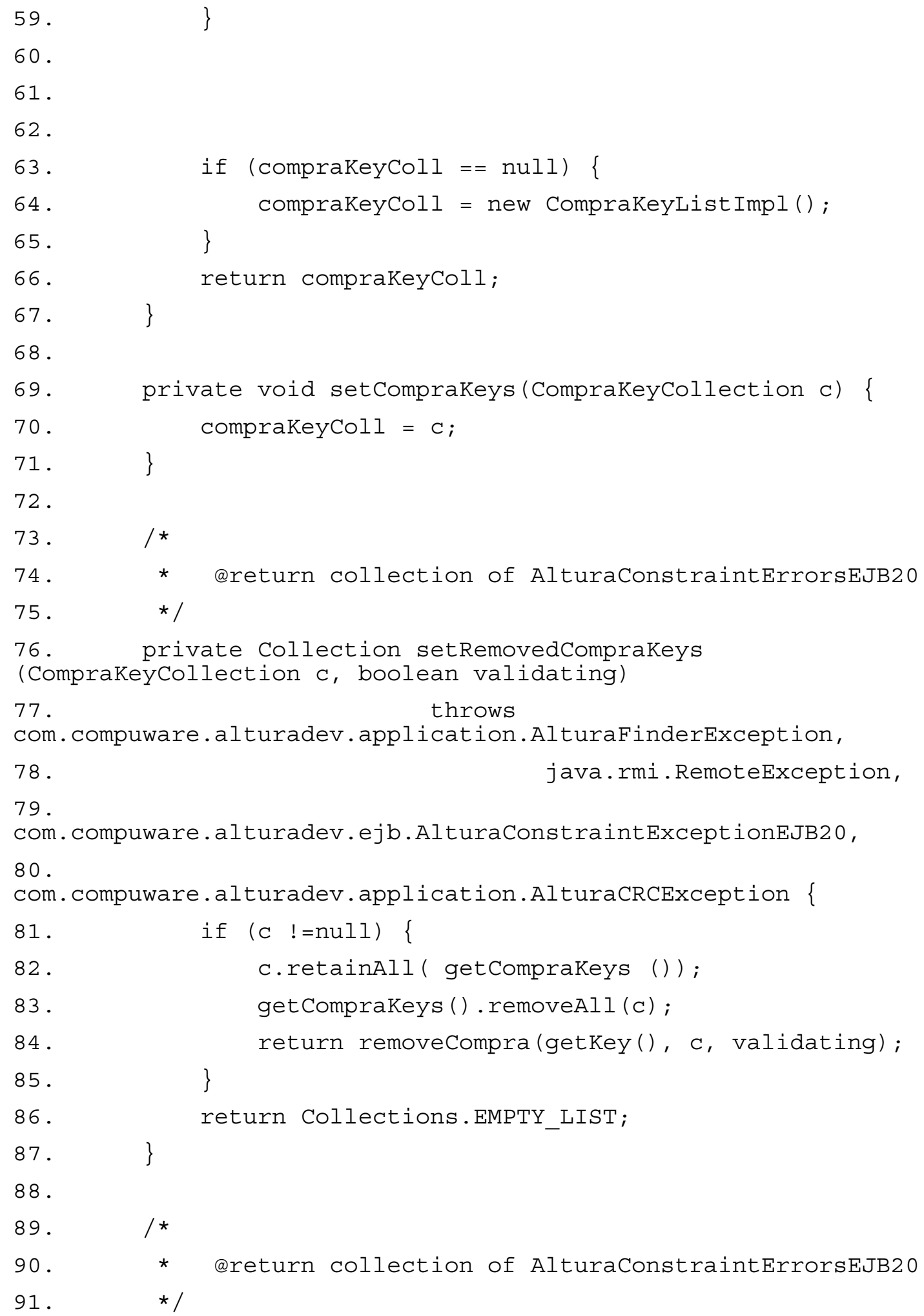


92. private collection

setAddedCompraKeys (CompraKeyCollection c, boolean validating, boolean beingCreated)

93 . throws

com.compuware.alturadev. application.AlturaFinderException,

94 .

java.rmi.RemoteException,

95.

com.compuware.alturadev.ejb.AlturaConstraintExceptionEJB20,

96.

com. compuware.alturadev. application.AlturaCRCException \{

97.

if (c !=null) \{

98.

Collection coll = new ArrayList $(\mathrm{c})$;

99.

coll.retainAll( getCompraKeys());

100 .

c.removeAll (coll);

101.

102 .

getCompraKeys () .addAll (c);

103 .

return addCompra(getKey(), c, validating,

beingCreated);

104 .

$105 . \quad\}$

106. return Collections.EMPTY_LIST;

$107 . \quad\}$

108.

109. public void ejbPostCreate (ClienteUpdateobject updateobject)

110.

111.

112 .

113. $\}$

114 .

115 .

116.

117 .

118.

119. ClienteUpdateObject updateobject $=$ (ClienteUpdateObject) getUpdateobject () ;

120 .

121. AlturaConstraintErrorsEJB20 errors $=$ new

SACliente () . validateData (updateobject);

122 .

if (!errors.empty()) \{ 
Página 112

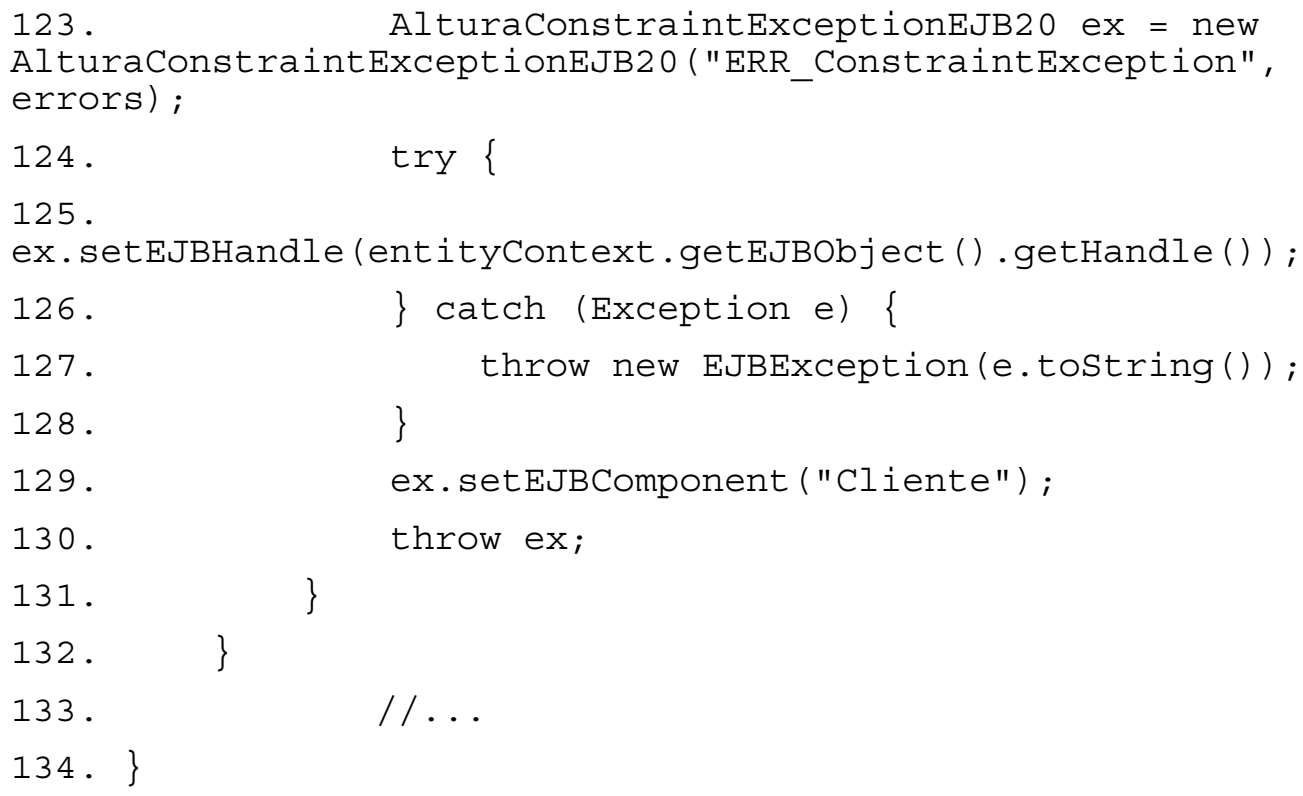




\section{Apêndice B - Código da classe Cliente gerado pela ferramenta AndroMDA}

Este apêndice apresenta alguns fragmentos do código resultante das transformações da ferramenta AndroMDA para a classe Cliente.

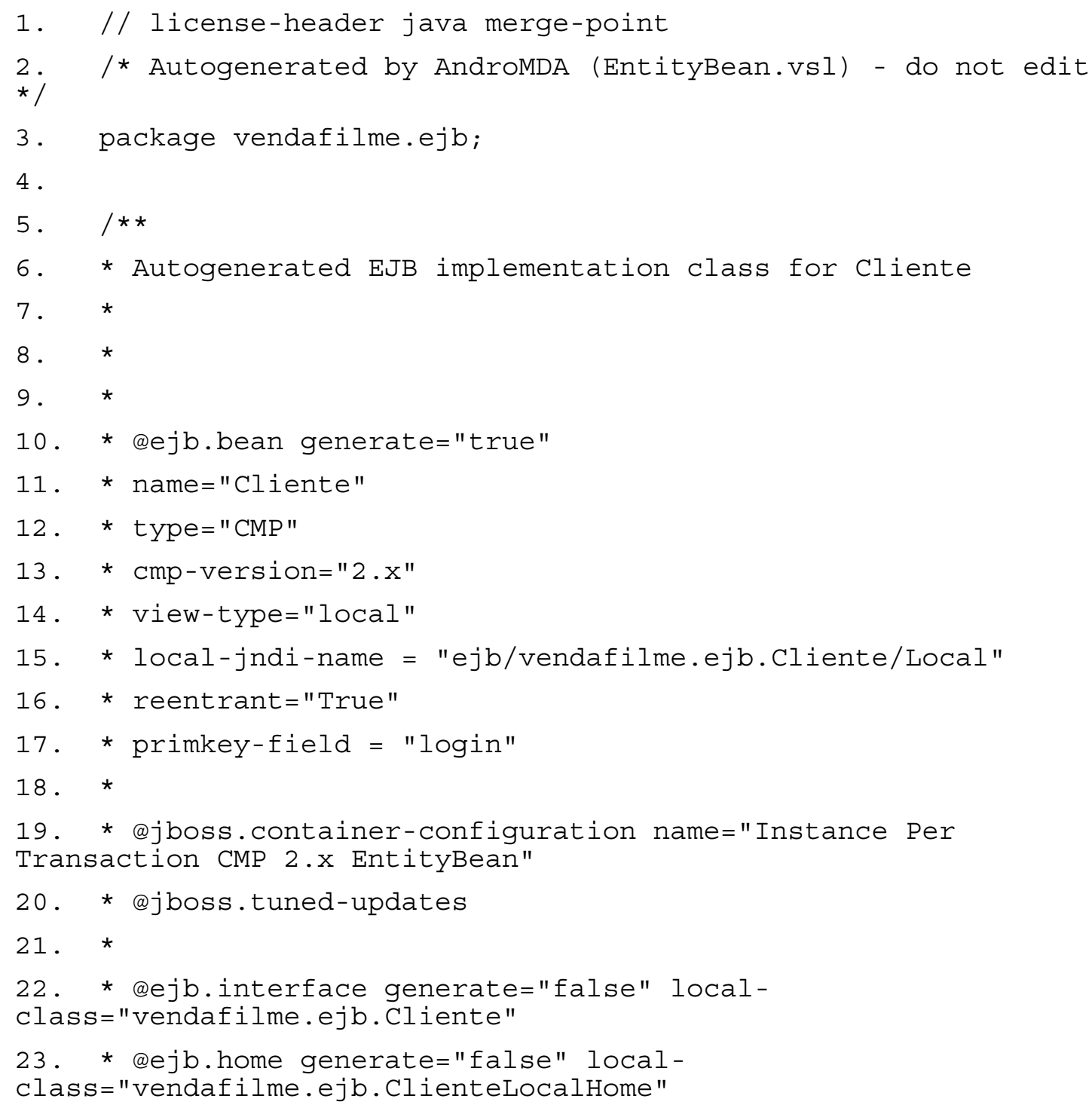




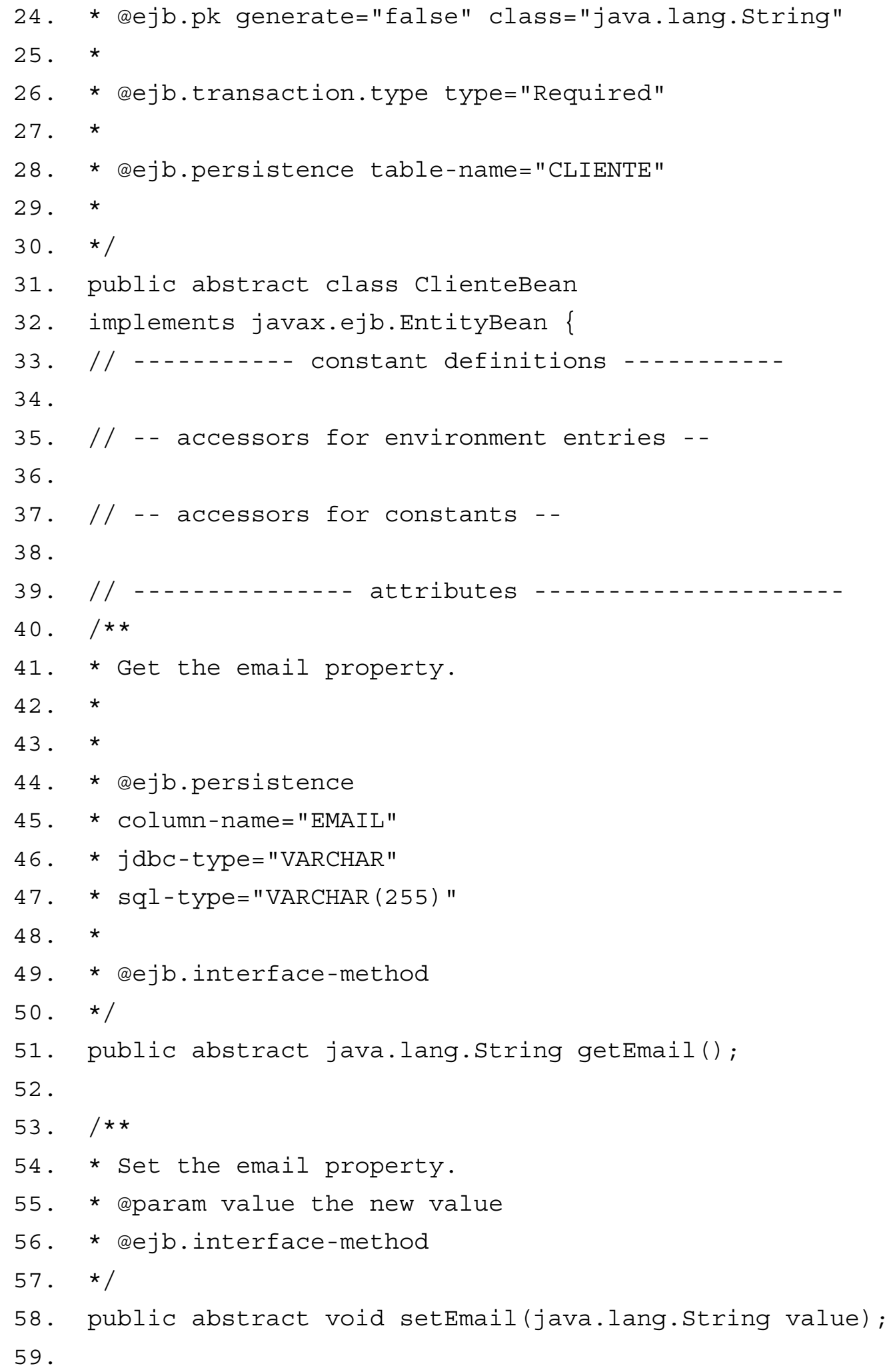


Página 115

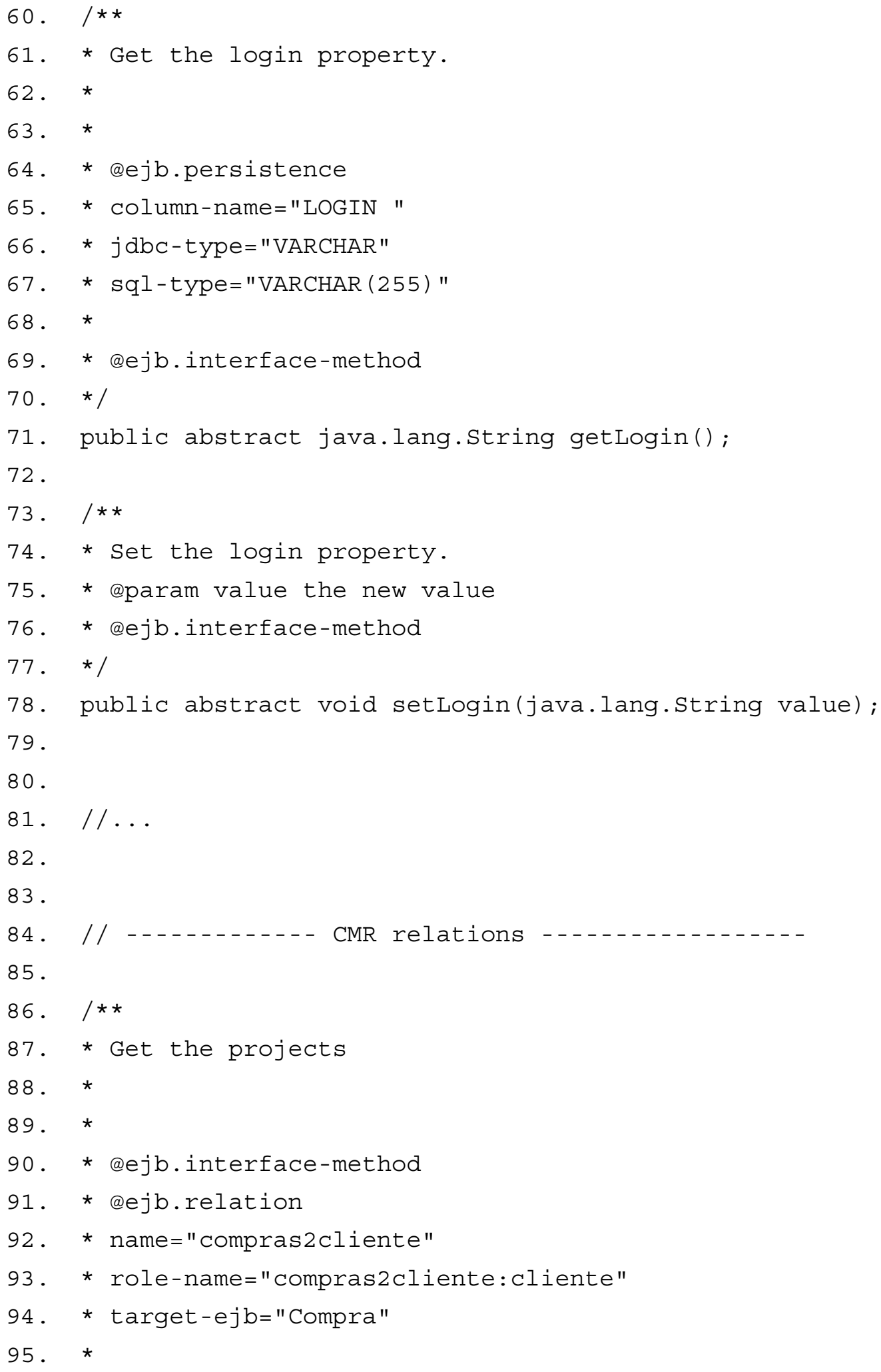




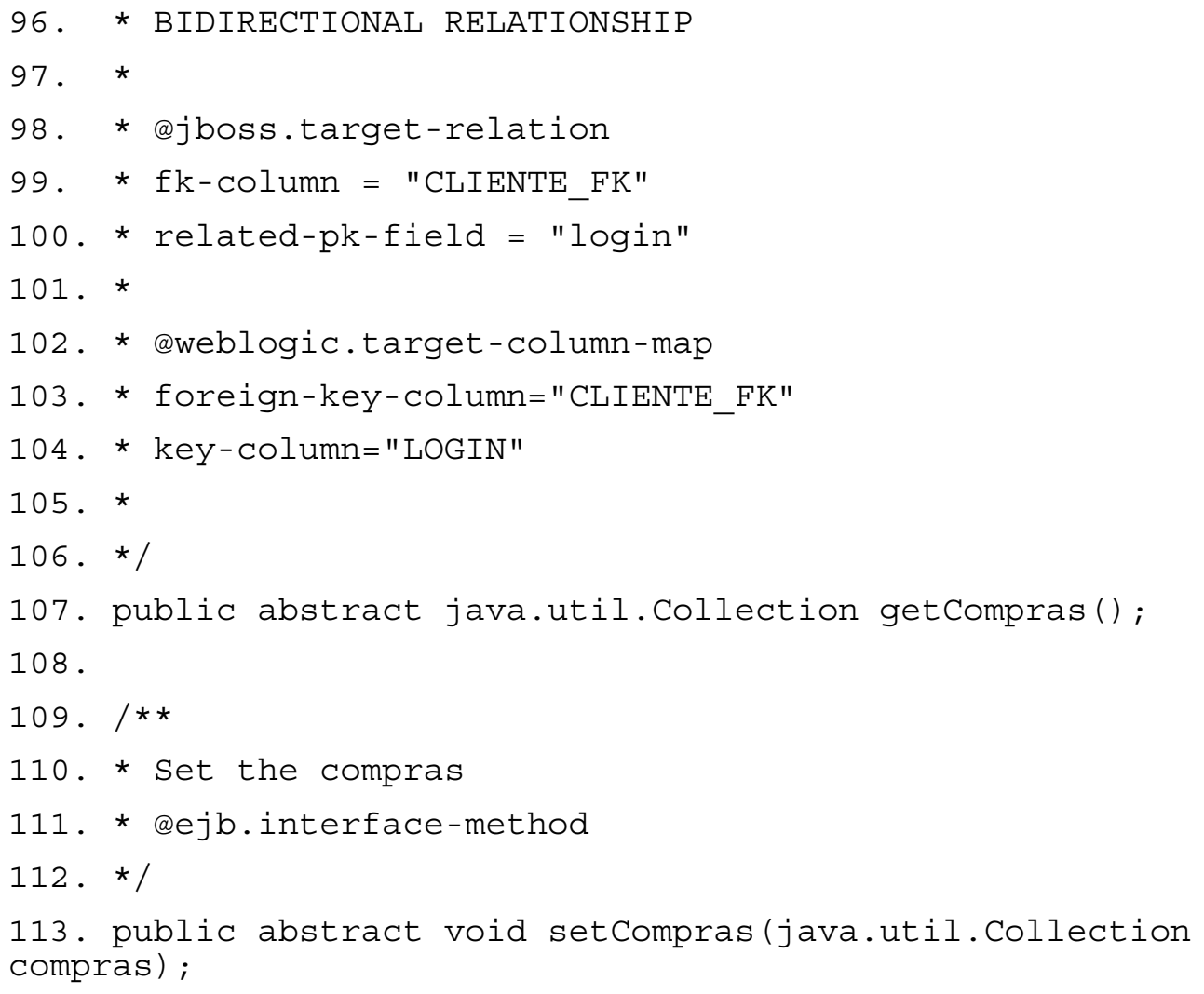




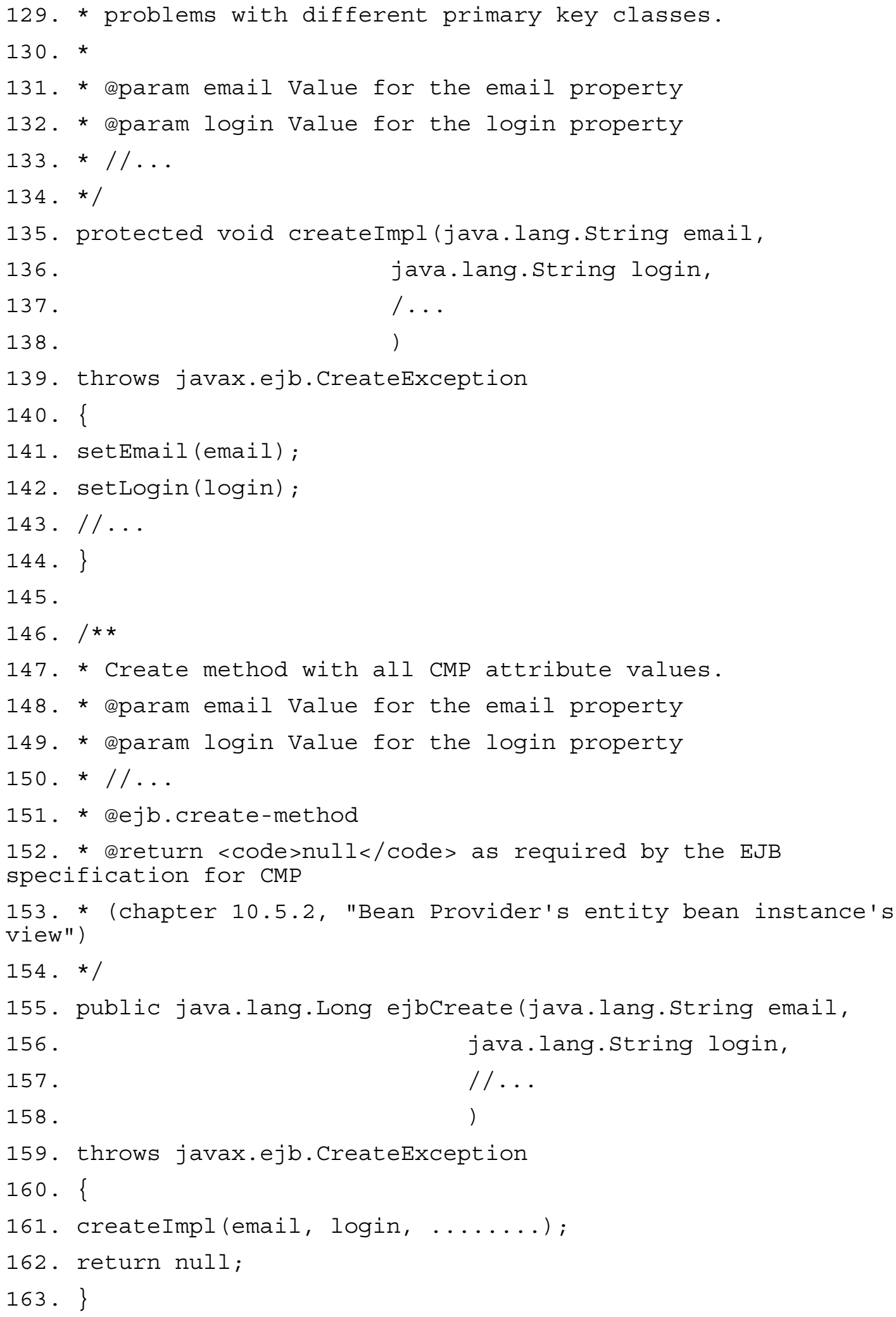


164 .

165. public void ejbPostCreate(java.lang.String email, 166. java.lang.String login,

167.

168.

169. throws javax.ejb.CreateException

170. \{

171. $\}$

$172 . / / \ldots$

173 .

174. // -..-.-.-.-- accessor methods for bean references -$--\cdots-\cdots-\cdots$

175.

176. private javax.ejb.EntityContext ctx;

177 .

178. public void setEntityContext (javax.ejb.EntityContext ctx)

179. \{

180. this.ctx $=$ ctx

181. $\}$

182 .

183. public void unsetEntityContext()

184. \{

185. $\operatorname{ctx}=$ null;

186. $\}$

187.

188. public void ejbRemove()

189. throws javax.ejb.RemoveException

190. \{

191. \}

192.

193. public void ejbLoad()

194. \{

195. \}

196.

197. public void ejbstore()

198. \{

199. \} 
Página 119

200.

201. public void ejbPassivate()

202. \{

203. $\}$

204 .

205. public void ejbActivate()

206. \{

207. $\}$

208 . $\}$ 


\section{Apêndice C - Código da classe Cliente gerado pela ferramenta ArcStyler}

Este apêndice apresenta alguns fragmentos do código resultante das transformações da ferramenta ArcStyler para a classe Cliente.

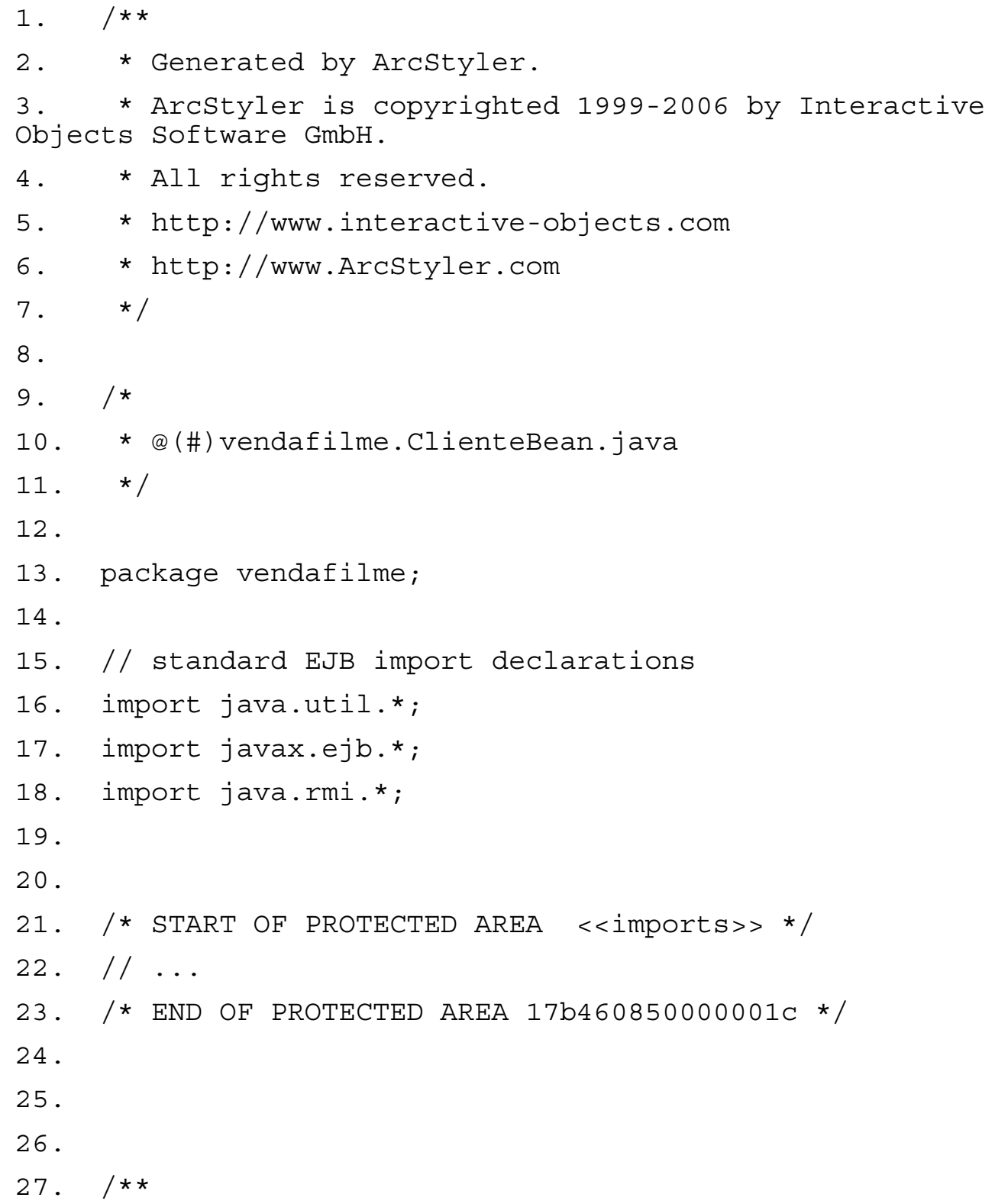




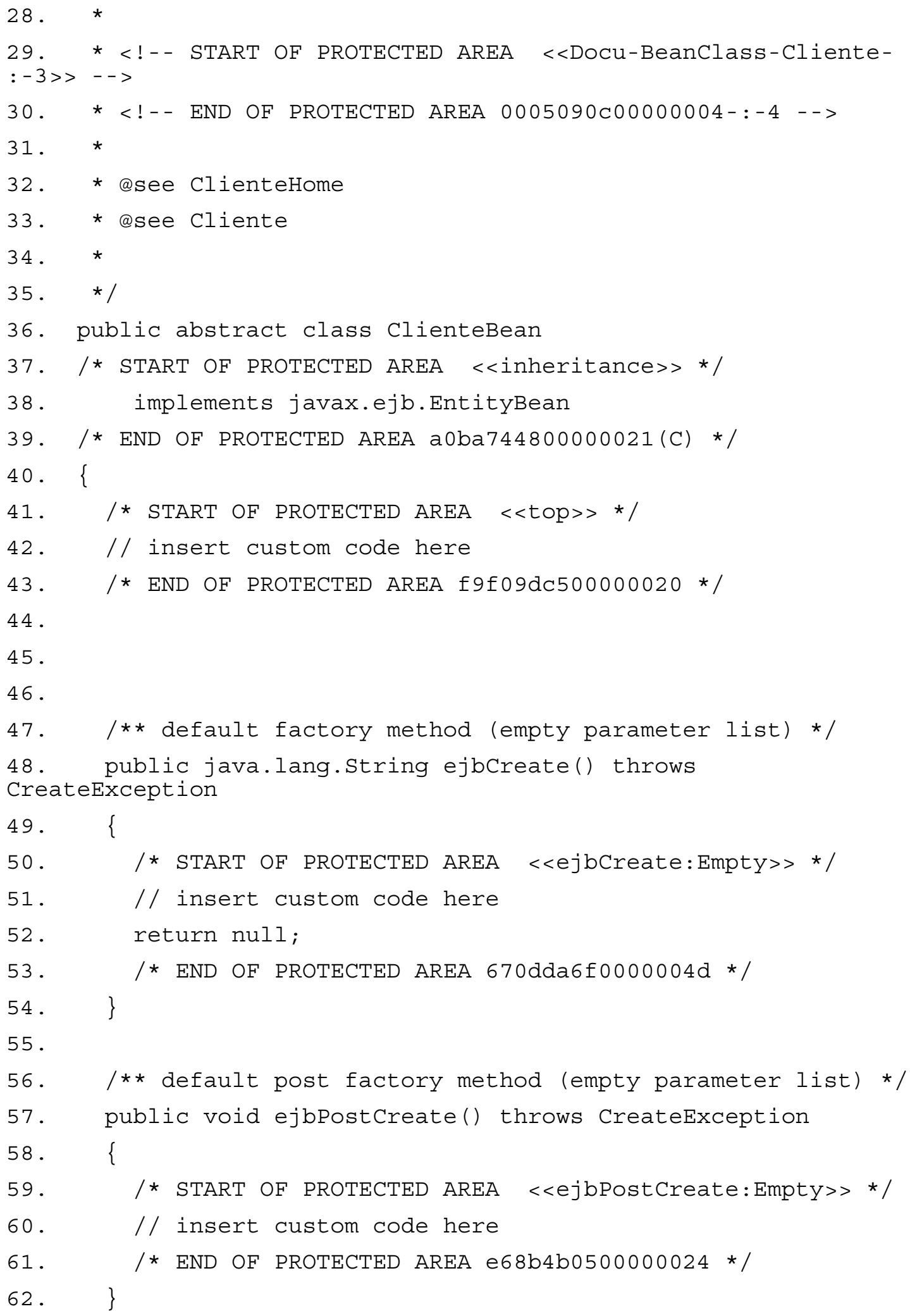


63.

64. $/ / \ldots$

65.

66. /** accessor for the beans corresponding EJB-Object */

67. private vendafilme.Cliente getRemoteReference()

68. \{

69. return (vendafilme.cliente)

javax.rmi.PortableRemoteobject.narrow (_getEntityContext ().getEJB object (), vendafilme.Cliente.class);

70. $\}$

71.

72.

73. /** helper to set the beans context object */

74. public void setEntityContext (javax.ejb.EntityContext context)

75. \{

76. /* START OF PROTECTED AREA <<setEntityContext>> */

77. entityContext $=$ context;

78. // insert custom code here

79. /* END OF PROTECTED AREA b8edced200000041 */

80$.

81.

82. /** helper to access the beans context object */

83. public EntityContext _getEntityContext()

84. \{

85. return entityContext;

86. \}

87.

88. protected java.lang.Long getNextKey() \{

89. if (keyGenerator $==$ null)

90. keyGenerator $=$

com.io_software.catools.carat_ejb20.PrimaryKeyGenerator.getInsta nce ();

91. return keyGenerator.getNextKey ();

92. \}

93.

94. /** accessor for the beans corresponding EJB-Local-Object $* /$

95. private vendafilme.ClienteLocal getLocalReference() 
Página 123

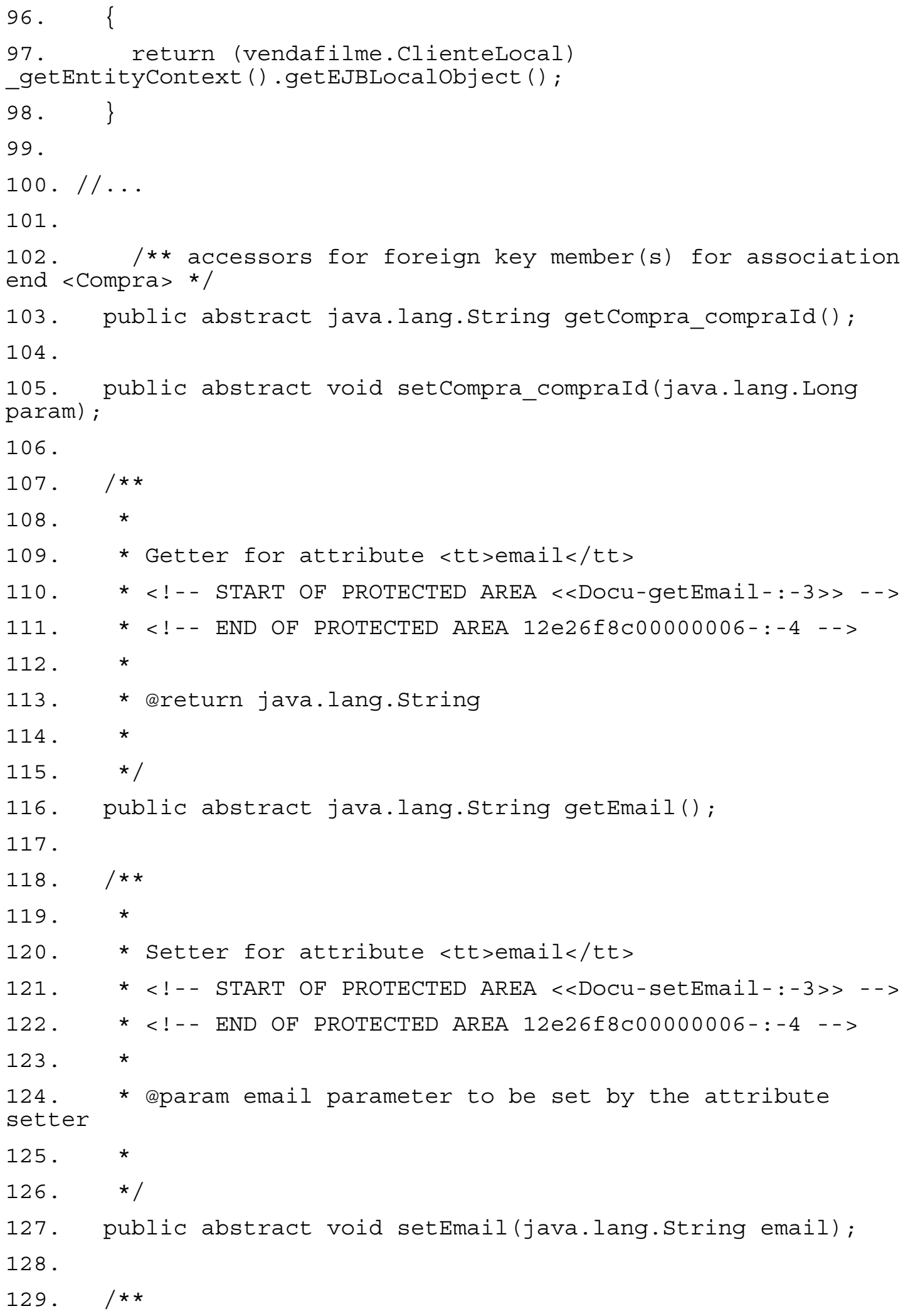




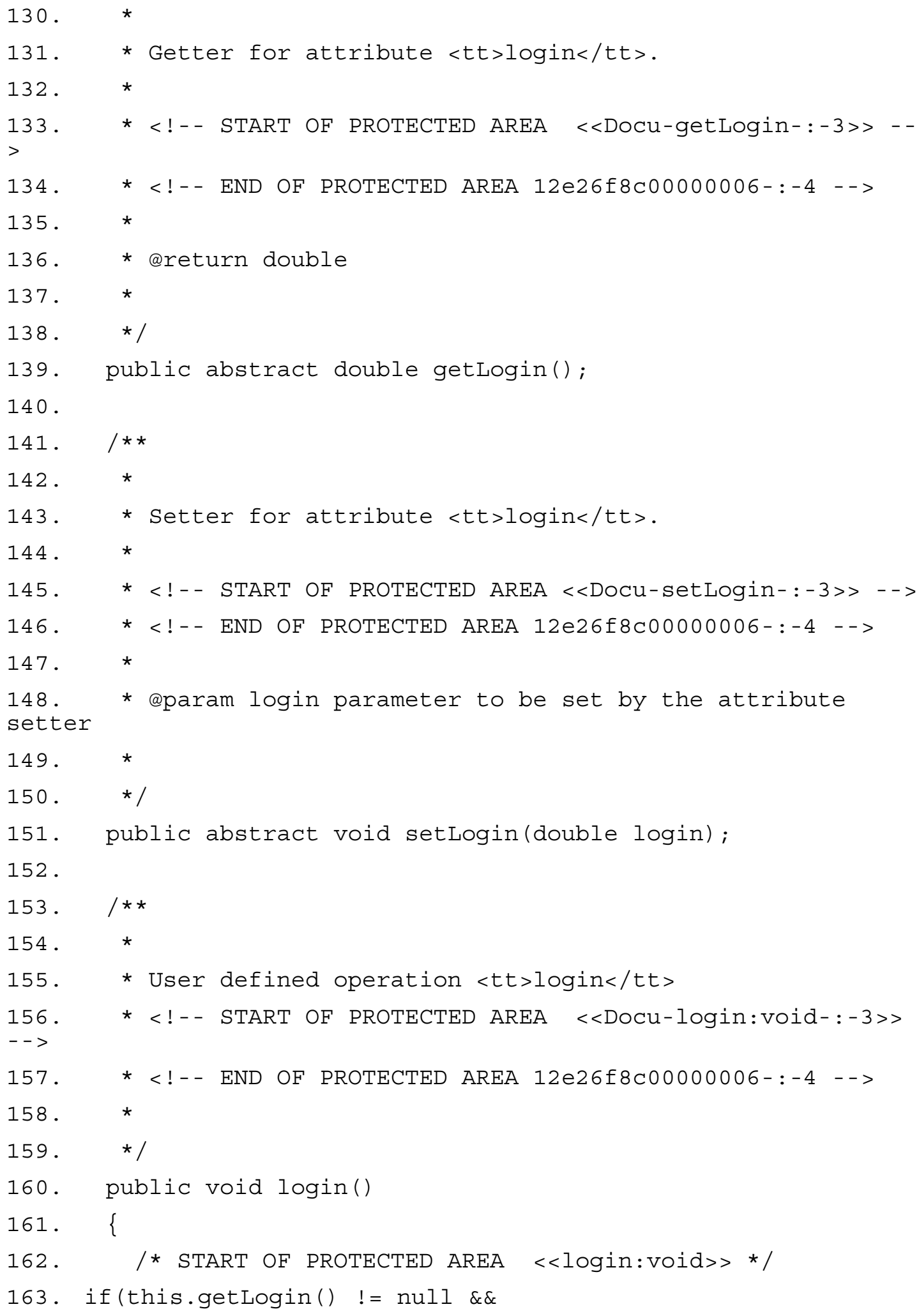




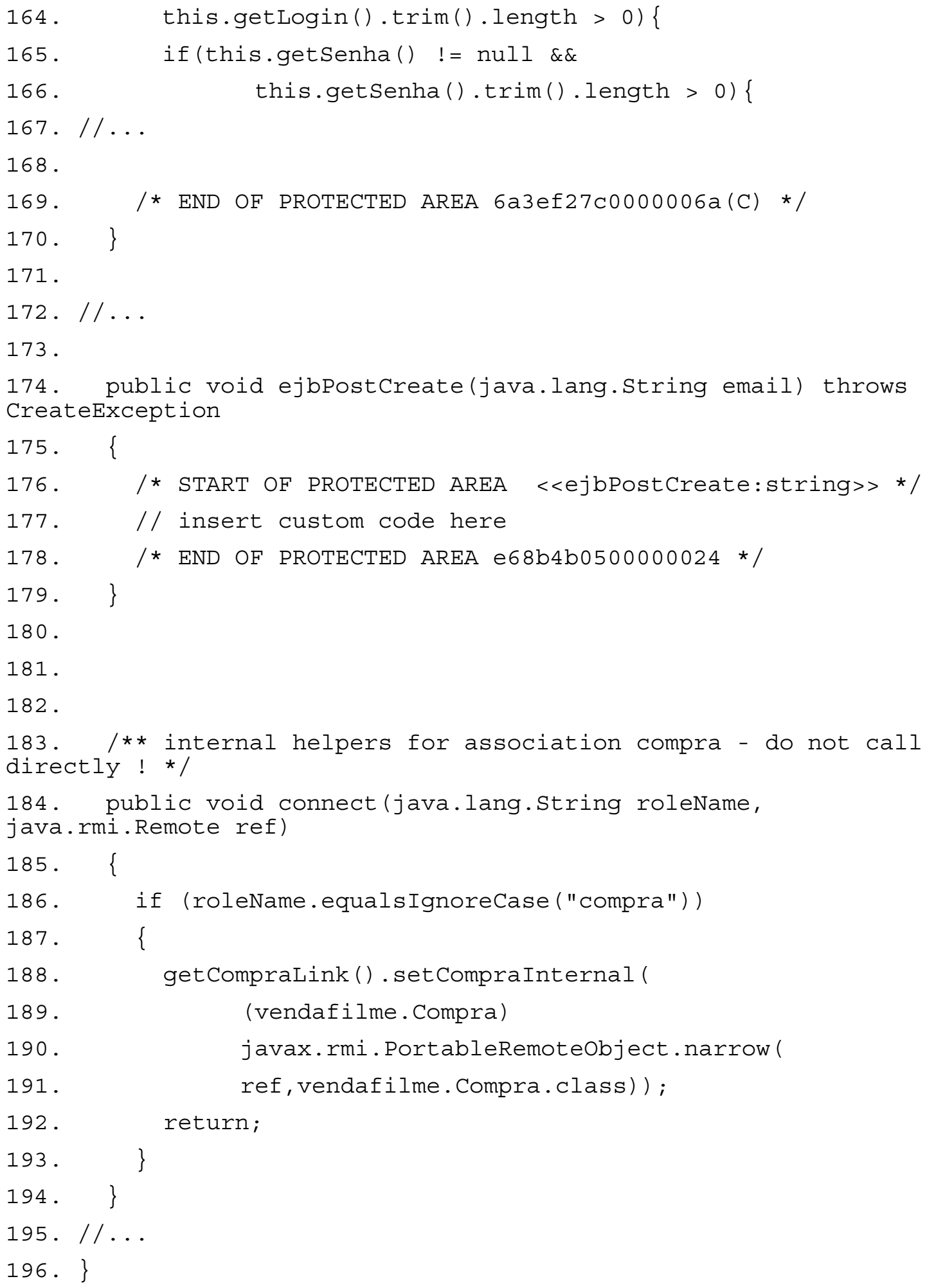

